\title{
How students learn in a problem-based curriculum
}

Citation for published version (APA):

Dolmans, D. H. J. M. (1994). How students learn in a problem-based curriculum. [Doctoral Thesis, Maastricht University]. Datawyse / Universitaire Pers Maastricht. https://doi.org/10.26481/dis.19940331dd

Document status and date:

Published: 01/01/1994

DOI:

10.26481/dis.19940331dd

Document Version:

Publisher's PDF, also known as Version of record

\section{Please check the document version of this publication:}

- A submitted manuscript is the version of the article upon submission and before peer-review. There can be important differences between the submitted version and the official published version of record.

People interested in the research are advised to contact the author for the final version of the publication, or visit the DOI to the publisher's website.

- The final author version and the galley proof are versions of the publication after peer review.

- The final published version features the final layout of the paper including the volume, issue and page numbers.

Link to publication

\footnotetext{
General rights rights.

- You may freely distribute the URL identifying the publication in the public portal. please follow below link for the End User Agreement:

www.umlib.nl/taverne-license

Take down policy

If you believe that this document breaches copyright please contact us at:

repository@maastrichtuniversity.nl

providing details and we will investigate your claim.
}

Copyright and moral rights for the publications made accessible in the public portal are retained by the authors and/or other copyright owners and it is a condition of accessing publications that users recognise and abide by the legal requirements associated with these

- Users may download and print one copy of any publication from the public portal for the purpose of private study or research.

- You may not further distribute the material or use it for any profit-making activity or commercial gain

If the publication is distributed under the terms of Article $25 \mathrm{fa}$ of the Dutch Copyright Act, indicated by the "Taverne" license above, 


\section{How Students Learn in a Problem-based Curriculum}




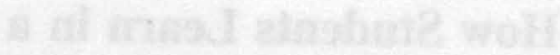

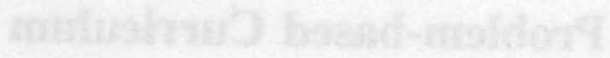




\section{How Students Learn in a Problem-based Curriculum}

\section{Proefschrift}

ter verkrijging van de graad van doctor aan de Rijksuniversiteit Limburg te Maastricht, op gezag van de Rector Magnificus, Prof. dr. H. Philipsen, volgens het besluit van het College van Dekanen, in het openbaar te verdedigen op donderdag,

31 maart 1994 om 14.00 uur

door

Diana Henriëtte Josephina Maria Dolmans

geboren te Hulsberg in 1966

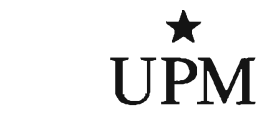

UNIVERSITAIRE PERS MAASTRICHT 


\section{Promotor:}

Prof. dr. H.G. Schmidt

\section{Co-promotor:}

Dr. W.H. Gijselaers

\section{Beoordelingscommissie:}

Prof. dr. M.J. Drop (voorzitter)

Prof. dr. B.P.M. Creemers (Rijksuniversiteit Groningen)

Prof. dr. G.J. van der Vusse

Prof. dr. W.H.F.W. Wijnen

Prof. dr. L. Wilkerson (University of California)

Drukwerk: Datawyse / Universitaire Pers Maastricht

CIP-DATA Koninklijke Bibliotheek, Den Haag Dolmans, Diana

How Students Learn in a Problem-based Curriculum / Diana Dolmans. - Maastricht Universitaire Pers Maastricht - III. Thesis Maastricht. - With ref. - With summary i Dutch.

ISBN 90-5278-130-3

Subject heading: problem-based learning. 


\section{Contents}

2 Problem Effectiveness in a Course Using Problem-based Learning Co-authors: W.H. Gijselaers, H.G. Schmidt, and S.B. van der Meer Published in Academic Medicine, 68, 3, 207-213, 1993

3 Utilization of Student-generated Learning Issues to Evaluate Problems in a Problem-based curriculum Co-authors: H.G. Schmidt and W.H. Gijselaers A shorter version is submitted for publication in Teaching and Learning in Medicine

4 Course Content Coverage as a Measure of Instructional Quality Co-authors: W.H. Gijselaers and H.G. Schmidt

Published in Evaluation of the Health Professions, 16, 4, 448-471, 1993

5 The Relationship between Student-generated Learning Issues and Self-study in Problem-based Learning Co-authors: H.G. Schmidt and W.H. Gijselaers

Submitted for publication in Instructional Science

6 What Drives the Student in Problem-based Leaming? Co-author: H.G. Schmidt

Submitted for publication in Medical Education

7 Discussion and Conclusion

Samenvatting

Curriculum Vitae 


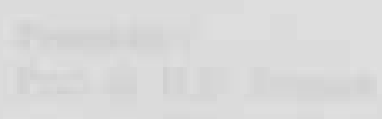

4

(1)

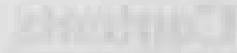

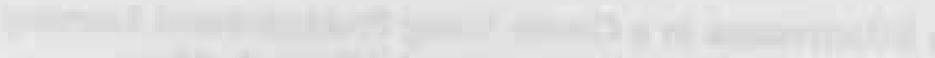

(1)

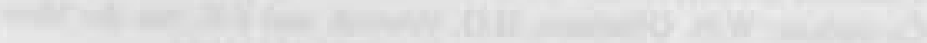

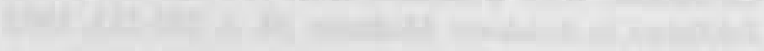
.

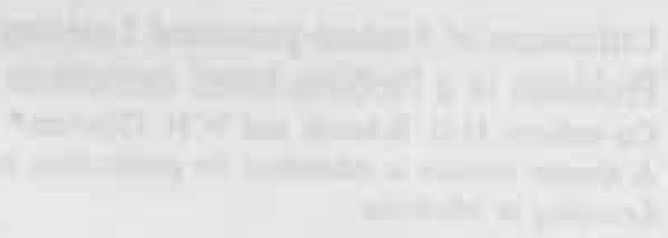

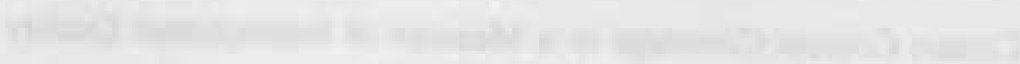

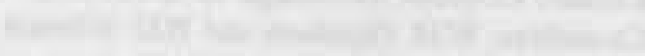

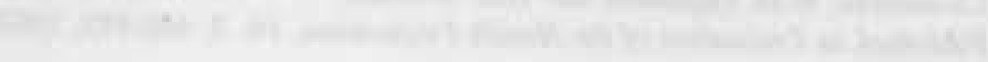

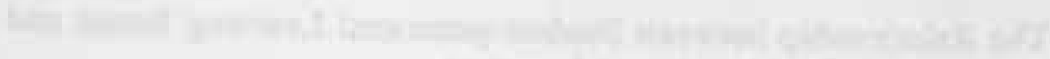

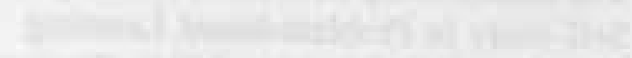

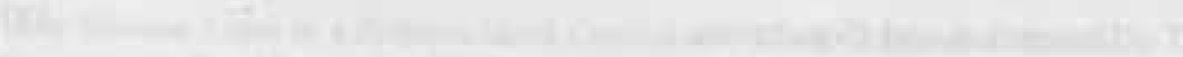

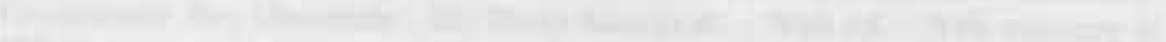
$\sqrt{2}$ 


\section{Preface}

At the Department of Educational Research and Development of the University of Limburg, several studies have been conducted into problembased learning. These studies were carried out within the project "Research in Problem-based Leaming".

The studies described in this thesis also form part of this project. In 1987 the Medical Faculty of the University of Limburg decided to renew the curriculum. The concept of problem-based learning remained unchanged, but the innovation included re-allocating subject-matter across the first four years of the curriculum. The faculty decided that research should be conducted regarding these curricular changes.

In July 1989, I started to work on this thesis. The final product is the result of a learning process in which several people played an important role. My promotor, prof. dr. Henk Schmidt, was the initiator of the ideas behind this thesis. Another person who has highly contributed towards the quality of this final work is dr. Wim Gijselaers, my co-promotor. This thesis benefited greatly from their ideas and comments. In addition, their enthusiasm was an important force driving me through this learning process. I am also grateful to the remarks on the manuscript that I received from the referees.

Syb van der Meer and all other members of the course planning group provided me with the opportunity to collect data, but were also helpful when interpreting the results. A lot of teachers and students were involved in the studies; their contributions were indispensible.

My thanks also go to Ineke Wolfhagen and Hetty Snellen, whom I often consulted about practical issues when conducting the studies. In addition, I am grateful to Maureen Machiels and Cita van Til, my roommates during these years. 
Bert Kerkhofs, Diana Riksen and Paul Jakobs helped me to solve the troubles that I experienced when working with large data sets. I would like to thank Bob Wilkinson and Maureen Machiels for correcting the text. Furthermore, I thank all my colleagues at the Department of Educational Development and Research for their support.

Finally, I like to thank my parents and friends. Last but not least, my thanks go to Jos Ploumen.

Diana Dolmans

March, 1994 


\section{Introduction}

The aim of this thesis is to explore what actually happens to the learner in problem-based learning ( $\mathrm{PBL}$ ). Although there are many ideas in the literature regarding this issue, little research has been conducted to find out whether these ideas are indeed reflected in everyday practice. Acquiring a fair understanding of what actually happens to the learner is difficult, simply because teachers in PBL have limited control over the learning activities of students. Students in PBL to a large extent define themselves the content to be mastered. As a consequence, what students will learn in a particular course may vary.

In this thesis several studies are reported which were aimed at obtaining information about actual student learning in PBL. Because student-generated learning issues and students' self-study activities are assumed to reflect student learning in PBL, the first step undertaken in exploring the issue described above was the development of two procedures, aimed at measuring student-generated learning issues and students' learning activities during self-study. Both procedures were used to collect data about aspects of the learning process, particularly in terms of content covered.

In this introductory chapter, information will be given about the educational context in which the studies described in this thesis are conducted. A detailed description of the learning process as intended in PBL will be presented. In addition, the rationale behind this approach will be discussed, as well as the empirical evidence regarding PBL. Furthermore, a fundamental dilemma, the extent to which students need guidance in deciding what to study, will be outlined. Subsequently, the focus will be on the methodology used. Finally, a brief outline of the contents of this thesis will be presented. 


\section{Broadening the Perspective}

The quality of medical education has attracted quite some interest during the last few years. This interest is especially concerned with the question how education can be more relevant to the needs of today's society. The report of the Association of American Medical Colleges (AAMC) panel on the General Professional Education of the Physician (GPEP), entitled "Physicians for the Twenty-First Century", contains a number of recommendations to improve the general professional education of the physician and stimulated broad discussion among medical schools (Association of American Medical Colleges, 1984). Emerging changes in today's society such as rapid advances in technology, changes in demographics, environmental factors and lifestyle may require a revision of the present system of education for the health professions. Education should be aimed at training students how to deal with problems in the future, preparing themselves to become independent, self-directed, lifelong learners. A worldwide change in education for health professions is needed such that education continues to contribute to health status of the population and reaches groups that do not have access to care yet. The Edinburgh Declaration (World Federation for Medical Education, 1989), which stemmed from a conference organized in response to the discussion raised in the GPEP report, suggests a number of ways along which the ideas of the GPEP report can be translated into effective instructional programs. Settings in which educational programs are conducted should include all health resources of the community, not hospitals alone. Curriculum content should reflect national health priorities and ensure continuity of learning throughout life. The Network of Communityoriented Educational Institutions for the Health Sciences, an organization of more than 200 schools for health professions education, has done much work in this domain and has advocated this position for more than ten years (Schmidt, Neufeld, Nooman, \& Ogunbode, 1991).

Problem-based learning is presented as an instructional approach solving some of the important problems of medical education such as the difficulties encountered by students to practice the knowledge gained in a clinical setting, the lack of integration of the knowledge acquired in the different disciplines and the need for continuing education (Barrows \& Tamblyn, 1980). 


\section{Description of Problem-based Learning}

The Medical Faculty of the University of Limburg in Maastricht, the Netherlands, was established in 1974. Problem-based learning was adopted as the leading approach to education. This educational approach was initially developed at the McMaster University in Hamilton, Canada (Neufeld \& Barrows, 1974).

Problem-based learning can be characterized as follows. Students are confronted with a series of problems. A problem usually consists of a description of a set of phenomena in need of some kind of explanation. For example:

In early morning Paul comes home drunk, after a night of heavy drinking. He tries to unlock the door, but the nearer he brings the key to the lock, the more his hand is shaking. Finally, he succeeds by facing the lock as straight as possible. Even then, it's difficult to turn the key. When he is finally inside, he feels the room reeling, even when he closes his eyes. His legs are wobbly. He tries to make a cup of coffee, but after breaking lots of matches and burning his hand, he gives up.

A group of 8 to 10 students, forming a tutorial group, discusses problems such as these and tries to explain the phenomena in terms of underlying processes, principles or mechanisms (Schmidt, 1983a). The tutorial group is guided by a tutor. The tutor, usually a faculty member, guides students through all steps of the learning process, encourages students to attain a deeper level of understanding, ensures that all students are involved in the group process, monitors progress of individual students, and motivates students (Barrows, 1988).

While working on the problem, the group is making use of a systematic working procedure to analyze the problem. This systematic working procedure consists of seven steps (Schmidt, 1983a). The first step includes clarification of terms and concepts not readily understood by making use of the knowledge of the group members. In the next step the group has to agree with the definition of the problem at hand. In the example given above, medical students may decide that the problem deals with movement control mechanisms and the role of alcohol in disturbing these mechanisms. The third step consists of analyzing the problem by means of generating hypotheses and ideas about the nature of the underlying processes of movement control mechanisms. These ideas and hypotheses are based on students' prior knowledge with regard to the problem at hand. For example: movement is coordinated by the central nervous system, so it may be possible that drinking alcohol 
influences the conductivity of the nerves, or, alcohol has a negative influence on powers of concentration due to which it is difficult to unlock the door, and so forth. In the fourth step the various explanations of the problem are summarized into a coherent model of the problem. During these four steps of problem analysis, issues emerge requiring further exploration. These student-generated learning issues are topics that in the tutorial group's opinion are essential to be studied for the problem at hand. Examples of learning issues generated for the problem described above could be as follows: How does control and regulation of movement take place via the central nervous system? and what is the influence of drinking alcoholic beverages on the central nervous system? Students generate these learning issues to acquire a better understanding of the problem under discussion. As such, these student-generated learning issues serve as a guide for studying the literature or searching for other sources, such as audiovisual aids relevant to the problem at hand. Thus, the sixth step comprises individual study activities and usually takes two days. Subsequently, the group meets again and tries to synthesize the newly acquired information. The students inform each other about their individual findings and correct each other where necessary. Issues still poorly understood are further clarified. This second meeting, step seven, is aimed at checking whether a deeper understanding of the problem and its underlying processes has emerged.

The tutorial group meets twice a week during 2-hour sessions. During the first hour of this session students report on problems discussed previously and report what they found when studying the literature. During the second hour of the meeting students discuss new problems and generate issues for further learning.

\section{Advantages Claimed for Problem-based Learning}

Student learning in PBL as described above is assumed to foster increased retention of knowledge, may improve students' general problemsolving skills, may enhance integration of basic science concepts into clinical problems, may foster the development of self-directed learning skills, and may strengthen intrinsic motivation. These advantages claimed for PBL will be outlined in the following.

The first of these advantages is that, PBL students are assumed to be better able to learn and recall information. Activation of prior knowledge, elaboration, and contextual learning are considered the cognitive processes responsible for this advantage. According to Schmidt (1983a), problem-based learning optimizes student learning because discussing 
problems facilitates the activation of relevant prior knowledge. Furthermore, discussion of a problem will activate previously acquired knowledge. Based on this prior knowledge, leamers actively construct explanatory models, which in turn facilitate the processing and comprehension of new information. The second advantage is that, new information is better understood if students are stimulated to elaborate on it through small-group discussion. Thus, both conditions, activation of prior knowledge and elaboration, facilitate student learning. Illustrative evidence for these claims comes from two experiments conducted by Schmidt, De Volder, De Grave, Moust, and Patel (1989) and Schmidt (1984). In these experiments, subjects were asked to discuss a problem and elaborate on possible explanations. Subsequently, these subjects were required to study a problem-relevant text. The subjects who had discussed the problem recalled much more information from the text than the control group. These data suggest that problem analysis is indeed an effective knowledge activation and knowledge elaboration procedure and that it facilitates comprehension of relevant new information. The third advantage is that learning in context is considered to make information more accessible for later use. In PBL, new knowledge is acquired in the context of some meaningful problem or situation. Situated knowledge is assumed to be more accessible, because the situational cues that activate the knowledge are stored within the same cognitive structures (Brown, Collins, \& Duguid, 1989; Tulving \& Thomson, 1973). Thus, matching context facilitates recall. Norman and Schmidt (1992), reviewing the literature for empirical evidence supporting theoretical advantages claimed for PBL, concluded that several studies consistently reported that PBL students retain knowledge much longer than students under conventional teaching conditions.

A second advantage of PBL would be that it enhances students' general problem-solving skills. Exposure to real-life problems is assumed to foster clinical reasoning or problem-solving skills in students. The interaction with the problem is an opportunity to practice one's problemsolving skills. However, a general problem-solving skill that can be taught and learned in PBL is probably a fallacy since this skill appears to be content specific. Knowledge gained in a particular case cannot easily be transferred to another case, unless students are explicitly asked to compare both cases. As a consequence, it is not surprising that until now there is no evidence indicating that PBL is able to enhance students' problem-solving skills, although there may be some kinds of discipline specific strategies that have not yet been identified (Norman \& Schmidt, 1992). 
A third advantage claimed for PBL is that students may be better able to integrate basic science knowledge into the solutions of clinical problems (Barrows, 1985). Since all the relevant concepts, from anatomy to epidemiology, are learned in the context of a clinical problem, they should be better integrated when a similar problem is encountered in a clinical setting. According to Norman and Schmidt (1992), some preliminary evidence suggests that students in a problem-based curriculum integrate their knowledge better than students in a conventional curriculum, since studies showed that PBL students tend to do better in causal explanation of the pathophysiological processes underlying diseases. Whether the basic principles or concepts of biomedical science learned during pre-clinical years are transferred to managing patients' problems in clerkship years, is not supported by research (Norman \& Schmidt, 1992).

A fourth advantage claimed is that PBL enhances self-directed learning skills. According to Barrows and Tamblyn (1980), students 'learn to learn', so that they can make their learning relevant to their own educational needs. By means of analyzing and discussing problems, students learn how to deal with problems in the future, preparing themselves to become independent, self-directed, lifelong learners. In addition, Barrows and Tamblyn (1980) claim that students learn to see gaps in their own knowledge and learn to evaluate their own strengths and weaknesses. In other words, students learn to reflect upon and control their own learning and develop self-regulatory skills (Glaser, 1991).

Moreover, because students conduct literature searches themselves, they learn to find the necessary materials independently and acquire the ability to continue their education after they graduate (Barrows \& Tamblyn, 1980). In other words, the emphasis on self-directed learning would promote an inquisitive learning style conducive to lifelong learning. That PBL is indeed successful in enhancing self-directed learning skills which are maintained is indirectly evidenced in a study by Blumberg and Michael (1992). Data from library circulation statistics showed that PBL students borrowed more material than students from a conventional curriculum during both pre-clinical and clerkship years.

A fifth advantage of PBL claimed by its advocates is that it enhances intrinsic interest in subject-matter. According to Barrows and Tamblyn (1980), the student-centered learning approach increases motivation because students themselves define the learning issues and decide for themselves what is relevant for their learning. In addition, problem discussion would enhance intrinsic interest in subject-matter because it involves the learners more actively in the issues at hand (Schmidt, 1983b). In an experiment, students discussed a problem and tried to 
explain the phenomena described in this problem in terms of their underlying mechanisms. At the end of this problem-discussion session, experimental subjects were more interested in studying the relevant literature, and more interested to attend a lecture on this issue than control subjects (Schmidt, 1983b). In summary, students in a problembased curriculum seem: (1) to be better able to learn and recall information, (2) to be better able to integrate basic science knowledge into the solutions of clinical problems, (3) to be better self-directed learners and, (4) more highly motivated.

From the discussion above, it might become apparent that PBL can be considered a systematic attempt to apply findings of psychological science to educational practice. Many studies in understanding cognition indicate that competence is fostered not primarily by teaching to deliver knowledge, but through teaching to engender specific kinds of cognitive activity (Glaser, 1991). Problem-based learning is assumed to be an instructional approach reflecting these scientific conceptions of the conditions of human cognition and learning.

\section{Self-directed Learning Skills versus Accountability}

Problem-based learning aims to foster students' ability to become architects of their own knowledge and encourages them to eventually take full responsibility for their own learning. This implies that students have to actively acquire information and skills, depending on their ability to identify their educational needs, preferred style of learning, pace of learning and ability to evaluate their own learning (Barrows \& Tamblyn, 1980). As such, this approach is quite different from teacher-centered approaches in which teachers determine what information should be learned, how it is to be learned, in what sequence, and at what pace. In such approaches, decisions concerning the pace and style of exposition are determined by the teacher and the student is the recipient of the information provided. In problem-based learning by contrast, students to a large extent define themselves the content to be mastered.

Although this approach to learning and instruction appears to have a number of advantages, several arguments have been mentioned against independent study (Cornwall, 1981). Criticisms presuppose that if students were 'left to themselves', they would work at a lower level and standards would drop (Albanese \& Mitchell, 1993). Students would lack the basic knowledge and skills to work independently. The self-directed learning approach requires too much discipline and initiative on the part of the student. Another argument often mentioned is that it would be 
more efficient to use a teacher-directed learning approach because allowing students to find out things for themselves would cost too much time. Especially in highly structured subject-domains it is essential for students to be given a firm foundation of basic facts or some prescribed basic knowledge on which they can build. Besides, it is argued that students cannot know what they ought to study. Students, at least initially, are thought to be unable to be responsible for their own education and would be unable to identify all the 'required' knowledge (Blumberg, Michael, \& Zeitz, 1990; Coulson \& Osborne, 1984). Consequently, the development of students' self-directed learning skills creates insecurity on the part of teachers (Barrows \& Tamblyn, 1980). Not only teachers, however, but also students, especially in the beginning, worry about their ability to determine what they need to know and to what depth (Barrows \& Tamblyn, 1980).

Faculty has to account for the quality of its educational program, and hence the quality of its graduates. Therefore, faculty is concerned that students may not learn all that is considered to be relevant or important. Society demands that students acquire sufficient knowledge to be qualified physicians. Lack of knowledge in certain subject-matter domains would influence the quality of the physicians and, ultimately, the quality of health care.

In summary, in a problem-based medical curriculum teachers feel a possibly justified need to ensure that their students possess sufficient knowledge and that no aggravating gaps in their knowledge exist. On the other hand, students are supposed to be responsible for their own learning and should be given the freedom to decide which subject-matter should be mastered and to what depth. This dilemma makes curriculum design in this area a painstaking activity, since the curriculum should neither prescribe what students should master, because this would be detrimental to the advantages of self-directed learning, nor give the students complete freedom, since the faculty has to ensure that students possess a sufficient knowledge base and cover the intended course content to a sufficient degree. Although these responsibilities seem to be contradictory, it will be shown in this thesis that the two requirements can be, and in fact are, successfully combined in PBL. We hope to demonstrate that the development of self-directed learning skills and subject-matter coverage, are not necessarily incompatible goals of education. Whether they can coexist is entirely dependent on the way the curriculum is developed and in particular on the effectiveness of problems as stimulus for self-directed learning activities and source of guidance. 


\section{Problems as an Important Feature of PBL}

According to Gijselaers and Schmidt (1990), the nature of student learning in a problem-based curriculum is to a large extent dependent on the quality of the didactic problems presented to the students. These authors developed a model characterizing important features of a problem-based curriculum. Their model distinguishes input, outcome and process variables. The input variables are the quality of the problems presented, students' prior knowledge with regard to the problem and the functioning of the tutor. These input variables influence process variables, such as students' individual study time and group functioning, which, in turn, influence the outcome variables. Outcome variables were student achievement and interest in subject-matter.

Gijselaers and Schmidt (1990) conducted a path-analysis to assess the adequacy of the model. The results showed that the variances in study time and functioning of small-group tutorials were, to a great extent, explained by the quality of problems used. One of the major findings of this study was that the quality of problems has a great overall influence on the process and outcome variables and is an important determinant of most elements of problem-based learning.

These findings imply that the learning of students in the problembased context can be improved by means of controlling the quality of problems. The content of a problem indirectly guides students to the intended learning issues and corresponding learning activities. In order to guide students, a problem should be at such a level of detail that it facilitates and regulates the exploration of alternatives on the part of the learner, but does not prescribe exactly what students should learn.

According to Majoor, Schmidt, Snellen-Balendong, Moust, and Stalenhoef-Halling (1990), problems to be designed for use in PBL should meet four criteria: (1) A problem should match the students' level of knowledge previously acquired, (2) a problem should be concretely formulated and preferably show clear linkage to the students' future profession, (3) a problem should be open enough to sustain discussion about possible solutions, and (4) a problem should direct the students to confrontation with one (or more) of the faculty's educational objectives.

Problems are assumed to be the starting-point for students' learning activities. Based on the content of a problem, students generate learning issues which are the driving force behind their self-study. As such, problems should be the major focus when assessing what actually happens to the learner in PBL. 


\section{Research Questions}

Since the aim of this thesis is to explore what actually happens to the learner in PBL, first a more detailed description of this process is necessary than the general outline provided above. For example, during the fourth unit in the first year medical students see the following problem:

A nineteen-year-old young man, George, is helping his womanfriend, Alice, to construct a book-rack during the weekend. After Alice has laboriously removed a splinter out of George's thumb, he decides to use gloves. Alice is not spared either. She cuts her forefinger with a knife while putting the finishing touches to the book-rack. The hard bleeding wound is washed under the water tap and after the bleeding is stopped, the wound is covered with a plaster. Two hours later, she removes the plaster and observes that the skin surrounding the wound has become red. The wound itself is covered with a small scab and the borders surrounding the cut are swollen. Ten days later, the scab is released spontaneously and only a red stripe underneath her unimpaired skin is visible. George, however, has more trouble. Tuesday morning he observes a red swelling near the edge of the nail of his right thumb which feels stiff. The skin around his thumb is tight and red and his whole thumb is throbbing. Moving his thumb is almost impossible and moving the pole is also painful. Thursday afternoon, George is feeling feverish and he decides to visit his general practitioner. The doctor observes a red stripe across the inside of his forearm. In addition, in both his elbow and his armpit the doctor feels swollen and painful glands. Out of the opening in the wound from which the splinter was removed, a small drop of pus is running slowly. This pus is sent to the laboratory. In addition, a blood sample is taken and sent to the laboratory. After a treatment with an antibiotic, George feels better quickly. Alice is wondering why George had such troubles, whereas her wound initially looked worse but recovered without any further problems.

When teachers design problems such as these, they have certain objectives in mind. The objectives for the problem described above, for instance, are: (1) The process of blood coagulation, (2) the natural healing process of a wound, (3) different stages in the process of inflammation, and (4) the relationship between infection and inflammation. In this thesis, the objectives that teachers have in mind while developing a problem will be called faculty objectives. A problem such as the one above is discussed in tutorial groups. During this discussion, questions arise which need to be clarified. These questions are formulated as learning issues for further study. With regard to the problem presented above, one tutorial group generated the following learning issues: (1) What happens during an inflammation reaction? (2) how to explain the 
red color, warmth, swelling and pain? (3) how does wound healing take place under normal circumstances? (4) what kind of defence mechanisms come into operation during a bacterial infection? (5) what is the role of lymph glands during the inflammation process? These questions that in the students' opinion are prerequisite to a better understanding of the problem at hand will be called student-generated learning issues in this thesis. These learning issues are assumed to guide students' learning activities. During self-study, students search for relevant information to answer the questions raised in the learning issues. Finally, what students have learned will be measured by achievement tests. In Figure 1, the process described thus far is presented in a scheme.

Student learning in PBL as depicted in Figure 1 is based on the idea that there is a one-to-one relationship between the various elements. The arrows indicate that elements at a certain stage are transformed in other elements. The faculty objectives are translated into a problem, the problem is translated into a set of learning issues through discussion, and so forth. The central research question, of course, is whether this account of what happens in PBL is a reasonable one. This leads to three fundamental research questions. First, to what extent do students generate learning issues which correspond with the pre-set faculty objectives? Second, do students perform learning activities as intended by faculty responsible for the design of problems? Finally, are student-generated learning issues the major force driving students' self-study or do several other factors have a significant influence? This third question is concerned with the relationship between the generation of learning issues and students' learning activities during self-study. 


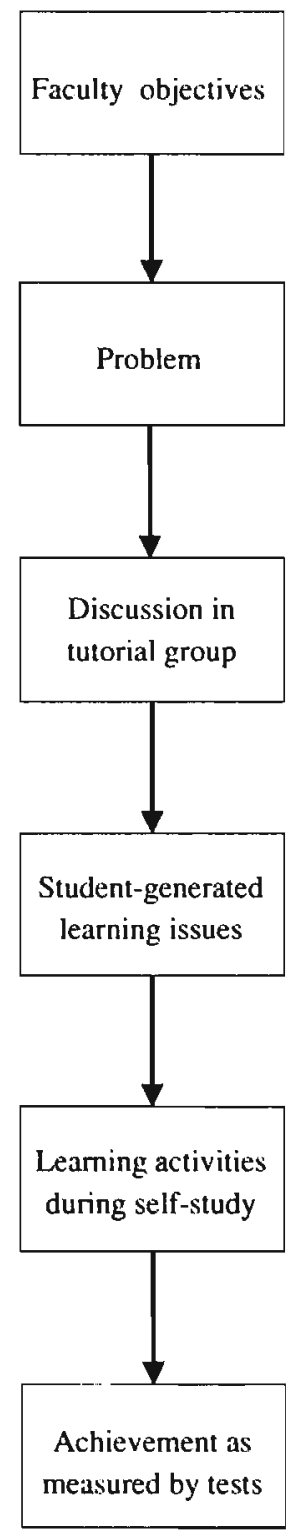

Figure 1

Student leaming in problem-based learning. 
In order to answer the research questions, two procedures were developed, specifically designed to measure subject-matter covered in PBL. One procedure focused on content covered through student-generated learning issues. This procedure consisted of comparing student-generated learning issues with pre-set faculty objectives. Tutors participating in tutorial groups were asked to record the learning issues generated by their tutorial group for each problem. These learning issues were listed for each problem. Subsequently, pairs of expert raters were asked to judge the match between faculty objectives and student-generated learning issues. The amount of content covered for each problem was computed as the average percentage of faculty objectives identified by the tutorial groups participating in a particular course.

The second procedure was aimed at measuring students' actual learning activities. This procedure consisted of a list of topics representing the subject-matter teachers expected students to study. Students were asked to indicate on a 5-point Likert scale how much time they had spent studying each topic and to what degree they assumed they had mastered the specified topics. This procedure was based on student ratings.

Since the ultimate concern of education is student learning, students' learning activities should be reflected on measures of achievement. Therefore, the relationship between students' learning activities as measured by topic scores, reflecting content covered during self-study, and students' scores on the achievement test is investigated.

The results of our analyses demonstrated that the relationship between the various elements of PBL was not as straightforward as was assumed. Therefore, additional data were collected aimed at identifying factors influencing students' learning activities during self-study.

\section{Evaluation of Problem Effectiveness}

Both procedures aimed at measuring course content coverage can also be used to evaluate the effectiveness of problems. In Chapter 2, problem effectiveness is defined as the extent to which students cover the subjectmatter as intended by faculty, without simultaneously, in any way, restricting the students' freedom to generate issues for independent learning. Information about the effectiveness of problems, collected through both procedures, can be used to improve their quality. 


\section{Contents of this Thesis}

The questions raised and the procedures described are each dealt with in separate chapters. Since Chapters 2 to 6 have been prepared as articles, this thesis contains some redundancy in information. The relationship between the different chapters is represented graphically in Figure 2.

Chapter 2 deals with the degree to which student-generated learning issues correspond with the pre-set faculty objectives. This chapter describes a procedure developed to compare faculty objectives and learning issues. The focus of Chapter 3 is on the practical utilization of collecting and reporting student-generated leaming issues for course improvement purposes. Results from a questionnaire, containing items about the usefulness of student-generated learning issues for problem improvement, were reported. In addition, two case studies were reported. The data consisted of the percentage faculty objectives identified for each problem before and after re-designing the problems of two particular courses. Chapter 4 deals with students' learning activities. The development of a procedure to measure students' learning activities is described as well as its reliability, validity, and utility. In addition, the correspondence between self-study and achievement is examined. Chapter 5 compares both procedures aimed at measuring subject-matter covered, student-generated learning issues and topics studied during selfstudy respectively. This comparison suggests that student-generated learning issues are not necessarily the major force driving student learning. In Chapter 6, therefore, additional data are presented which indicate that several other factors, unrelated to the generation of learning issues, have an important influence on student learning. 


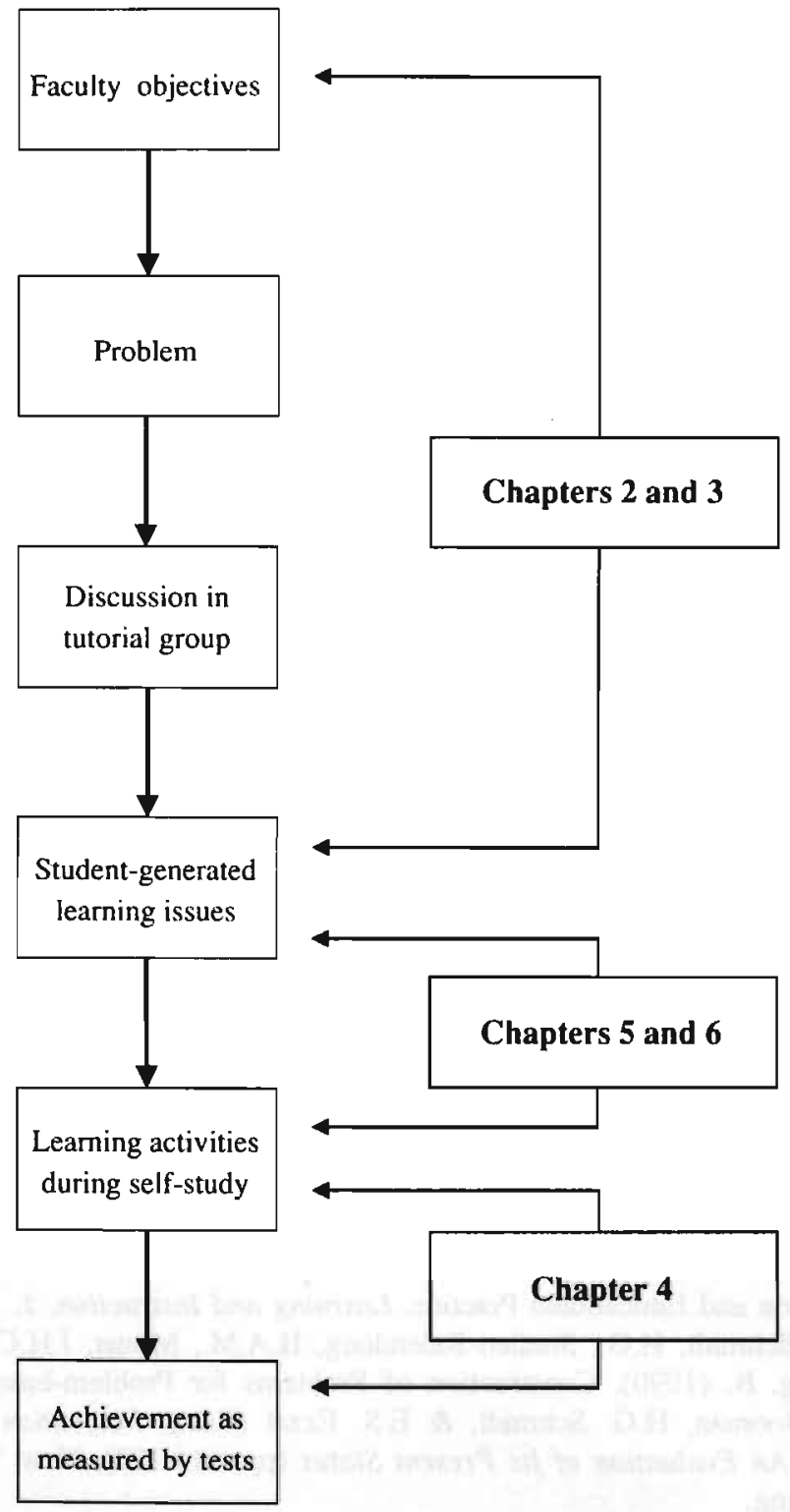

Figure 2

Relationship between different chapters of this thesis. 
Albanese, M.A. \& Mitchell, S. (1993). Problem-based Learning: A Review of Literature on Its Outcomes and Implementation Issues. Academic Medicine, 68, $1,52-81$.

Association of American Medical Colleges. (1984). Physicians for the Twenty-First Century. Washington, DC.

Barrows, H.S. (1985). How to Design a Problem-based Curriculum for the Pre-clinical Years. New York: Springer.

Barrows, H.S. (1988). The Tutorial Process. Illinois: Southem Illinois University School of Medicine.

Barrows, H.S. \& Tamblyn, R.M. (1980). Problem-based Learning. An Approach to Medical Education. New York: Springer.

Blumberg, P. \& Michael, J.A. (1992). Development of Self-directed Learning Behaviors in a Partially Teacher-directed Problem-based Learning Curriculum. Teaching and Learning in Medicine, 4, 1, 3-8.

Blumberg, P., Michael, J.A., \& Zeitz, H. (1990). Roles of Student-generated Learning Issues in Problem-based Learning. Teaching and Learning in Medicine, 2, 149154.

Brown, J.S., Collins, A., \& Duguid, P. (1989). Situated Cognition and the Culture of Learning. Educational Researcher, 18, 32-42.

Cornwall, M. (1981). Putting it into Practice: Promoting Independent Learning in a Traditional Institution. In: D. Boud (Ed.). Developing Student Autonomy in Learning (pp. 189-204). London: Kogan Page.

Coulson, R.L. \& Osbome, C.E. (1984). Insuring Curricular Content in a Studentdirected Problem-based Learning Program. In: H.G. Schmidt \& M.L. De Volder (Eds.). Tutorials in Problem-based Learning. A New Direction in Teaching the Health Professions (pp. 225-229). The Netherlands: Van Gorcum.

Gijselaers, W.H. \& Schmidt, H.G. (1990). Development and Evaluation of a Causal Model of Problem-based Learning. In: A.M. Nooman, H.G. Schmidt, \& E.S. Ezzat (Eds.). Innovation in Medical Education: An Evaluation of Its Present Status (pp. 95-113). New York: Springer Publishing.

Glaser, R. (1991). The Maturing of the Relationship Between the Science of Learning and Cognition and Educational Practice. Learning and Instruction, 1, 129-144.

Majoor, G.D., Schmidt, H.G., Snellen-Balendong, H.A.M., Moust, J.H.C., \& Stalenhoef-Halling, B. (1990). Construction of Problems for Problem-based Learning. In: A.M. Nooman, H.G. Schmidt, \& E.S. Ezzat (Eds.). Innovation in Medical Education: An Evaluation of Its Present Status (pp. 114-122). New York: Springer Publishing.

Neufeld, V.R. \& Barrows, H.S. (1974). The "McMaster Philosophy": An Approach to Medical Education. Journal of Medical Education, 49, 1040-1050.

Norman, G.R. \& Schmidt, H.G. (1992). The Psychological Basis of Problem-based Learning: A Review of the Evidence. Academic Medicine, 67, 557-565.

Schmidt, H.G. (1983a). Problem-based Learning: Rationale and Description. Medical Education, 17, 11-16. 
Schmidt, H.G. (1983b). Intrinsieke motivatie en studieprestaties: Enkele verkennende onderzoekingen. [Intrinsic Motivation and Achievement: Some Investigations]. Pedagogische Studieën, 60, 385-395.

Schmidt, H.G. (1984). Activatie van voorkennis en tekstverwerking. [Activation of Prior Knowledge and Text Processing]. Nederlands Tijdschrift voor de Psychologie, 39, 335-347.

Schmidt, H.G., De Volder, M.L., De Grave, W.S., Moust, J.H.C., \& Patel, V.L. (1989). Explanatory Models in the Processing of Science Text: The Role of Prior Knowledge Activation through Small-group Discussion. Journal of Educational Psychology, 81, 4, 610-619.

Schmidt, H.G., Neufeld, V.R., Nooman, Z.M., \& Ogunbode, T. (1991). Network of Community-oriented Educational Institutions for the Health Sciences. Academic Medicine, 66, 5, 259-263.

Tulving, E. \& Thomson, D.M. (1973). Encoding Specificity and Retrieval Processes in Episodic Memory. Psychological Review, 80, 5, 352-373.

World Federation for Medical Education (1989). The Edinburgh Declaration. Annals of Community-oriented Education, 2, 111-113. 


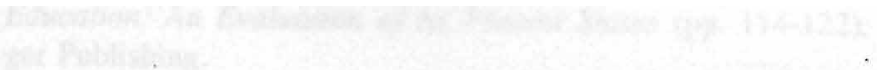

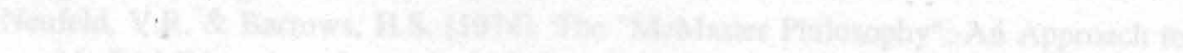

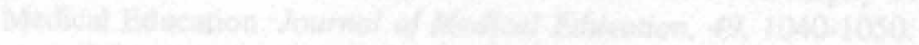

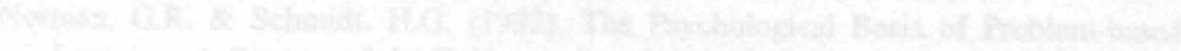

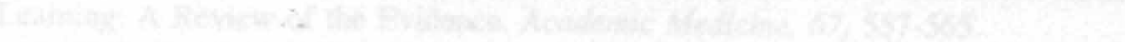

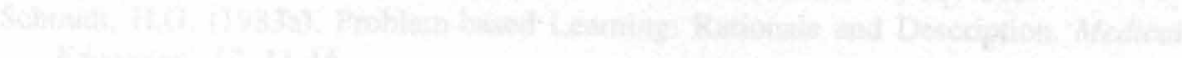




\section{Problem Effectiveness in a Course Using Problem-based Learning}

\section{Abstract}

Problem-based learning (PBL) emphasizes active generation of learning issues by students. Both students and teachers, however, tend to worry that not all important knowledge will be acquired. To explore this question, problem effectiveness (i.e., for each problem, the degree of correspondence between student-generated learning issues and pre-set faculty objectives) was examined in three interdependent studies. The three studies used the same participants: about 120 second year students and 12 faculty tutors in a 6-week course on normal pregnancy, delivery, and child development at the Medical Faculty of the University of Limburg in the Netherlands, 1990-1991. The participants were randomly assigned to 12 tutorial groups that were each given the same 12 problems; the problems were based on 51 faculty objectives; the tutors were asked to record all learning issues generated by their groups. Study 1 addressed the question: To what degree are faculty objectives reflected by student-generated learning issues? Study 2 addressed the question: To what extent do students miss certain objectives, and are these objectives classifiable? Study 3 addressed the question: Do students generate learning issues not expected by faculty, and are these issues relevant to the course content, and finally, why do students generate these issues? To help answer these questions, the studies employed expert raters and a teacher familiar with the course content. The results of Study 1 showed

1 Parts of this chapter were presented at the Annual Meeting of the American Educational Research Association, April 1992, San Francisco, Califormia. (ERIC Document Reproduction Service No. ED 343 955) 
that for the set of 12 problems, the average overlap between learning issues and faculty objectives was $64.2 \%$, with the percentages for individual problems ranging from $27.7 \%$ to $100 \%$. The results of Study 2 revealed that of the 51 objectives, 30 were not identified by at least one tutorial group; on average, each group failed to identify 7.4 objectives $(15 \%)$; these objectives were grouped into three categories. Study 3 showed that 32 learning issues of $520(6,2 \%)$ were unexpected; 15 of these were judged to be at least fairly relevant to the course content; they were grouped into four categories. It was concluded that PBL seems to permit students to adapt learning activities to their own needs and interests.

\section{Introduction}

The concept of problem-based learning (PBL) is generally seen as an attempt to apply modern cognitive views on teaching and learning to instructional practice and curriculum design (Norman \& Schmidt, 1992). Many investigations indicate that competence is fostered not primarily by teaching to deliver information but through teaching to encourage specific kinds of cognitive activities (Glaser, 1991). Learning needs to be an active, constructive mental activity that enables students to build from what they already know. Students should become architects of their own knowledge and eventually take full responsibility for their own learning. Problem-based curricula are assumed to reflect these scientific conceptions of the conditions of human cognition and learning (Norman \& Schmidt, 1992).

First, it is assumed that PBL promotes contextual learning, since new knowledge is acquired in the context of some meaningful problem or situation. Situated knowledge is considered to be more accessible because the situational cues that activate the knowledge are stored within the same cognitive structures (Brown, Collins, \& Duguid, 1989; Tulving \& Thomson, 1973). Second, discussion of a problem will activate previously acquired knowledge in order to construct a mental representation or model of the problem, which, in turn, would facilitate the comprehension of new information relevant to that particular problem (Barrows \& Tamblyn, 1980; Schmidt, De Volder, De Grave, Moust, \& Patel, 1989). Third, problem discussion would increase intrinsic motivation because it involves the learners more actively in the issues at hand (Barrows \& Tamblyn, 1980). And fourth, the emphasis on self-directed learning would encourage students to reflect upon and control their own 
learning activities and develop self-regulatory skills conducive to lifelong learning (Barrows \& Tamblyn, 1980; Glaser, 1991).

In PBL students are confronted with a problem, consisting of a description of a set of phenomena in need of explanation. The problem has been specifically designed for instructional purposes. A group of 8 to 10 students, guided by a tutor, discuss the problem and try to explain the phenomena in terms of their underlying processes, principles, or mechanisms (Schmidt, 1983). During this initial discussion, issues emerge that require further exploration. These student-generated learning issues are topics that each tutorial group decides are prerequisites for a better understanding of the problem under discussion (Blumberg \& Michael, 1992; Blumberg, Michael, \& Zeitz, 1990). Thus, learning issues are the starting point for students' learning activities and serve as a guide for studying literature relevant to the problem at hand. Students engage in self-directed learning activities in order to find information regarding the issues raised. In a second tutorial session each participant reports on what information he or she has found. During this meeting an attempt is made to integrate information collected and to draw conclusions.

When teachers design problems, they have certain topics in mind that students are expected to cover. Hence, a goal of curriculum design in this area should be to construct problems that are indeed effective in reaching the intended learning outcomes. Whether students undertake learning activities planned by faculty members is to a large extent determined by the learning issues generated. If students fail to generate the appropriate issues, the pre-set objectives are not identified, and hence the intended learning outcomes are not accomplished. Ineffective problems cause difficulties for students in generating the appropriate learning issues, implying that students' learning activities may not cover the intended subject-matter, which in turn will lead to lack of content coverage. Consequently, the effectiveness of a problem may be defined as the degree of correspondence between student-generated learning issues and pre-set faculty objectives. This definition is illustrated by a problem presented to the students at the Medical Faculty of the University of Limburg, the Netherlands, during a second year course about normal child development in the 1990-1991 academic year.

\section{Problem: Tall girl}

During the last few years, Ellen has grown tall very quickly. She has always been a tall girl, but at an age of 11 years and a height of five feet, four inches, she rises head and shoulders above her age group. People always take her to be older, which sometimes becomes wearisome. What will become of her? She still has not reached the age of puberty. 
While designing this problem, teachers had five objectives in mind: (1) What are the normal rates of child growth? (2) what are the normal stages in secondary sexual characteristics? (3) what endocrine control processes influence growth? (4) what are the psychological effects of being extremely tall compared with others in one's age group? and (5) what diagnostic procedures are available to predict ultimate height? Given the problem, one tutorial group generated five learning issues: (1) What are the normal patterns of growth rate? (2) what factors influence growth, what hormones are concerned with growth and what are their effects? (3) what kinds of physical changes take place during puberty and what are the possible explanations? (4) what test can be used with regard to growth? and (5) what kind of medical interventions are possible in a case of abnormal growth?

Comparing the learning issues of this tutorial group with the pre-set faculty objectives in detail reveals that this tutorial group only partially covered the faculty objectives. Four out of five objectives were identified by the tutorial group. The fourth objective, addressing the psychological effects of being extremely tall, is not identified by this tutorial group. This is a Type A mismatch. Interestingly, the tutorial group generated one learning issue, what a doctor can do with a case of abnormal growth (issue 5), that does not correspond to any of the faculty objectives and as such was not expected. This is a Type B mismatch.

Whereas problem effectiveness can be expected to determine students' learning, only a few studies have actually addressed the relationship between the nature of problems and students' learning activities (Coulson \& Osborne, 1984; Shahabudin, 1987; Tans, Schmidt, SchadéHoogeveen, \& Gijselaers, 1986). The purpose of the present article is: (1) to provide an overview of previous research conducted in this area and (2) to describe three interdependent studies on the overlap between faculty objectives and student-generated learning issues.

\section{Review of the Literature}

The discussion about the effectiveness of problems in PBL is dominated by the question whether students are able to generate all the appropriate learning issues and are able to identify the required knowledge. Faculty members' observations with regard to the effectiveness of problems suggest that students sometimes tend to focus on just one detail of the problem that is most appealing to them.

The PBL literature contains several examples of studies that examine whether students actually identify the required knowledge (Coulson \& 
Osborne, 1984; Shahabudin, 1987; Tans et al., 1986). These studies have investigated the match between course objectives and student-generated learning issues. Tans et al. (1986), for example, studying a problembased course on muscle physiology for physiotherapy students, used two techniques to analyze the match between faculty objectives and students' learning issues: (1) a method based on experts' judgements and (2) a text-reduction method. The first method consisted of requiring experts to judge for each faculty objective whether it was reflected in learning issues or not. This method resulted in an average percentage of overlap of 68.3 ( $S D=24.6)$. The second method, a text-reduction technique, consisted of reducing both faculty objectives and learning issues into a list of concepts and comparing these lists to determine the overlap. The percentage of overlap between the two lists of concepts was 39.6 $(S D=22.9)$. The authors argue that the text-reduction technique is more stringent in determining the percentage of overlap than the technique of using experts' judgements. The difference between the two techniques may be explained by the fact that text-reduction is based on the assumption that two concepts correspond with each other only if exactly the same terminology is used, whereas experts tend to interpret what is intended rather than focus on precise formulations.

Coulson and Osborne (1984) also conducted a study to examine to what extent students are able to identify all course objectives. With specific objectives in mind, a couple of teachers selected seven patientproblem simulations in a PBL module. Learning issues generated by the tutorial groups were collected and three raters compared them with a faculty-generated list of objectives. The results showed that, for all the tutorial groups taken as a whole, the groups succeeded in identifying all course objectives. However, at the individual group level, each faculty objective was identified on the average by 5 out of the 12 tutorial groups $(42 \%)$. No information was provided as to whether the unidentified objectives were important or not.

Students' success in identifying faculty objectives was also tested in a study conducted by Shahabudin (1987). In this study, a conventional course was compared with a parallel problem-based track. The former course consisted of lectures in systemic pathology and clinical microbiology as part of a conventional medical curriculum. The problem-based course included a 10-week period during which tutorial groups discussed a series of problems selected from the conventional systemic pathology course. Each tutorial group was asked to list all the learning issues that arose from the discussion. At the end of the period, all learning issues were compiled into a smaller set of more general subjects. This list of subjects was compared with the faculty members' list of topics to be 
covered by the tutorial groups and the list of topics to be covered in the conventional curriculum. It was found that, in general, the tutorial groups succeeded in identifying all required topics. The author concludes that this congruence indicates that learning from problems is not entirely student-directed but can largely be influenced by teachers.

The results of the studies discussed thus far indicate that students succeed reasonably well in identifying pre-set faculty objectives. The studies fail, however, to suggest why some faculty objectives are not always identified by students. Exploring the nature of these unidentified objectives, or searching for their common characteristics, can probably give more insight into why they were not identified. Furthermore, the studies discussed do not provide any hints as to the nature of the unintended learning issues. Tans et al. (1986) conclude that a majority of the unexpected learning issues were relevant to the course content, without further specifying why these issues were generated.

\section{Three Studies}

The purpose of the present investigation is to analyze the relationship between pre-set faculty objectives and student-generated learning issues, both with regard to faculty objectives not identified by students (Type A mismatches) and with regard to learning issues not expected by teachers (Type B mismatches). Three studies were designed to suggest answers for three sets of questions: (1) To what degree are faculty objectives reflected by student-generated learning issues? (2) to what extent do students miss certain objectives, and are these faculty objectives classifiable? and (3) do students generate learning issues not expected by the faculty, are these issues relevant to the course content, and why do students generate these issues?

All three studies used the same group of participants: about 120 second year students at the Medical Faculty of the University of Limburg in the Netherlands, 1990-1991. This medical faculty has a problem-based curriculum. In addition, 12 faculty tutors were part of the experiments. Both students and tutors were randomly assigned to 12 tutorial groups. All analyses were conducted at the level of the tutorial group.

The three studies also used the same basic data. The course under study was a 6-week course that covered themes related to normal pregnancy, delivery, and child development, represented by 12 problems about topics such as childbirth, psychomotor development, and psychosexual development. The problems were based upon 51 faculty objectives that covered the course as a whole; for each problem, the number 
of objectives ranged from 1 to 8 , with an average of 4.3. For each problem, the tutors were asked to record all learning issues generated by their tutorial groups. The tutorial groups generated 1 to 10 learning issues per problem, with an average of 3.6 .

\section{Study 1}

Study 1 was designed to assess to what degree pre-set faculty objectives are reflected by student-generated learning issues. This study can be considered as a conceptual replication of the Tans et al. (1986) study. Experts' judgements were used to measure the degree of concordance between course objectives and student-generated issues.

\section{Procedure}

12 pairs of expert raters (24 in total) were asked to judge the match between faculty objectives and student-generated learning issues. For a given problem and a given tutorial group, the pairs were instructed to compare each student issue with each objective, with each rater individually judging the correspondence between faculty objectives and learning issues. For example, a problem may have contained five objectives and the tutorial group may have generated five learning issues. Hence, each rater in the pair would have had to make 25 comparisons for a single problem and a single group. To reduce the total number of comparisons to be made by each pair of raters, a design was used in which raters were nested within problems and within tutorial groups, i.e., each pair rated each group's performance on only one problem. ${ }^{2}$

For each comparison, the raters had to judge whether a particular learning issue definitely corresponded with a particular faculty objective or definitely did not correspond with that objective. (For the purpose of analysis, the few cases where raters could not give definite judgments were considered as non-correspondences.) A faculty objective was assumed to have been identified by the students if both raters agreed that a learning issue corresponded with the objective. If both raters agreed that there was no correspondence, then an objective was assumed not to have been identified by the students. Presumably, they had failed to study the subject-matter specified by the objective. If the raters disagreed, i.e., if one rater indicated a correspondence and the other indica-

2 If each pair had been required to judge all learning issues generated for 12 problems by each of the 12 tutorial groups, each individual rater would have had to make about 2,200 comparisons. 
ted a non-correspondence, then an objective was also assumed not to have been identified by the students.

\section{Results}

The level of interrater agreement for each pair of raters varied between $67.5 \%$ and $97.3 \%$, with an average of $78.9 \%$. Since these percentages may have overestimated the true interrater agreement, because of agreement based on chance alone, Kappa coefficients were computed for each pair of raters as an alternative measure for interrater reliability. The Kappa coefficient takes into account the expected proportion of agreement due to chance alone. It can take values between zero and one (Landis \& Koch, 1977). The Kappa coefficient for the pairs of observers varied between .23 and .64 , with an average of .45 . The average Kappa value of .45 demonstrates a moderate level of agreement between raters.

It should be noted that the correspondence between faculty objectives and student-generated issues is quite difficult to judge, since a learning issue arises from a discussion in the tutorial group that, in itself, is not available to the raters. This lack of background information in some cases makes it quite difficult to judge to what extent a learning issue is relevant to a particular objective, although the students involved probably know exactly what is intended by the learning issues. The level of agreement between the raters, however, was fairly high, indicating that in most cases the raters were able to make clear judgements, even without additional contextal information. Given the results of both methods for assessing reliability, the conclusion may be drawn that the rating procedure provides fairly reliable ratings.

The effectiveness of the problems was measured as the degree of overlap between faculty objectives and learning issues. The degree of overlap between objectives and issues for each of the 12 problems varied between $27.7 \%$ and $100 \% \quad(F(11,143)=6.84, p<.001)$. The average overlap for the set of 12 problems was $64.2 \%$. For 10 of the 12 problems, the overlap was close to this average (within 15 percentage points).

In summary, an average of $64 \%$ of the faculty objectives were identified by the 12 tutorial groups. However, the percentages differed across problems, implying that some problems were more effective than others.

\section{Study 2}

The purpose of Study 2 was to explore why some tutorial groups do not identify certain faculty objectives. Thus, the attention in this study was focused on those faculty objectives definitely not identified by one or 
more tutorial groups (i.e., Type A mismatches). To investigate why some tutorial groups had failed to identify certain faculty objectives, further analyses were conducted.

\section{Procedure}

Faculty objectives not identified by one or more tutorial groups were ranked in a list, based on the number of tutorial groups omitting that specific faculty objective. This list was presented to a teacher who was familiar with the course content. He was asked to categorize the objectives listed using any classification he considered meaningful.

\section{Results}

The results of the match procedure described in Study 1 showed that 30 of 51 faculty objectives were omitted by one or more tutorial groups. The numbers of tutorial groups failing to identify one or more of these objectives ranged from one to eight. Of the 30 unidentified faculty objectives, nine were missed by one tutorial group, and another nine by two tutorial groups. Only two objectives were not identified by 8 of the 12 tutorial groups. On average, each tutorial group failed to identify 7.4 objectives. This implies that about $15 \%$ of the course objectives ( 7.4 out of 51) intended by the teachers were definitely not identified by the students as relevant to their learning.

The teacher's classifying procedure revealed three major categories of Type A mismatches: (1) Faculty objectives related not so much to problems as to other curricular activities, (2) objectives spanning more than one problem, and (3) psychological and sociological objectives. Although these categories are not mutually exclusive and exhaustive, they suggest why these faculty objectives were not identified by the students.

The first category consists of faculty objectives to be attained through curricular activities other than small-group work. It should be noted that the Medical Faculty of the University of Limburg not only tries to stimulate learning through problems, but also offers opportunities to master the medical domain through other instructional means. Some curricular objectives are to be achieved through laboratory work. Others are mastered through skills training such as physical examination training. Students participating in these curricular activities might have found it unnecessary to generate learning issues with regard to these objectives, because they had already studied the subject-matter in the context of other curricular activities. For example, training was offered to the students in which they learned how to examine the position of the fetus. One problem presented to the students also dealt with prenatal examina- 
tion, and the students were intended to study the different positions of the fetus. It appeared that some students did not identify this objective.

The second category consists of objectives broadly defined and requiring an extensive search into the literature. Examples of such objectives are "the influence of the environment on child development" and "theories of child development". These objectives hardly guide students in studying a specific topic, since they refer to very broad issues.

The third category consists of psychological and sociological faculty objectives, such as "psychological effects of being extremely tall compared to the age group" or "psychological well-being of a woman during pregnancy". The first example reflects an objective of the tall girl problem, described in the introduction section of this article. This objective was not identified by 8 out of the 12 tutorial groups.

Furthermore, the data suggest that, if faculty objectives of a certain problem focus on both biological and psychological objectives, students generate biological learning issues at the expense of psychological issues. By contrast, if a problem only contains psychological objectives, students do generate these issues and do identify the required course objectives.

\section{Study 3}

Self-directed learning implies that students are free to choose their own learning issues. As a consequence, they may generate issues not expected by faculty. These learning issues may still fit within the framework of the course, since PBL accords students an active role in the acquisition of knowledge. Study 3, therefore, concentrates on the nature of issues generated beyond faculty objectives (i.e., Type B mismatches). The guiding questions of Study 3 are: (1) To what degree do students generate unexpected learning issues? (2) to what extent may these issues be considered relevant to the course as a whole? and (3) why do students generate these issues?

This study highlights student-generated learning issues rather than faculty objectives. The data consisted of the student issues judged as 'not reflecting any of the faculty objectives'. If both raters agreed that a student-generated learning issue definitely did not correspond to any of the faculty objectives, this issue was categorized as an unexpected learning issue. 


\section{Procedure}

Unexpected learning issues were examined regarding their relevance to the content of the course. A faculty member who was familiar with the course content (i.e., the teacher who was responsible for the design of the course) was asked to judge the relevance of these learning issues. He had to indicate whether an issue was: (1) irrelevant, (2) fairly irrelevant, (3) neutral, (4) fairly relevant, or (5) relevant. In addition, exploratory analyses were conducted to examine why students generated unexpected learning issues. For this purpose the teacher was asked to sort these learning issues into meaningful categories.

\section{Results}

The 12 tutorial groups generated 520 leaming issues for the 12 problems. The raters agreed that 32 learning issues (6.2\%) definitely did not correspond to any of the faculty objectives. Of these 32 issues, eight were then judged as fairly irrelevant, nine as neutral, 14 as fairly relevant, and one as relevant. Consequently, $47 \%$ of the unexpected learning issues seemed to be at least fairly relevant to the course content.

The sorting procedure, which was conducted to identify key features of these unexpected issues, revealed four categories: (1) Learning issues related to prior knowledge deficiencies; (2) leaming issues focusing on patient management and medical intervention rather than on physiology or pathophysiology; (3) learning issues associated by faculty with additional curricular activities; and (4) learning issues arising from students' personal interests in, and experiences with the subject-matter.

The first category consists of learning issues associated with deficiencies in the students' prior knowledge. Faculty had not expected these learning issues to be generated because the issues were assumed to be a prerequisite to an initial understanding of the problem, studied by students in courses earlier in the curriculum. For example, a problem concerning the topic of child vaccination was developed to encourage students to study child vaccination schedules. Some tutorial groups, however, generated issues related to the immune system, although teachers assumed that this basic knowledge already had been mastered during a particular first year course. Thus, the learning issues associated with the immune system were related to deficiencies in the students' prior knowledge.

The second category contains learning issues to be addressed in later years of the program. The first two academic years at the Medical Faculty of the University of Limburg emphasize normal physiological and pathophysiological processes. Patient management and medical intervention are addressed in the third and fourth academic years. The 
problem of the tall girl, described in the introductory section, gave rise to learning issues such as "medical intervention of abnormal growth", "medication side-effects influencing normal growth", and "abnormal growth rate due to an intracerebral tumor". These learning issues focus on diagnosis and therapy rather than physiological processes. This implies that students sometimes generate learning issues that normally would be dealt with in later parts of the program.

Learning issues in the third category are associated with additional curricular activities such as training in physical examination skills. Although these issues are presented to the students in the laboratory rather than through problems, some students did generate these issues. A possible explanation is that these students actually did not participate in the training. For example, one tutorial group generated the learning issue "examination of the reflexes of a newborn", whereas this topic could have been addressed during skills training. Another possible explanation is that skills training has raised students' interest in the subject-matter, motivating them to spend more time on it.

The fourth category contains learning issues that can only partially be derived from the content of the course, because they were generated in response to salient details in the text of the problem rather than to the main focus of the problem. For example, a problem dealt with prenatal examination. One tutorial group generated the issue "purpose of physical training during pregnancy", referring to one sentence in the text of the problem in which the phrase "physical training during pregnancy" was mentioned. It was assumed that such learning issues arose from the students' personal interest or experiences. Furthermore, these issues are mostly connected with topics often discussed on television, newspapers, and other mass media.

In summary, it can be concluded that the students mainly generated unexpected learning issues in response to their own needs and interests. Although these issues were not planned by faculty, $47 \%$ of them were rated as either fairly relevant or relevant to the course content.

\section{General Discussion}

The result of the present study that an average of $64 \%$ of the faculty objectives for the set of 12 problems were actually generated as learning issues by the students, corresponds closely to the results reported by Tans et al. (1986). They found an overlap of $68.3 \%$. Both of these results differ from the percentage of overlap that was found in a study conducted by Coulson and Osborne (1984), who concluded that each 
faculty objective was generated on average by 5 out of 12 tutorial groups, an overlap of $42 \%$.

In the present study, the tutorial groups definitely failed to identify about $15 \%$ of the faculty objectives as being relevant to their learning. Analysis showed that these objectives were directly related to curricular activities other than specific problems, spanned more than one problem, or were psychological and sociological objectives rather than biological ones.

The percentage of student-generated learning issues that were not expected (i.e., did not correspond to any of the pre-set faculty objectives) was $6.2 \%$. Of these unexpected learning issues, $47 \%$ were judged by a teacher to be either fairly relevant or relevant to the objectives. Both of these percentages are low in comparison with the findings of Tans et al. (1986) who found that $21 \%$ of learning issues did not correspond to faculty objectives and that $77 \%$ of unexpected issues were either fairly relevant or relevant.

The results of the present study, including the nature of the unexpected learning issues (relating to students' deficiencies in knowledge of previous course work, anticipations of future course work, non-smallgroup curricular activities, personal activities, and personal interests and experiences), suggest that students in a problem-based curriculum are able to determine what they need to know and what is relevant to learn. Further, students seem to modify their learning to satisfy their own needs and interests.

It should be noted that it is not always certain that students actually pursue the learning activities suggested by the learning issues they raise. Probably, students will not study certain issues related to a particular problem when they have already studied the relevant material. It is also possible that students, during self-study, spend time on issues that were not generated initially but, nevertheless, appear from their study of the literature to be related to the problem. Moreover, it is possible that students pay much attention to a specific issue during discussion in the tutorial group but eventually decide not to list this issue. Thus, studentgenerated learning issues define what students plan to study, but it is not certain that students will actually study the issues they generate. Learning issues may only to some extent reflect actual learning. However, the available evidence suggests that learning issues are reasonably valid indicators of students' learning, since Tans et al. (1986) found a correlation coefficient of .42 between the frequency with which certain issues were listed and achievement on corresponding test items. Additional research is needed to further clarify the relationship between learning issues, learning activities, and outcomes. 
The percentage of overlap between faculty objectives and learning issues provides opportunities to detect ineffective problems, i.e., problems that do not lead students to generate the appropriate learning issues. The degree of overlap can be used to evaluate the effectiveness of newly designed problems, for instance, during curricular innovations. In the present study, the overlap between the faculty objectives and studentgenerated learning issues varied between $27.7 \%$ and $100 \%$ for the 12 problems. This is illustrated in Figure 1.

The one problem with an overlap percentage of only $27.7 \%$ seems to have been an ineffective problem. Although examining overlap percentages seems to be useful in detecting ineffective problems, additional information about the nature of the specific shortcomings of the problems is required to improve them. Problems to be designed for use in problem-based curricula should match the students' level of previously acquired knowledge, should be concretely formulated, should refer to students' future professions, and should be briefly formulated. Besides, problems should be open enough to stimulate discussion (Majoor, Schmidt, Snellen-Balendong, Moust, \& Stalenhoef-Halling, 1990). However, further research is needed to concentrate on the question of how to design effective problems. Despite the importance of problem effectiveness to guarantee coverage of a problem's content, little is known about the criteria by which problems could be designed or improved in order to guide students to pre-set faculty objectives.

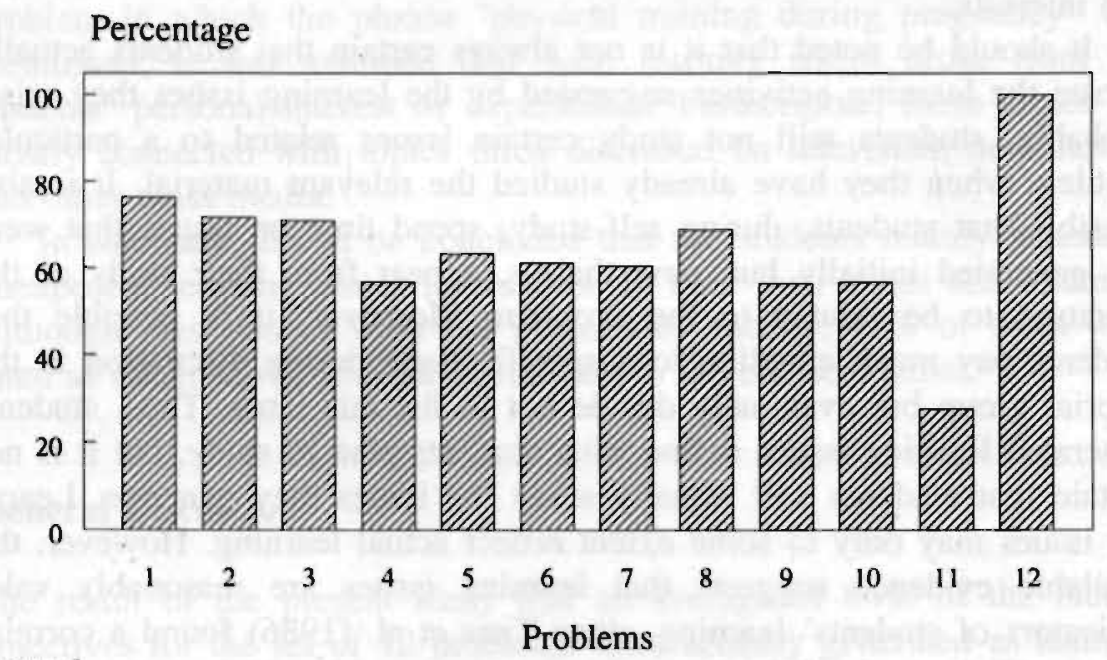

Figure 1

Percentages of overlap between pre-set faculty objectives and student-generated learning issues for problems in a second year course on normal pregnancy, delivery, and child development, academic year 1990-1991. 
Barrows, H.S. \& Tamblyn, R.M. (1980). Problem-based Learning. An Approach to Medical Education. New York: Springer.

Blumberg, P. \& Michael, J.A. (1992). Development of Self-directed Learning Behaviors in a Partially Teacher-directed Problem-based Learning Curriculum. Teaching and Learning in Medicine, 4, 1, 3-8.

Blumberg, P., Michael, J.A., \& Zeitz, H. (1990). Roles of Student-generated Learning Issues in Problem-based Learning. Teaching and Learning in Medicine, 2, 149-154.

Brown, J.S., Collins, A., \& Duguid, P. (1989). Situated Cognition and the Culture of Learning. Educational Researcher, 18, 32-42.

Coulson, R.L. \& Osborne, C.E. (1984). Insuring Curricular Content in a Studentdirected Problem-based Learning Program. In: H. G. Schmidt \& M. L. De Volder (Eds.). Tutorial in Problem-Based Learning. A New Direction in Teaching the Health Professions (pp. 225-229). The Netherlands: Van Gorcum.

Glaser, R. (1991). The Maturing of the Relationship Between the Science of Learning and Cognition and Educational Practice. Learning and Instruction, 1, 129-144.

Landis, J.R. \& Koch, G.G. (1977). The Measurement of Observer Agreement for Categorical Data. Biometrics, 33, 159-74.

Majoor, G.D., Schmidt, H.G., Snellen-Balendong, H.A.M., Moust, J.H.C., \& Stalenhoef-Halling, B. (1990). Construction of Problems for Problem-based Learning. In Z.M. Nooman, H.G. Schmidt, \& E.S. Ezzat (Eds.). Innovation in Medical Education: An Evaluation of Its Present Status (pp. 114-122). New York: Springer.

Norman, G.R. \& Schmidt, H.G. (1992). The Psychological Basis of Problem-based Learning. A Review of the Evidence. Academic Medicine, 67, 9, 557-565.

Schmidt, H.G. (1983). Problem-based Learning: Rationale and Description. Medical Education, 17, 11-16.

Schmidt, H.G., De Volder, M.L., De Grave, W.S., Moust, J.H.C., \& Patel, V.L. (1989). Explanatory Models in the Processing of Science Text: The Role of Prior Knowledge Activation Through Small-Group Discussion. Journal of Educational Psychology, 8, 4, 610-619.

Shahabudin, S.H. (1987). Content Coverage in Problem-based Learning. Medical Education, 21, 310-313.

Tans, R.W., Schmidt, H.G., Schade-Hoogeveen, B.E.J., \& Gijselaers W.H. (1986). Sturing van het onderwijsleerproces door middel van problemen: Een veldexperiment. [Directing the Learning Process by Means of Problems: A Field Experiment]. Tijdschrift voor Onderwijsresearch, 11, 1, 35-46.

Tulving, E. \& Thomson, D.M. (1973). Encoding Specificity and Retrieval Processes in Episodic Memory. Psychological Review, 80, 5, 352-373. 



\section{Utilization of Student-generated Learning Issues to Evaluate Problems in a Problem-based Curriculum}

\section{Abstract}

Student learning in a problem-based curriculum is largely dependent on the quality of the problems presented to students. Based on the discussion of these problems, students generate learning issues, defining the subject-matter to be studied during a course. These student-generated learning issues can be used as a review tool in improving problem effectiveness. At the Medical Faculty of the University of Limburg, the Netherlands, learning issues were collected in several courses during two consecutive academic years. The goal of the study was to investigate to what extent these learning issues can be used as a tool for problem evaluation and improvement. A questionnaire was administered to faculty to assess their perceptions. The results indicated that indeed studentgenerated learning issues were used for problem improvement. As a case study, the percentage of faculty objectives identified and the number of learning issues generated for each problem were computed for two courses during two consecutive years, to document to what extent problems were improved by making use of student-generated learning issues. Results showed that the percentages of faculty objectives identified and number of learning issues generated did not increase after improvements were made. It is argued that trade-off mechanisms may play a role, e.g., changing a particular problem influences the effectiveness of other problems. In addition, students may prioritize the generation of biological and physiological issues at the expense of psychological issues. Furthermore, faculty priorities assigned to their objectives should be taken into account when assessing problem effectiveness. 
Problems are essential as tools for problem-based learning (PBL). Students in a problem-based curriculum meet in small-group tutorials. During these sessions, they are confronted with problems. An example of such a problem is:

A few days ago Sophie's child was bom. The delivery took place without any complications. At home normal life has continued. Her husband has been working since yesterday. Sophie, however, sleeps badly and is tired all day. Breast feeding the child is painful. Above all, the baby starts crying when being fed. He is crying almost all day. A few minutes of walking hurts Sophie's legs. Furthermore, she is still bleeding. Although the obstetrician told her that this is quite normal, Sophie is worried about it. (1990-1991)

This problem was presented to students in a course in the second curriculum year which deals with normal child development. The tutorial group discusses problems such as this and tries to explain the phenomena described in terms of underlying processes, principles or mechanisms. During this discussion, issues emerge requiring further exploration (Schmidt, 1983). With regard to the problem described above, students might ask themselves questions about postnatal phenomena of the mother of the newborn child, such as, "how do uterus changes take place?", "what kind of hormonal changes take place?", "what is the psychological condition of the mother of a newborn child?", "what are differences between breast feeding and bottle feeding?", "how does recovery of the menstrual cycle take place?", "when are contraceptives required?", and "how to examine the growth and development of the newborn child?". In the context of PBL, these questions are considered learning issues in need of further investigation. They are assumed to be prerequisites to a better understanding of the problem (Blumberg, Michael, \& Zeitz, 1990). During the days before the next tutorial group session, students study material relevant to these learning issues. Usually, various learning resources are available, such as literature and audiovisual equipment. In the next session, students report what information they have assimilated and try to synthesize the newly acquired information (Barrows \& Tamblyn, 1980). Each tutorial group is guided by a tutor, a faculty member whose role is to facilitate the ongoing learning.

From this description, it becomes apparent that student learning in a problem-based curriculum is assumed to be largely dependent on the nature of the problems presented. Illustrative evidence comes from research conducted by Gijselaers and Schmidt (1990). They developed a 
causal model characterizing the important features of a problem-based curriculum. This model distinguishes between input variables such as tutor functioning, problem quality and prior knowledge, process variables such as group functioning and study time, and output variables, like student achievement and interest. A major result of their study was that problem effectiveness has a great overall influence on both process and outcome variables of problem-based learning. This is an important finding, since it provides opportunities for educational improvement; i.e., their findings suggest that student learning in a problem-based medical curriculum can be optimized by improving the effectiveness of problems.

Whereas problem effectiveness seems to have a great overall influence on student learning, interestingly, research conducted in this area tends to primarily focus on tutor characteristics influencing student learning (Eagle, Harasym, \& Mandin, 1992; Silver \& Wilkerson, 1991; Swanson, Stalenhoef-Halling, \& Van der Vleuten, 1990; Wilkerson, 1992). Only a few studies in problem-based learning address the issue of problem design. Majoor, Schmidt, Snellen-Balendong, Moust, and Stalenhoef-Halling (1990) and Bouhuijs and Gijselaers (1987) developed several criteria or rules which should be applied to the construction of problems. Solomon, Blumberg, and Shehata (1992) examined the extent to which age-related information in a problem influenced the tutorial discussion. Snellen-Balendong (1985) reported experiences with different problem formats. These studies all focus on problem design and do not suggest methods to assess problem effectiveness.

In this article, we will describe an attempt to assess the effectiveness of problems by comparing learning issues generated for a particular problem with the objectives that teachers had in mind while developing that problem. For example, the staff's objectives with regard to the problem described in the introduction were stated as follows: "Students should know which postnatal phenomena manifest themselves with respect to the mother of a newborn child, such as uterus changes, breast feeding, hormonal changes, psychological condition, recovery of menstrual cycle, and contraception. In addition, students should study examination of the growth and the development of the newborn child". It may be obvious that, if students fail to generate the appropriate learning issues, the pre-set faculty objectives are not identified. This is more or less equal to not accomplishing the intended learning goals, which in turn causes lack of content coverage. As a consequence, problem effectiveness may be defined as the match between student-generated learning issues and the pre-set objectives (Dolmans, Gijselaers, Schmidt, \& Van der Meer, 1993). In addition, we will demonstrate how results of this 
approach may contribute to the decision-making with regard to assessing and improving problem effectiveness.

In problem-based learning, a number of studies can be found that deal with student-generated learning issues. These studies primarily focus on examining whether students do actually identify the required knowledge, by comparing student-generated learning issues with the intended faculty objectives at the course level (Coulson \& Osborne, 1984; Shahabudin, 1987; Tans, Schmidt, Schade-Hoogeveen, \& Gijselaers, 1986). Despite the importance of student-generated learning issues in a problembased curriculum, it is surprising that until now only one study can be cited in the literature that focuses on the usefulness of student-generated learning issues as a tool in a larger policy-making process. Blumberg et al. (1990) conducted a study on the use of student-generated learning issues at seven North American Medical Faculties with a problem-based curriculum. These researchers concluded that student-generated learning issues play a varying role across institutions. In the 'classical' problembased medical curricula, as described by Barrows and Tamblyn (1980), student-generated learning issues define the entire content that students need to know. In less student-directed problem-based curricula, students also determine their own learning issues, but moreover compare their learning issues with faculty-derived objectives. Thus, the degree to which learning issues guide student learning is dependent on the extent to which the problem-based program is more or less student-centered or faculty-centered. Surprisingly, Blumberg et al. (1990) report that even in the student-centered problem-based curricula, unanimously recognizing the key role of learning issues, these issues are only scarcely used as a way of practicing quality control on the problem-based curriculum. Only 1 out of 7 faculties, under scope of the study of Blumberg et al. (1990), namely Rush Medical College, uses student-generated learning issues as feedback to faculty. In this school, learning issues generated by all tutorial groups for each problem are reviewed at the end of each quarter. These issues indicate which topics are covered by students. This information is used to prepare resource sessions in which basic-science faculty meet students to explain difficult concepts.

In summary, whereas research stresses the importance of problem effectiveness on student leaming in a problem-based curriculum and problems are assumed to be controllable and manageable, it is striking to see that until now little effort has been devoted to investigate how problem effectiveness can be improved. In addition, it is even more surprising to note that, even in those curricula in which learning issues are assumed to define content studied by students, these learning issues are not used as a review tool to improve problems. The purpose of the 
study reported here was to demonstrate that student-generated learning issues can indeed be used to do just that.

To that end, learning issues were collected in courses of the University of Limburg's problem-based medical curriculum during two consecutive academic years. These learning issues were reported to faculty responsible for problem design. This information should provide them with feedback about problem effectiveness. An example of the life cycle of a problem studied will elucidate how student-generated learning issues were used as a tool for problem review.

The fourth course in the first curriculum year deals with human life from the perspective of threat of proteins, cells, tissues, and organs through exogenous factors. The fourth problem addresses issues related to reactions to toxic substances. The text of Problem 4 in the academic year 1988-1989 is shown below.

\begin{abstract}
Problem 4: Acetaminophen (Paracetamol@) ${ }^{1}$
Acetaminophen is a valued pain-killer, which can be bought without prescription in a drugstore and is used by millions of people. After taking a tablet, the analgetic effect usually starts within one hour and lasts four to five hours. Acetaminophen is easily metabolized (half-life 1-3 hours) and normally has hardly any side-effects. There is, however, a snag somewhere. Acetaminophen has become one of the most popular suicidal drugs in Great Britain. After intake of more than 20 tablets, a dosage of 10 grams, in the first few hours often nausea and vomiting occur. After two days an acute liver damage manifests itself, which may be accompanied by jaundice. Depending on the dosage and individual sensitivity, the liver damage can become irreversible and in the end lead to hepatic coma and death. Early detection of the symptoms of acetaminophen intoxication is of great importance, since the hepatotoxity can be opposed by means of the antidotum N-Acetylcysteine. Adequate treatment with this drug can save a life. (1988-1989)
\end{abstract}

The objectives specified for this problem are: (1) What are the dynamics of drug absorption and distribution and how is acetaminophen metabolized? (2) which biotransformation reactions take place in the liver, especially first-phase reactions (oxidation, reduction, hydrolysis) and conjugations? (3) what is the cytochrome P-450 system? (4) what are the different ways of formation of metabolites? and (5) what is the influence of $\mathrm{N}$-acetylcysteine? Students should not focus on mechanisms of actions and side-effects of acetaminophen or other analgesics. Screening for and

1 Most PBL curricula are dominated by clinical cases. However, Schmidt (1983) considers a problem to be a description of a set of phenomena in need of some kind of explanation. 
treatment of intoxications should also not be issues to be studied. These issues are addressed in later years of the medical curriculum of the University of Limburg. ${ }^{2}$ Scrutinizing the learning issues generated for this problem demonstrated that many tutorial groups generated issues such as: (1) How does acetaminophen operate? (2) how does the antidotum operate? (3) what are the side-effects of acetaminophen? and (4) what is the relationship between acetaminophen and intoxication? The list of student-generated learning issues was discussed in the course planning group. One of the points highlighted during this discussion was that only a few tutorial groups generated learning issues referring to pharmacokinetics, whereas this was the most important objective that teachers had in mind while designing the problem. Most tutorial groups focused on mechanisms of action of acetaminophen. Based on these findings, the course planning group suggested changing the problem. It was decided that in the text of the problem too much attention was paid to the effects of an overdose of acetaminophen on the liver. Eliminating this effect and focusing the text of the problem on pharmacokinetics would probably improve the problem's effectiveness. This suggestion was discussed in the curriculum committee, which agreed with the proposed changes, since medical intervention should be studied by students in the third and fourth curriculum year. According to the curriculum committee, pharmacokinetics is an important issue to be addressed during this course. The course planning group changed the problem. The text of the re-designed problem, in the academic year 1989-1990, is shown below.

Problem: Acetaminophen

Henk is a first year medical student and a bit of a health freak. He is a jogger, uses little fat and alcoholic beverages, does not smoke and dislikes drugs. Recently, he has been regularly suffering from headaches. He considers taking a pain-killer, but after reading a chapter about pain-killers in a pharmacology textbook, he cannot see the wood for the trees. Therefore, Henk decides to visit his general practitioner (GP). The GP advises acetaminophen, which can be bought without prescription in a drugstore. The GP informs him furthermore that, after taking a tablet, the analgetic effect, usually starts within one hour and lasts four to five hours. Acetaminophen is easily metabolized (half-life 1-3 hours) and normally has hardly any side-effects. In addition, the GP tells that an overdose of

2 In 1987 the curriculum committee designed a blueprint of the program which indicates that the first two study years emphasize normal physiological and pathophysiological processes, whereas patient management and medical intervention are addressed in the third and fourth study year. 
acetaminophen, more than 20 tablets or a dosage of 10 grams, may cause severe liver damage, which sometimes can lead to death. This is closely related to the kinetics of acetaminophen and the biotransformation in the liver. The GP talks about metabolites, hydrophilia, cytochrome P450 and incomplete conjugation. Arriving at home, Henk still does not know exactly what the GP was talking about and decides to search for relevant literature. (1989-1990)

Scrutinizing the learning issues generated by the tutorial groups for this re-designed problem indicate that considerably more learning issues were generated with reference to pharmacokinetics, as compared to the year before. This finding provides evidence that this problem's quality was actually improved. However, some tutorial groups still generated learning issues about the mechanisms of action and side-effects of acetaminophen. But, since these tutorial groups also identified the pre-set faculty objective about pharmacokinetics, the problem needed no major revisions anymore according to the teachers responsible for the design of the problem.

Two sources of data were collected to investigate the usefulness of student-generated learning issues as a tool in improving problem effectiveness. First, faculty were asked to fill out a questionnaire to assess their experiences with the use of learning issues to review problems. Second, a case study was conducted to assess the actual effects of student-generated learning issues as a review tool. The percentage of faculty objectives identified were computed for each problem, before and after feedback was given to faculty responsible for problem design.

\section{Method}

\section{Subjects}

Learning issues were collected in six first year courses and five second year courses during two consecutive years. The number of tutorial groups attending each course was 18. These tutorial groups comprised about 150 students. Each course contained a number of problems varying between 10 and 19. The staff involved consisted of 11 planning groups, each including five to nine teachers. The course planning group is responsible for the construction, implementation, organization and evaluation of the course materials.

\section{Procedure}

The Medical Faculty of the University of Limburg initiated the collection of student-generated learning issues in the academic year 1988-1989. Faculty's need for this information was manifested, since a new curric- 
ulum, and, hence, new problems were being implemented in the first curriculum year. In all six courses of the first curriculum year, learning issues were collected. Since one year later newly designed problems were introduced in the second curriculum year as well, the collection of learning issues was also implemented in five second year courses during the academic year 1989-1990. In each curriculum year, learning issues were collected during two consecutive academic years, since it was assumed that problem effectiveness would be optimized within two years if student-generated learning issues were available to provide faculty with feedback about problem effectiveness.

Student-generated learning issues were collected by asking each tutor to note on a form the learning issues generated for each problem by his or her tutorial group. Besides, the tutor could add comments with regard to problem effectiveness on this form. The completed forms were sent to the educational administration office within two weeks after the end of course. The average response rate of these 11 courses during two consecutive years was 73 percent, and varied for each course between 56 and 94 percent. Subsequently, a report was produced containing a list of learning issues generated by all tutorial groups for each problem. Copies of the report were sent to the coordinator of the course planning group and its members. As already said before, the course planning group, consisting of a multidisciplinary team of five faculty members, is responsible for carrying out changes to improve problem effectiveness. In addition, the curriculum committee received copies of the reports. The curriculum committee keeps track of the adequacy and relevance of the course materials and gives advice to the course planning group. These committees and individuals use the list of student-generated learning issues as a tool in a larger policy-making process of improving problem effectiveness. The course planning group assessed the adequacy of the problems. If a problem leads students to the generation of learning issues similar to the pre-set faculty objectives, the problem is decided to be effective and no changes are required. However, if the problem failed to guide students to identifying important objectives, the course planning group is required to improve the problem. The priority of objectives to be identified by tutorial groups is decided by the course planning group. The course planning group discusses these priorities and suggests which major revision they are going to carry out. These suggestions are reported to the curriculum committee, which gives advice to the course planning group.

Subsequently, a questionnaire was constructed to assess faculty experiences with the use of student-generated learning issues. After one year of collecting student-generated learning issues, six course coordina- 
tors of the first curriculum year (1988-1989), and five members of the curriculum committee were asked to fill out a questionnaire, consisting of eight statements. These statements were, for example: "Studentgenerated learning issues indicate whether students are able to identify the pre-set faculty objectives" and "problems were actually improved by making use of student-generated learning issues". The statements are listed in Table 1. Respondents were asked to indicate on a 5-point Likert scale whether they (1) totally disagree, (2) disagree, (3) are neutral, (4) agree or (5) totally agree with each statement. The questionnaire also included an open-ended question in which respondents were offered the opportunity to suggest possible improvements.

In addition, as a case study, learning issues collected during two courses were studied to assess how much problems improved by making use of student-generated learning issues. To that end, registration was made of the percentage of faculty objectives that were identified and the extent to which learning issues were generated for each problem, before and after problem review. The first course in the scope of this case study was a 6-week second year course on normal child development. This course dealt with subject-matter related to childbirth, psychomotor development, and psychosexual development. The course contained 13 problems in the academic year 1989-1990 and 12 problems in 1990-1991 that were presented to the students for discussion. The tutors participating in this course were asked to record for each problem all learning issues generated by their tutorial group, in both the academic years 19891990 and 1990-1991. The average number of learning issues generated for each problem were calculated. Subsequently, 13 and 12 pairs of expert raters respectively were asked to judge the match between faculty objectives and student-generated learning issues. They were instructed to judge individually the correspondence between student issues and faculty objectives (Dolmans et al., 1993). For each comparison, raters had to judge whether a particular learning issue was definitely similar to a particular faculty objective or was definitely dissimilar. The cases in which raters could not give definite judgements were considered dissimilar. A faculty objective was assumed to be identified if both raters agreed about its similarity to the learning issue judged. If both raters agreed that there was no similarity, then an objective was considered as being not identified by the students. If both raters disagreed, i.e., if one rater observed similarity and the other failed to do so, then an objective was also assumed not to have been identified. The average percentage of faculty objectives identified by the 12 tutorial groups for each problem was computed. These data were presented to the course planning group, during both academic years. Based on these data and on the list of 
learning issues generated for each problem, some problems were improved. The same procedure was conducted in a first year course. This course dealt with social, legal, economic and ethical aspects of health care. The materials in this study consisted of nine problems in the academic year 1990-1991 and 11 problems in 1991-1992. 9 and 11 pairs of expert raters respectively were asked to judge the match between faculty objectives and learning issues. They were instructed in the same way as the expert raters in the second year course, described above. For each problem, the average percentage of faculty objectives identified and the number of learning issues generated were computed.

\section{Results}

\section{Faculty Perceptions}

A questionnaire was constructed to assess the adequacy of learning issues in improving problem effectiveness. The respondents were six course coordinators of the first curriculum year, in the academic year 1988-1989, and five members of the curriculum committee. The response rate was 79 percent. These respondents were asked to rate nine statements on a 5-point Likert scale from: (1) totally disagree, to (5) totally agree. The results of this questionnaire are reported in Table 1.

These results indicate that learning issues are clearly presented in the reports. Besides, learning issues seem to provide information whether students were able to identify the pre-set objectives. The lowest scoring statement insisted that learning issues provide information about subjectmatter lacking in a course. In addition, the results indicate that learning issues provide additional information about problem effectiveness as compared to program evaluation instruments regularly used at the Medical Faculty of the University of Limburg, in which students are asked to indicate on a 5-point Likert scale how much they agree with statements insisting that: "Problems were clearly stated", "problems stimulated the discussion in the tutorial group", and "the number of problems included in the course was adequate". The average score on the overall statement insisting that learning issues contain valuable information about problem effectiveness was $3.9(S D=.83)$. Moreover, the course coordinators highly agreed with the statement insisting that problems were actually improved by making use of learning issues; an average score of $3.8(S D=.75)$. Respondents' comments on the open-ended question revealed that learning issues are especially useful when implementing newly designed problems. After two years of experiences with a course, learning issues should only be collected for newly designed or 
improved problems. Furthermore, respondents reported that tutor's comments with regard to the problems contain important guidelines how to improve a poor problem. Based on these tutor comments problems were actually improved. One respondent suggested including the course objectives in the list of learning issues, since this would enable the course planning group to evaluate problems more easily. In general, the results of this questionnaire indicate that faculty perceive learning issues as a relevant source of information to improve problems.

\section{Table 1}

Results from the questionnaire to assess the usefulness of student-generated learning issues, mean scores, standard deviation (SD) and number of respondents $(\mathrm{N})$.

Mean

SD

$\mathrm{N}$

1 The report containing student-generated learning issues was clearly presented

2 Student-generated learning issues indicate whether students are able to identify the pre-set faculty objectives

3 Student-generated learning issues provide information about subject-matter lacking in the course content

4 Student-generated learning issues provide insight into students' learning activities regarding a particular problem

$\begin{array}{lll}3.1 & 94 \quad 11\end{array}$

5 Student-generated learning issues contain relevant information to improve problems

6 Student-generated leaming issues provide additional information about problem effectiveness as compared to program evaluation instruments regularly used

\begin{tabular}{l|l|l}
4.2 & .98 & 11
\end{tabular}

7 In general, student-generated learning issues contain valuable information about problem effectiveness

8 Problems were actually improved by making use of student-generated learning issues

3 This question was addressed only to the coordinators of the course planning group, since they were responsible for the design of the problems. 


\section{The Case Study}

The percentages of faculty objectives identified and number of learning issues generated for each problem were computed for two courses during two consecutive years to document to what extent problems were improved by making use of learning issues. The results of a second year course on normal child development for the academic years 1989-1990 and 1990-1991 are presented in Table 2. The results indicate that at the course level, an average percentage of 62.4 of the faculty objectives was identified by students. For each problem, the percentage of overlap varied between 33.3 and 77.0. Low scoring problems were in order problems 12,9 , and 4 . The course planning group decided to change problems $5,8,11$, and 12 . It is clear that the re-designed problems were only to some extent those which scored low on the percentage of faculty objectives identified. This finding indicates that problems were changed not only by making use of these data.

The changes that were carried out will be briefly summarized. First, Problem 5 was changed. This problem deals with postnatal phenomena of the mother of the newborn child from a physiological perspective as well as a psychological perspective. In addition, the examination of growth and development of the newborn child is a central issue. In the academic year 1989-1990, the text of this problem consisted of a description of a general practitioner who visits the mother of the newborn child in the first week after delivery to examine the condition of mother and child. Learning issues generated for this problem were for the most part related to physiological processes, whereas psychological processes were systematically ignored. Only one tutorial group generated a learning issue related to the psychological condition of the mother during childbed. Discussing this result in the course planning group resulted in changing the problem because of a discrepancy between the faculty objectives and student-generated learning issues. The improvements carried out consisted of adding a few cues to the text of the problem related to psychological well-being of mother and child. The text of the re-designed problem was shown in the first paragraph of the introduction section of this chapter. The list of learning issues in the academic year 1990-1991 showed that 9 out of 12 tutorial groups generated a learning issue related to the psychological condition of the mother during childbed. The results in Table 2 show that, for Problem 5, the percentage of overlap between faculty objectives and learning issues was nearly similar, whereas the number of learning issues identified increased from $2.6(S D=1.3)$ to $4.5(S D=1.7)$. 
Table 2

Percentages of overlap between faculty objectives and student-generated learning issues and number of learning issues generated for each problem in a second year course on normal child development during two consecutive academic years, 19891990 and 1990-1991. Mean scores and standard deviations (SD) are shown.

\begin{tabular}{|c|c|c|c|c|c|c|c|c|c|}
\hline \multirow{2}{*}{$\begin{array}{l}\text { Problems } \\
89-90\end{array}$} & \multicolumn{2}{|l|}{ Overlap } & \multicolumn{2}{|c|}{$\begin{array}{l}\text { Number of } \\
\text { learning } \\
\text { issues }\end{array}$} & $\begin{array}{l}\text { Problems } \\
90-91\end{array}$ & \multicolumn{2}{|l|}{ Overlap } & \multicolumn{2}{|c|}{$\begin{array}{l}\text { Number of } \\
\text { learning } \\
\text { issues }\end{array}$} \\
\hline & Mean & SD & Mean & SD & & Mean & SD & Mean & SD \\
\hline 1 & 77.0 & 19.8 & 5.9 & 1.5 & 1 & 76.3 & 16.4 & 7.1 & 2.0 \\
\hline 2 & 70.3 & 27.5 & 3.5 & 2.2 & 2 & 71.7 & 21.7 & 2.8 & 1.1 \\
\hline 3 & 70.8 & 31.7 & 4.7 & 1.2 & 3 & 70.8 & 20.9 & 4.3 & 1.4 \\
\hline 4 & 50.1 & 23.2 & 4.9 & 3.0 & 4 & 56.7 & 25.3 & 5.3 & 1.8 \\
\hline 5 & 65.2 & 28.3 & 2.6 & 1.3 & $5 *$ & 63.3 & 20.6 & 4.5 & 1.7 \\
\hline 6 & 63.7 & 23.5 & 2.8 & 1.3 & 6 & 61.1 & 28.0 & 3.0 & 1.3 \\
\hline 7 & 70.8 & 20.9 & 3.4 & 1.1 & & & & & \\
\hline 8 & 72.3 & 31.3 & 4.0 & 1.1 & $7 *$ & 60.4 & 27.1 & 3.6 & 1.4 \\
\hline 9 & 50.0 & 20.0 & 3.1 & 0.7 & 8 & 68.8 & 15.5 & 3.4 & 1.8 \\
\hline 10 & 62.5 & 25.0 & 2.4 & 0.9 & 9 & 56.3 & 21.7 & 2.9 & 1.2 \\
\hline 11 & 62.5 & 16.9 & 3.1 & 1.0 & $10 *$ & 56.7 & 29.3 & 3.3 & 0.6 \\
\hline 12 & 33.3 & 24.7 & 2.2 & 0.7 & $11 *$ & 27.7 & 24.0 & 2.4 & 1.1 \\
\hline 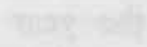 & & & & & $12 *$ & 100.0 & 00.0 & 2.3 & 0.8 \\
\hline Total & 62.4 & 26.6 & 3.6 & 1.8 & & 64.2 & 26.7 & 3.7 & 1.9 \\
\hline
\end{tabular}

* These problems were re-designed in the academic year 1990-1991. Problems 7 and 8 were combined in one problem, due to which the numbering of problems changed.

Problems 7 and 8 about the development of the immune system were also changed, although the percentages of overlap seem to be sufficiently high. During the discussion in the course planning group it was argued that relatively too much time was spent on this issue, due to which less time was paid on problems that were of higher importance. Therefore, the course planning group decided to combine both problems in one problem. Probably as a result of this combination, the percentage of overlap decreased. In addition, Problem 11 on normal rates of child growth was changed. The text of the problem was re-designed, based on tutors' comments that this problem was not clearly stated and contained 
too many cues that were not relevant. Moreover, the course planning group decided that psychological aspects of being extremely tall should be included. The percentage of overlap actually declined after improvements were carried out, probably due to the fact that a psychological objective was added. Problem 12, the lowest scoring problem, was also changed. This problem dealt with puberty. Although the text of the problem was changed, because some cues in the text of the problem led students to the generation of learning issues that were not intended, the percentage of overlap did not change. Finally, the 1989-1990 course also contained a problem about psychosexual development during puberty and adolescence, Problem 13. However, no learning issues were generated for this problem, due to end-of-the-course effects whereby students are less motivated. Besides, no tutorial session was left to discuss the learning issues generated for this problem. In the academic year 1990-1991, the percentage of faculty objectives identified for this problem was 100 percent. Since the course contained 12 instead of 13 problems, students could spent time on this issue. However, because this problem was the last one in the course, the course planning group had only one objective in mind that students should identify. They argued that students during the last tutorial session are less motivated to spend a lot of time and energy on studying the learning issues they generated. All tutorial groups identified the objective that faculty had in mind while developing the problem. The average percentage of faculty objectives identified at the course level was quite similar to that of the same course in the year before changes were carried out. This also holds for the average number of learning issues identified.

The same procedure was conducted in a first year course on social, legal, economic and ethical aspects of health care. The results, presented in Table 3, indicate that at the course level, an average percentage of 67.4 percent of the faculty objectives was identified by students in 1990-1991. For each problem, the percentage of overlap varied between 50.0 and 80.1 percent. Although only Problem 3 scored low, the course planning group decided to change quite a number of problems: $1,3,4,5,8$, and 9. Problem 2 on individual and social aspects of chronic diseases was removed, because the objectives specified for this problem were judged to be of low importance. These findings indicate that problems were not only changed by making use of student-generated leaming issues. The changes were merely based on students' complaints that the problems were too intangible. The planning group decided to rewrite the problems and tried to make them more concrete. The percentage of faculty objectives identified was higher for all the re-designed problems, with the 
exception of Problem 8, dealing with economic aspects of health care. However, although Problems 5 and 6 in 1990-1991 were not changed, the percentage of faculty objectives identified for these problems was also higher. The average percentage of faculty objectives identified at the course level improved from 67.4 to 75.7 percent, after changes were carried out. The average number of learning issues generated at the course level was quite similar before and after improvements were made. In summary, the results of both courses do not provide clear evidence that problem effectiveness actually improved by making use of studentgenerated learning issues.

\section{Table 3}

Percentages of overlap between faculty objectives and student-generated learning issues and number of learning issues generated for each problem in a first year course on social, legal, economic and ethical aspects of health care during two consecutive academic years, 1990-1991 and 1991-1992. Mean scores and standard deviations (SD) are shown.

\begin{tabular}{|c|c|c|c|c|c|c|c|c|c|}
\hline \multirow[t]{2}{*}{$\begin{array}{l}\text { Problems } \\
90-91\end{array}$} & \multicolumn{2}{|c|}{ Overlap } & \multicolumn{2}{|c|}{$\begin{array}{l}\text { Number of } \\
\text { learning } \\
\text { issues }\end{array}$} & \multirow[t]{2}{*}{$\begin{array}{l}\text { Problems } \\
91-92\end{array}$} & \multicolumn{2}{|c|}{ Overlap } & \multicolumn{2}{|c|}{$\begin{array}{l}\text { Number of } \\
\text { learning } \\
\text { issues }\end{array}$} \\
\hline & Mean & SD & Mean & SD & & Mean & SD & Mear & $S D$ \\
\hline 1 & 66.7 & 27.4 & 2.7 & 0.9 & $1 *$ & 90.9 & 21.6 & 3.0 & 0.8 \\
\hline 2 & 75.0 & 29.7 & 2.4 & 1.1 & & & & & \\
\hline 3 & 50.0 & 50.0 & 3.6 & 1.3 & $2 *$ & 65.9 & 30.2 & 1.5 & 0.5 \\
\hline 4 & 65.0 & 33.7 & 3.7 & 1.8 & $5 *$ & 83.4 & 32.4 & 3.8 & 1.9 \\
\hline 5 & 58.0 & 22.0 & 4.3 & 2.6 & 6 & 80.0 & 23.7 & 3.5 & 1.2 \\
\hline 6 & 67.5 & 20.6 & 3.4 & 1.5 & 7 & 84.1 & 20.2 & 3.2 & 1.1 \\
\hline 7 & 72.2 & 44.1 & 1.9 & 0.8 & 10 & 72.7 & 34.4 & 2.5 & 0.9 \\
\hline 8 & 80.1 & 23.3 & 2.1 & 1.0 & $9 *$ & 59.1 & 34.0 & 2.5 & 0.9 \\
\hline 9 & 75.0 & 27.4 & 2.3 & 0.5 & $8 *$ & 85.0 & 31.6 & 2.9 & 2.1 \\
\hline & & & & & $3 *$ & 69.8 & 23.4 & 3.6 & 1.1 \\
\hline & & & & & $4^{*}$ & 84.1 & 20.2 & 3.8 & 1.2 \\
\hline & & & & & $11 *$ & 59.1 & 43.7 & 2.0 & 0.8 \\
\hline Total & 67.4 & 31.8 & 3.0 & 1.6 & & 75.7 & 30.2 & 2.9 & 1.4 \\
\hline
\end{tabular}

* These problems were re-designed in the academic year 1991-1992. Problem 2 was removed, due to which the numbering of problems changed. 


\section{Discussion}

The aim of this article was to demonstrate that student-generated learning issues may provide rich and descriptive information about problem effectiveness suggesting avenues for improvement. The collection of student-generated learning issues at the Medical Faculty of the University of Limburg is actually incorporated in program evaluation as a review tool. The course planning group, responsible for the construction, implementation and evaluation of the course, uses the learning issues as a source of information to assess problem effectiveness. This was illustrated through an example of a problem about acetaminophen.

In addition, results from a questionnaire indicated that information about student-generated learning issues was actually used to improve problem effectiveness. Especially, when newly designed problems are implemented, student-generated learning issues seem to provide the course planning group with useful information about problem effectiveness. Tutors' comments with regard to the learning issues generated provide many suggestions about how problems could be improved. At present, the collection of learning issues takes place at the Medical Faculty when a course contains several newly designed problems.

Since the results of the questionnaire reflect faculty perceptions about the usefulness of student-generated leaming issues, a case study was conducted to obtain data on the extent to which problems actually improved by making use of learning issues. These data consisted of the percentage of faculty objectives identified for each problem and the number of learning issues generated before and after renewing the problems. The results showed that decisions made in the course planning group with regard to necessary improvements to be carried out were not based only on the percentage of faculty objectives identified or the number of learning issues generated, since even high scoring problems were changed; i.e. although a problem scored high with respect to the percentage of faculty objectives identified, the problem was re-designed. Moreover, the results demonstrated that the percentage of faculty objectives identified did not automatically increase after improvements were carried out. Several reasons may account for these results.

First, trade-off mechanisms may occur when problems are changed within a course; i.e., changing a particular problem influences the effectiveness of other problems. Several examples can illustrate this effect. Although Problems 5 and 6 of the first year course on social, legal, economic and ethical aspects were not changed, the percentages of faculty objectives identified were higher. The same holds for Problem 4 in the second year course about normal child development. Furthermore, 
Problems 7 and 8 about the development of the immune system in the second year course were combined into one problem, due to which the percentage of overlap decreased. This demonstrates that problems cannot be designed or re-designed in isolation, because they belong together and build upon each other.

Second, students' priorities regarding particular learning issues may influence problem effectiveness. For example, the results for both Problems 11 and 12 in the second year course might be explained by faculty observations that students do not study the social science issues or even consider them to be learning issues to the same extent as to which they study biological or physiological issues. Problem 11 in the second year course dealt with normal rates of child growth. The text of the problem was re-designed and a faculty objective about psychological aspects of being extremely tall was added. The percentage of faculty objectives identified declined after revision. Problem 12 in the same second year course which dealt with puberty was also changed. The percentage of overlap did not change and was still very low. Both Problems 11 and 12 address social science issues and as such are not favorite problems for most medical students. A previous study (Dolmans et al., 1993) assessing problem effectiveness also indicated that students prefer biological and physiological learning issues at the expense of psychological issues. These preferences may also account for the results of the case study demonstrating that although problems were changed, the percentage of faculty objectives identified did not improve.

Third, percentages of faculty objectives identified provide only partial information about the effectiveness of problems. The priority of certain faculty objectives should also be taken into account to assess problem effectiveness adequately. For example, Problems 7 and 8 about the immune system were combined into one problem, since the members of the course planning group were of opinion that too much time was spent on this issue at the expense of other faculty objectives, which they perceived to be of greater importance. This illustrates that faculty decisions regarding problem effectiveness are not only based on the percentages of faculty objectives identified. Faculty priorities assigned to the faculty objectives incorporated in problem design should also be taken into account when assessing problem effectiveness. Presenting a list of student-generated learning issues initiates a discussion in a course planning group about the major objectives to be achieved for each problem. As such, student-generated learning issues encourage faculty to clearly specify what the objectives of each problem are. This discussion increases the possibility that problems are designed based on explicit rational considerations which may contribute towards high quality 
problems. Thus, student-generated learning issues provide a useful tool to improve problem effectiveness.

In summary, it is argued that trade-off mechanisms, i.e., changing a particular problem influences the effectiveness of other problems, and students' priorities to generate biological and physiological issues at the expense of psychological issues may explain why the percentage of faculty objectives identified did not increase after improvements were made. Furthermore, preferences assigned to faculty objectives should be taken into account when assessing problem effectiveness and deciding to review problems. Nevertheless, student-generated learning issues can be used as a review tool incorporated in program evaluation. Faculty perceptions suggest that learning issues can be used as a tool of practicing quality control aimed at improving problem effectiveness. 
Barrows, H.S. \& Tamblyn, R.M. (1980). Problem-based Learning. An Approach to Medical Education. New York: Springer.

Blumberg, P., Michael, J.A., \& Zeitz, H. (1990). Roles of Student-generated Learning Issues in a Problem-based Curriculum. Teaching and Learning in Medicine, 2, 3, 149-154.

Bouhuijs, P., \& Gijselaers, W. (1987). De constructie van taken in probleemgestuurd onderwijs. [Construction of Problems in a Problem-based Curriculum]. Vorming, 36, 26-39.

Coulson, R.L. \& Osborne, C.E. (1984). Insuring Curricular Content in a Studentdirected Problem-based Learning Program. In: H.G. Schmidt \& M.L. De Volder (Eds.). Tutorials in Problem-based Learning. A New Direction in Teaching the Health Professions (pp. 225-229). The Netherlands: Van Gorcum.

Dolmans, D.H.J.M., Gijselaers, W.H., Schmidt, H.G., \& Van der Meer, S.B. (1993). Problem Effectiveness in a Course Using Problem-based Learning. Academic Medicine, 68, 3, 207-213.

Eagle, C.J., Harasym, P.H., \& Mandin, H. (1992). Effects of Tutors with Case Expertise on Problem-based Leaming Issues. Academic Medicine, 67, 7, 465-469.

Gijselaers, W.H. \& Schmidt, H.G. (1990). Development and Evaluation of a Causal Model of Problem-based Learning. In: Z.M. Nooman, H.G. Schmidt, \& E.S. Ezzat, (Eds.). Innovation in Medical Education. An Evaluation of Its Present Status (pp. 95-113). New York: Springer.

Majoor, G.D., Schmidt, H.G., Snellen-Balendong, H.A.M., Moust, J.H.C., \& Stalenhoef-Halling, B. (1990). Construction of Problems for Problem-based Leaming. In: Z.M. Nooman, H.G. Schmidt, \& E.S. Ezzat, (Eds.). Innovation in Medical Education. An Evaluation of Its Present Status (pp. 114-122). New York: Springer.

Schmidt, H.G. (1983). Problem-based Learning: Rationale and Description. Medical Education, 17, 11-16.

Shahabudin, S.H. (1987). Content Coverage in Problem-based Learning. Medical Education, 21, 310-313.

Silver, M. \& Wilkerson, L. (1991). Effects of Tutors with Subject Expertise on the Problem-based Tutorial Process. Academic Medicine, 66, 5, 298-300.

Snellen-Balendong, H. (1985). Development of Formats for Tasks and Problems in Problem-based Learning. In: W.S. De Grave, J.H.C. Moust, \& H.G. Schmidt (Eds.). Tutorials in Problem-based Learning. A New Direction in Teaching the Health Professions (pp. 83-94). The Netherlands: University of Limburg.

Solomon, P.E., Blumberg, P., \& Shehata, A. (1992). The Influence of Patient Age on Problem-based Tutorial Discussion. Academic Medicine, 67, 10, S31-S33.

Swanson, D.B., Stalenhoef-Halling, B., \& Van der Vleuten, C.P.M. (1990). Effect of Tutor Characteristics on Test Performance of Students in a Problem-based Curriculum. In: W. Bender, R.J. Hiemstra, A.J.J.A. Scherpbier, \& R.P. Zwierstra (Eds.). Teaching and Assessing Clinical Competence (pp.129-133). Groningen: Boekwerk. 
Tans, R.W., Schmidt, H.G., Schade-Hoogeveen, B.E.J., \& Gijselaers, W.H. (1986). Sturing van het onderwijsleerproces door middel van problemen: Een veldexperiment. [Directing the Learning Process by Means of Problems: A Field Experiment]. Tijdschrift voor Onderwijsresearch, 11, 1, 35-46.

Wilkerson, L. (1992, April). Identification of Skills for the Problem-based Tutor: Student and Faculty Perspectives. Paper presented at the Annual Meeting of the American Educational Research Association, San Francisco, CA. 


\title{
4
}

\section{Course Content Coverage as a Measure of Instructional Quality'}

\begin{abstract}
In order to measure instructional quality, several methods have been proposed in the literature, among them student performance on achievement tests and student ratings of the quality of instruction. Both methods have in common that they tend to ignore course content coverage, whereas this is an important determinant of instructional quality. In this chapter a procedure is described which is used to assess students' actual learning activities. This procedure, the Topic Checklist, makes use of student ratings. Reliability, validity and utility studies were conducted. The results suggest that the Topic Checklist is a reliable and fairly valid procedure to evaluate course content coverage and to detect problem areas in a course providing feedback useful for carrying out improvements.
\end{abstract}

\section{Introduction}

Assessment of instructional quality in higher education is usually based upon two methods: (1) the measurement of educational outcomes, expressed as students' performances on various tests; and (2) measurement of the educational process by making use of student ratings. Each method has its own strengths and shortcomings. The first method focuses

1 Parts of this article were presented at the Annual Meeting of the American Educational Research Association, April 1991, Chicago, Illinois. (ERIC Document Reproduction Service No. ED334 220) 
on measuring learning outcomes by means of achievement tests. Student performances on achievement tests are assumed to be a direct measure of student mastery of the course objectives. Scores on achievement tests reflect the actual knowledge of a group of students or an individual student in the subject-matter domain. As such, they provide evaluative information whether the educational goals are attained.

The second method focuses on the educational process rather than on educational outcomes. The most widely used method in this field takes the form of a questionnaire through which students are asked to rate several aspects of the program such as adequacy of instructional materials and teaching skills. In this tradition it is assumed that the quality of a program influences educational effectiveness. As a consequence, evaluation should focus on measuring and improving the quality of various aspects of the program. This evaluation method is commonplace in many institutions of higher education. According to Marsh (1984), the purposes of this evaluation are to provide: (1) diagnostic feedback to faculty about their effectiveness, (2) a measure of teaching effectiveness to be used in promotion decisions, (3) information for students in the selection of courses, and (4) evaluation of the process for research on teaching. Several studies indicate that student ratings provide reliable and valid information on the quality of instruction (Costin, Greenough, \& Menges, 1971; Feldman, 1977; Marsh, 1982). Besides, student ratings provide information for diagnosing instructional strengths and weaknesses which can be used to improve the program. As such, student ratings have had a positive impact on quality of teaching in higher education (Murray, 1990). In summary, student ratings are assumed to be an indirect measure of educational quality, since it is generally accepted that quality of instructional materials and lectures positively influences student learning, which in turn influences student mastery of course objectives. Evaluation based on achievement test scores, on the other hand, is assumed to be a direct measure of educational effectiveness.

Despite the obvious advantages of using test scores for evaluating educational effectiveness, achievement tests have certain shortcomings for evaluation purposes. One of the major criticisms is that we do not know what factors might have contributed to or hindered the achievement of the course objectives. Low test scores on tests or parts of them may be due to various deficiencies which cannot easily be discerned. For example, poor performances may be a result of (1) lack of effort by students, (2) difficulty level of items, or (3) inadequate match between course content and test content. First, lack of effort implies that students have spent less time on studying the course content, which in turn 
influences the degree to which they master the course objectives, reflected by low test scores. In addition, low scores may be caused by test items that are too difficult to be answered correctly. Students might have spent a lot of time on studying the test content, but the high difficulty level of the items results in low scores. Finally, poor performances on specific parts of the test could indicate that the subject-matter to be tested does not adequately correspond with the objectives set for the course. In this case, students are tested about topics not included in the course objectives. Besides, test items, although reflecting the course objectives, may not correspond with the instructional materials used, or with topics addressed during instruction (Schmidt, Porter, Schwille, Floden, \& Freeman, 1983). In such cases, students did not have the opportunity to learn the information tested and are being penalized for the failures of instruction. Naturally, the same arguments hold for high performance scores. In summary, it can be concluded that test performance is a questionable measure to evaluate instructional quality because the source of performance cannot easily be discerned.

Although student ratings are accepted as reliable and valid measures, they also have certain shortcomings. One of the major objections is that these ratings do not reflect how well students have learned or have achieved the educational goals (Rotem \& Glasman, 1979). For example, it may be possible that a certain lecture was rated highly, whereas the content of the lecture did not correspond with the course objectives. This implies that the educational goals may not be realized. Although instruction and materials used might be adequate, this will not guarantee that the course objectives are achieved by students. In other words, highly rated instruction does not compensate for missing content. This notion is confirmed by research conducted by Cooley and Leinhardt (1980).

Cooley and Leinhardt (1980) conducted a study, the Instructional Dimensions Study, which attempted to identify effective classroom processes. They investigated a model of classroom processes that identifies variables that attempts to explain the variation in student performances. These variables or constructs included opportunity to learn, motivators, instructional events and structure. Opportunity deals with how time is spent in classrooms and the overlap between test and curriculum. This variable consisted of two measures: (1) teachers' estimates of what was covered during a certain period, and (2) a result of content analysis of the curricular materials used in the classroom. Motivators consisted of aspects encouraging learning. Instructional events included the content, frequency, quality and duration of instruction. Structure considers the organization of the curriculum. The results of their study revealed that the variable opportunity to learn correlated most 
highly with achievement gain. They concluded that students perform better on a test if they have been taught the materials covered by the test. An implication of the importance of opportunity to learn is, according to Cooley and Leinhardt (1980), that evaluation studies should include information on how time is spent and the degree of overlap between what is tested and what is taught.

In summary, methods assessing educational quality focus on either educational outcomes or educational processes. Both methods have in common that they tend to ignore course content coverage as an important determinant of instructional quality. However, ignoring what is actually covered during a course seems to be in contradiction with the generally accepted finding that emphasizing different curricular content produces correspondingly different patterns of achievement (Madaus \& Kellaghan, 1992). As Cooley and Leinhardt (1980) showed, opportunity to learn is the strongest and most consistent predictor of achievement. As a consequence, evaluation of educational effectiveness should also focus on what actually happens during instruction or what content is covered during instruction.

Indeed, several attempts have been made to develop evaluation procedures considering course content coverage. Schmidt et al. (1983) described a procedure measuring curricular content which consists of constructing a detailed taxonomy. Test items and curricular materials are examined and classified according to the taxonomy. The result is a visual representation of the areas covered. Next, the distribution of topics across the categories of the taxonomy are compared. These researchers concluded that the taxonomy is useful for classifying achievement tests and curricular materials in terms of their overlap. Leinhardt and Seewald (1981) investigated two other approaches measuring overlap between what is tested and what is taught: (1) instruction-based estimates and (2) curriculum-based estimates. The instruction-based measure consists of teachers' estimates of students' opportunity to learn the content tested by test items. Teachers were asked to estimate the percentage of students who had been taught the minimum material necessary to pass each item of an achievement test. They concluded that their estimates are an important variable in predicting test performance. Curriculum-based measures of overlap are based on a computer-based curriculum analysis technique. Each item of a test is analyzed to assess what kind of information is needed to answer the item correctly. A dictionary of test relevant information is then constructed. In addition, a dictionary of the content of curricular materials exposed to students is constructed. The dictionaries are next matched to determine what percentage of the test had been covered through curricular materials (Leinhardt \& Seewald, 
1981). This procedure is often referred to as content analysis (Holsti, 1969; Krippendorf, 1981; Weber, 1985). Leinhardt and Seewald (1981) concluded that curriculum-based estimates as well as instruction-based estimates do equally well in predicting test performance. In summary, the results of these studies provide evidence for the importance of course content coverage when assessing instructional effectiveness. However, the primary purpose of the procedures described thus far is to select the test which reflects the curriculum best. As a consequence, they merely focus on how much of the test was covered by instruction, not on how much instructional time was actually spent on the intended course content. Besides, these procedures are too time-consuming and too costly to implement in program evaluation (Leinhardt \& Seewald, 1981).

The purpose of the present study is to investigate an evaluation procedure including course content coverage as an important educational variable. In particular, attention is paid to time actually spent by students on the intended course content. Data are collected at the student level for several reasons. First, students are the primary recipients of instruction. As such they provide an important and unique perspective to judge course content coverage (Braskamp, Brandenburg, \& Ory, 1984). Second, time needed in learning differs across students depending on students' aptitude, quality of instruction, and students' ability to understand instruction (Carroll, 1963). Third, students differ in time they are willing to spend in learning (Gettinger, 1984). These differences between students require that information about course content coverage be collected at the level of the individual student. In order to guarantee successful implementation of such a procedure in program evaluation, the procedure should not be time-consuming or costly, should be easy to implement in educational settings and should provide suggestions for educational improvement. Questionnaires on which students rate what content was covered and how much time was spent seem to meet these requirements. First, student ratings are easy to collect, not very timeconsuming and fairly effective in providing results that can be used to make instructional improvements (Rotem \& Glasman, 1979). Second, students' self-assessments appear to be at least as good predictors of academic performance as other assessment methods, as claimed by Shrauger and Osberg (1981).

The procedure described in this chapter makes use of a TOpic Checklist (TOC). The TOC consists of a list of topics reflecting the intended course content. These topics were derived from the intended course content. Since the intended course content differs across courses, for each course a new list of topics needs to be generated. The list of topics can be seen as a blueprint of the course content. At the end of the 
course, students are asked to rate to what extent they master each topic and how much time they had spent on studying each topic. These data provide detailed information about course content covered by students. If students fail to master certain topics, instructors should ask themselves how well they had covered this content. As such, these scores may also provide feedback suitable for carrying out improvements.

Which subject-matter is actually covered by students during a course, is especially important in a new approach to professional education like problem-based learning (Barrows \& Tamblyn, 1980). Students in a problem-based curriculum select their own topics for self-study and decide for themselves how much time will be spent on studying each topic. As a consequence, students' actual learning activities may not cover the curriculum content expected to be covered by teachers. Therefore, it is obvious that problem-based programs need adequate evaluation instruments. These instruments should provide information about what content is covered by students during a course and provide useful feedback to carry out instructional improvements.

The purpose of the present study is to examine the TOC's reliability and validity. In addition, the practical utility of the TOC in improving educational quality in the setting of a problem-based medical curriculum will be illustrated.

\section{Method}

\section{Subjects}

The study was conducted at the Medical Faculty of the University of Limburg, the Netherlands. The first four years of the problem-based curriculum are structured as a series of 6-week courses. In total, 142 students in the 1991-1992 academic year attended a 6-week course on normal pregnancy, delivery and normal child development. The course is organized around 12 problems focusing on subject-matter domains related to normal child development, such as childbirth, vaccination schemes, psychological and social aspects of child development, normal rates of child growth, normal stages in secondary sexual characteristics, puberty, adolescence and psychosexual development. Thus, these 12 problems reflect the course content and can be seen as a kind of instructional subunits.

\section{Materials}

At the beginning of the course, topics were derived from the 12 problems reflecting the intended course content. The TOC contained a list of 
144 topics covering the course content as intended by the teachers. Examples of topics related to a problem about the development of the fetus are: "blood circulation in the fetus", "oxygen supply of the fetus", "influence of smoking on the fetus' body weight", and "organ development of the fetus". In addition, eight topics not directly related to the course content were included to estimate response set effects. Thus, the total number of TOC topics was 152. For each topic a Likert-type question was formulated. Students were asked to indicate whether they mastered each topic from: (1) not at all, (2) insufficiently, (3) reasonably well, (4) sufficiently, to (5) well (5). Secondly, they had to indicate whether they had spent: (1) no time at all, (2) little time, (3) a reasonable amount of time, (4) much time, or (5) very much time on studying each particular topic. The first question intended to measure students' perceptions about the degree to which they mastered the subject-matter as specified by the topic. The second question intended to measure students' subjective perception about time spent on learning a particular topic.

Furthermore, an end-of-unit examination was administered to the students. The end-of-unit examination included 179 items of the truefalse type and was developed by teachers responsible for the development of the course. Students' scores on this achievement test consisted of the percentage items correctly answered. The coefficient alpha for this achievement test was .86 , indicating that the internal consistency was high. In addition, at the end of the course students were asked to estimate the number of hours actually spent on self-study during the course per week.

\section{Procedure}

At the end of the unit, students were required to fill out the TOC. Subsequently, an achievement test was administered to the students. The number of students participating in this study was 98 out of 142 . Hence, a response rate of 69 percent.

\section{Results}

\section{Reliability}

Generalizability studies were conducted to estimate the TOC's reliability. One of the advantages of the use of generalizability theory over classical test theory is that it recognizes multiple sources of error, such as differences among students and differences in topics, instead of only a single undifferentiated error component (Brennan \& Kane, 1979). Generaliza- 
bility theory is based upon analysis of variance (Crick \& Brennan, 1983). The TOC consists of a list of 144 topics answered by 98 students. In terms of generalizability theory, this is a design in which topics are crossed with students (Brennan \& Kane, 1979; Crick \& Brennan, 1983). The object of measurement is topics, since the purpose of the TOC is to evaluate course content coverage. This implies that differences in topic scores are the most important source of variability to be identified. Both the student sample and the topic sample are treated as 'random', since they both are considered to be exchangeable with any other sample of the same size drawn from the universe (Shavelson \& Webb, 1991). According to generalizability theory, students are considered to be the facet. As a consequence, this is a one-facet study. This design has four sources of variability: (1) differences in topics (object of measurement), (2) differences among students, (3) differences arising from educational and experiential histories of students or topic by student match, and (4) error effects or unidentified events such as student's attention. In a single facet design the third and fourth component cannot be disentangled (Shavelson \& Webb, 1991). In Table 1 , the sources of variability are summarized for both mastery rating scores and time rating scores. The first source of variance in this table involves topics, and the second source involves students. The third source of variance in this table consists of the topic by student interaction and unidentified sources of variance or error.

The estimated variance component for the topic source reflects the magnitude of error in generalizing from a topic score to the universe of topic scores. The standard error indicates the accuracy of the estimated variance component. The standard error is relatively low because of the large number of topics (144) and students (98). As can be seen in the last column of Table 1, the percentage of variance associated with topics is 25.0 percent for the mastery rating scores and 24.6 percent for the time rating scores. This percentage is the true variance or the variance of interest. This percentage is higher than the percentage of variance for students, 12.2 and 16.5 percent respectively. The largest effect, however, is the topic by student interaction effect and the error effect, 62.7 and 58.9 percent respectively. The interaction effect indicates that the relative standing of topics changes from student to student. In other words, topics are ordered differently by students. This result is comparable with findings in studies about testing in which the error component also proved to be a large source of variance. 
Table 1

Results from generalizability study: Topic by student $\left(T^{*} S\right)$ design.

$\begin{array}{crrr}\text { Source DF } & \begin{array}{r}\text { Estimated } \\ \text { variance } \\ \text { component }\end{array} & \begin{array}{r}\text { Standard } \\ \text { error }\end{array} & \begin{array}{r}\text { Percentage } \\ \text { of total } \\ \text { variance }\end{array}\end{array}$

Mastery scores

Topics (T)

Student (S)

TS, error

$\begin{array}{rlll}143 & 0.2957 & 0.0356 & 25.0 \\ 97 & 0.1443 & 0.0212 & 12.2 \\ 13871 & 0.7407 & 0.0089 & 62.7\end{array}$

Time scores

Topics (T)

Student (S)

TS, error

$\begin{array}{rrr}143 & 0.2614 & 0.0315 \\ 97 & 0.1752 & 0.0255 \\ 13871 & 0.6244 & 0.0075\end{array}$

24.6

16.5

58.9

The estimated variance components presented in Table 1 can be used to compute reliability indices. Since the ultimate concern of the TOC is to draw inferences about topics with reference to other topics, or on relative decisions, the reliability coefficient can be computed by means of the fraction between true variance or variance caused by the object of measurement and the true variance plus error variance. This error variance should be divided by the number of students. The error variance in this study is composed of the topic by student interaction and the random events. In other words, only components influencing the ordering of topics are included. The variance component for students is not included in this computation, since this component does not affect the relative standing of topics. The student component only indicates whether students vary in degree of content covered, averaging over all topics (Shavelson \& Webb, 1991). For the mastery rating scores this computation revealed a percentage of .98 and for the time rating score also .98. This generalizability coefficient indicates the correlation between the topic scores on this TOC and any other randomly selected TOC including 144 topics referring to the same course content. As already said before, the estimated variance components can be used to compute reliability indices. On the basis of these components, the number of students needed to obtain reliable ratings of content coverage as measured by the TOC can be determined. In generalizability theory this is called a decision study. The results are shown in Table 2. 
Table 2

Reproducibility of TOC scores as a function of the numbers of student responses (generalizability coefficient $\mathrm{G}$ ) and the corresponding standard error of measurement (SEM).

Number of

students

Mastery scores

Time scores

G SEM

G

SEM

5

10

15

20

30

98
0.67

0.80

0.86

0.89

0.92

0.98
0.3849

0.2722

0.2222

0.1924

0.1571

0.0869
0.68

0.81

0.86

0.89

0.93

0.98
0.3534

0.2828

0.2040

0.1767

0.1443

0.0798

Table 2 represents the reproducibility of TOC scores as a function of the numbers of student responses (generalizability coefficient $G$ ) and the corresponding standard error of measurement (SEM). The generalizability coefficient indicates how many students are required to obtain a minimal generalizability coefficient of .80 . The standard error of measurement (SEM) also provides important information with regard to the reliability of the TOC scores. The SEM can be used to estimate confidence intervals for individual scores. For example, the 95 percent confidence interval of a score can be estimated by multiplying the SEM by 1.96 (Ferguson, 1981). Starting from the assumption that at least a difference of .5 , on the 5-point scale, between topics is required to obtain practical significant differences between topic scores, the SEM should be lower than or equal to $0.26(.5 / 1.96)$ at the level of 95 percent. When this practical significance level is taken into account, at least 15 students are required to obtain reliable results.

The reliability results presented thus far are computed at the topic by student level. As already described above, topics were derived from the 12 problems reflecting the course content. Consequently, topics could be clustered around problems. This made it possible to carry out the analysis described above at the problem level. The number of topics corresponding with each problem differs between 6 and 29, as is shown in Table 3. Table 3 also contains a summary of the mean scores and standard deviations for each problem for the entire group of students. 
Table 3

Number of topics ( $\mathrm{N}$ topics), mean scores and standard deviations (SD) for each problem for both the mastery scores and the time scores, academic year 1991-1992.

Problem $\quad \mathrm{N}$ topics

Mastery scores

Time scores

Mean SD Mean SD

\begin{tabular}{llllll}
1 & 29 & 3.31 & .41 & 2.70 & .45 \\
2 & 11 & 3.45 & .53 & 2.92 & .60 \\
3 & 9 & 3.34 & .60 & 2.61 & .56 \\
4 & 13 & 3.79 & .44 & 3.18 & .56 \\
5 & 21 & 3.07 & .48 & 2.49 & .46 \\
6 & 5 & 3.49 & .53 & 2.97 & .58 \\
7 & 5 & 3.43 & .68 & 2.94 & .70 \\
8 & 15 & 3.47 & .54 & 2.94 & .57 \\
9 & 16 & 3.15 & .61 & 2.51 & .59 \\
10 & 7 & 3.29 & .53 & 2.47 & .49 \\
11 & 7 & 3.65 & .54 & 2.95 & .64 \\
12 & 6 & 2.68 & .68 & 2.16 & .58 \\
Total & 144 & & & & \\
& & 3.34 & .39 & & \\
\hline
\end{tabular}

In order to carry out the analysis described above at the problem level, average cluster scores were computed for each problem at the student level. In terms of generalizability theory, this is an all random clusterscrossed-with-persons design. The object of measurement in this study is problems or clusters. Both the student sample and the cluster sample are treated as 'random'.

In Table 4, the sources of variability are summarized for both mastery rating scores and time rating scores. As can be seen in the last column of Table 4, the percentage of variance associated with clusters is 21.1 percent for the mastery rating scores and 20.7 percent for the time rating scores. This percentage is the variance of interest. This percentage is lower than the percentage of variance for students, 35.3 and 41.4 percent respectively. The largest effect for the mastery scores is the cluster by student effect and the error effect, 43.6 percent. The largest effect for the time scores is the student effect, 41.4 percent. 
Table 4

Results from generalizability study: Cluster by student $\left(C^{*} S\right)$ design.

$\begin{array}{rrrr}\text { Source DF } & \begin{array}{r}\text { Estimated } \\ \text { variance }\end{array} & \begin{array}{r}\text { Standard } \\ \text { error }\end{array} & \begin{array}{r}\text { Percentage } \\ \text { of total } \\ \text { component }\end{array} \\ & & \text { variance }\end{array}$

Mastery scores

Cluster or problem (C)

Student (S)

$\mathrm{CS}$, error

$\begin{array}{rrr}11 & 0.0815 & 0.03264 \\ 97 & 0.1367 & 0.02144 \\ 1067 & 0.1688 & 0.00730\end{array}$

21.1

35.3

43.6

Time scores

Cluster or problem (C)

Student (S)

CS, error

$\begin{array}{rrr}11 & 0.0845 & 0.03376 \\ 97 & 0.1688 & 0.02583 \\ 1067 & 0.1548 & 0.00670\end{array}$

20.7

41.4

37.9

The estimated variance components in Table 4 can be used to compute reliability indices, following the same procedure as described with respect to the topic by student level. Bașed on these components, the number of students needed to obtain reliable ratings can be determined. These results are shown in Table 5. The generalizability coefficient (G) indicates how many students are required to obtain a minimal generalizability coefficient of .80 . The standard error of measurement (SEM) can be used to estimate confidence intervals for particular scores.

Starting from the assumption that at least a difference of .5 , on the 5-point scale, between average cluster scores is required to obtain practical significant differences between problems, the SEM should be lower than or equal to $0.26(.5 / 1.96)$ at the 95 percent level. When this practical significance level is taken into account, even a number of five students is sufficient. However, a sufficient reliability coefficient requires about ten students. Thus, at the cluster by student level, fewer students are required to obtain reliable results than at the topic by student level, whereas the variance of interest is lower at the cluster by student level. This finding is attributable to the fact that, if relative decisions are applied, the reliability coefficient does not include the variance component for students, but only the true variance and the error variance. The error variance component is smaller at the cluster level than at the topic level, at the expense of the student variance component. 
Table 5

Reproducibility of cluster or problem scores as a function of the numbers of student responses (generalizability coefficient $\mathrm{G}$ ) and the corresponding standard error of measurement (SEM).

Number of

students

Mastery scores

Time scores

$\begin{array}{lllll}5 & 0.71 & 0.1836 & 0.73 & 0.1760 \\ 10 & 0.83 & 0.1299 & 0.85 & 0.1244 \\ 15 & 0.88 & 0.1061 & 0.89 & 0.1016 \\ 20 & 0.91 & 0.0919 & 0.92 & 0.0880 \\ 30 & 0.94 & 0.0750 & 0.94 & 0.0718 \\ 98 & 0.98 & 0.0414 & 0.98 & 0.0398\end{array}$

\section{Validity}

In this section the TOC's content validity and criterion validity will be assessed. First, the TOC's content validity. Ebel (1983) states that the basis for the content validity of any measurement lies in the rationale for its construction. In order to assure the TOC's content validity, the process of sampling topics from the course content should be based on rational considerations. This process will be described. As mentioned earlier, the TOC topics were derived from the 12 problems. The process of generating topics consists of two stages. First, the researcher specified for each problem a list of topics reflecting the intended course content. Second, this list of topics was presented to three teachers, responsible for the development of the course. They first individually assessed whether these topics were intended while constructing the course. Topics which were not intended according to all three teachers were removed and topics lacking in this list were added. In the few cases in which the teachers disagreed, i.e., one teacher considered the topic as important to be listed, and the others failed to do so, then the topic was discussed by the teachers to reach consensus. Since these teachers were responsible for the development of the course, they were assumed to be experts in examining which topics were to be studied by students. As a consequence, the TOC's content validity seems to be guaranteed.

Second, the TOC's criterion validity is assessed. In order to examine the TOC's criterion validity average TOC mastery and time scores of each problem were computed for each student. In addition, the total average TOC time and mastery score of all 12 problems together were 
computed for each student. These total average scores for each student were correlated with the average percentage of test items correctly answered by each student and the number of hours spent on self-study during the course by each student. As already described in the materials section of this chapter, at the end of the course an achievement test was administered to the students and all students were asked to estimate the actual number of hours spent on self-study during the course per week. Based on these scores at the student level, several correlation coefficients were computed. Since not all data were available for all students, the number of students included in the analysis varies. The coefficients are summarized in Table 6. First, the correlation coefficient between total average TOC time scores and total average TOC mastery scores for each student is $.61(p<.001, \mathrm{~N}=98)$, indicating a strong to moderate relationship between the two concepts according to students' subjective feelings.

Second, a relationship would be expected between total average TOC time scores and the average number of hours spent on self-study during the course. The total average time spent during the course by individual students varied between 3 and 35 hours per week; the total average time spent on self-study for all students was 18.72 hours per week $(S D=6.75)$. The correlation coefficient between the total average TOC time scores and the estimated hours spent during the course for each student is .42 $(p<.001, \mathrm{n}=64)$, as shown in Table 6 . This coefficient indicates that both measures, evaluating the actual time spent during the course, correspond moderately with each other. At the level of individual problems, this correlation coefficient varies between $.16(n . s ., n=64)$ and $.50(p<.001$, $\mathrm{n}=64)$.

Third, correlation coefficients were calculated between the total average TOC scores of each student and the corresponding scores on the achievement test. The percentage of items correctly answered by individual students varied between 32 and 70 . The total average percentage of items correctly answered for all students was 53.9 ( $S D=7.67)$. The correlation coefficient between the total average time spent on the TOC and the test scores is $.22(p<.05, \mathrm{n}=94)$. This coefficient is also shown in Table 6. At the level of individual problems, this correlation coefficient varies between .01 (n.s., $\mathrm{n}=94)$ and $.36(p<.001, \mathrm{n}=94)$. The fairly low correlation between time spent on the TOC and student achievement is either due to the procedure under scope of this study or to the questionable quality of the achievement test. However, in this particular case, the achievement test scores seem to be questionable, because low correlation coefficients were found between time spent on some problems and their corresponding test scores. These results suggest that the achievement test does not adequately cover course content. TOC topics related to some 
problems seem to reflect the intended course content more adequately than TOC topics related to some other problems.

Since both TOC mastery scores and achievement test scores intend to measure students' mastery of the course content, a relationship would also be expected between these mastery scores and students' test scores. The correlation coefficient between the total average TOC mastery score and the average test score for each student is .36 $(p<.001, n=94)$, as shown in Table 6 . With regard to the statements made above about the questionable validity of the achievement test, this fairly low coefficient is not surprising. In addition, Table 6 shows the correlation coefficient between the actual numbers of hours spent on self-study and test scores. The correlation coefficient between the average number of hours spent on self-study during the course and students' corresponding test scores is .11 (n.s., $n=63$ ). This coefficient is lower than the correlation between TOC time scores and test scores $.22(p<.05, \mathrm{n}=94)$.

In summary, the correlation coefficient between total average TOC time scores and the achievement test scores is low. This result is probably due to the questionable validity of the achievement test. As a consequence, the fairly low correlation between total average TOC mastery scores and achievement test scores was not surprising. However, the relationship between TOC time scores and the actual number of hours spent during self-study is moderate, which seems to provide some evidence for the criterion validity of the TOC.

Table 6

Correlation coefficients between TOC time and mastery scores, achievement test scores and hours spent on self-study.

$\begin{array}{cccc}\text { TOC Time } & \text { Test } & \text { Mastery } & \text { Hours } \\ \text { score } & \text { score } & \text { score } & \text { spent }\end{array}$

\begin{tabular}{|c|c|c|c|}
\hline TOC time score & 1 & $.22^{*}$ & $.61^{\circ \bullet}$ \\
\hline Test score & & 1 & $.36^{\circ *}$ \\
\hline TOC mastery score & & & 1 \\
\hline Hours spent & & & \\
\hline
\end{tabular}

Note: ${ }^{*} p<.05,{ }^{* *} p<.001$. 


\section{Utility}

In a problem-based curriculum, problems are the starting-point for students' self-intended learning activities. Teachers design these problems with certain topics in mind that students are expected to cover. Whether students undertake these learning activities planned by teachers is to a large extent determined by problem effectiveness. The effectiveness of a problem may be defined as the match between student-generated learning issues and the pre-set faculty objectives (Dolmans, Gijselaers, Schmidt, \& Van der Meer, 1993). Ineffective problems hamper the process of generating learning issues, implying that course content is not entirely covered by students. Since the TOC topics were derived from the 12 problems, it was possible to categorize the topics across the 12 problems and for each problem average time scores and mastery scores could be computed. These results are shown in Table 3.

To judge whether the TOC is a useful procedure for indicating problem areas in a course content, time spent on studying topics connected to a problem and the average mastery scores should differ across problems. One-way analysis was conducted to reveal these differences. The data consisted of the average time and mastery score of each problem for each individual student. The average mastery score on the TOC (144 topics) was $3.34(S D=.39)$ and the average time spent was 2.74 $(S D=.43)$. The average problem mastery scores varied between 2.68 $(S D=.68)$ and $3.79(S D=.44)$, as depicted on the left vertical axis in Figure 1. The average mastery scores differed across problems $(F(11,1146)=25.92, p<.001)$. The average time spent varied between 2.16 $(S D=.58)$ and $3.18(S D=.56)$. These results are also depicted in Figure 1 on the right vertical axis. One-way analysis indicated that time spent on certain topics also differed across problems $(F(11,1131)=25.55, p<.001)$. The average time spent on studying the eight 'filler' topics that were included to estimate response set effects, was 1.78 ( $S D=.56)$. The average mastery score for these eight 'filler' topics was 2.69 ( $S D=.54)$. Response set effects seem to be less likely, since time spent was low for these eight 'filler' topics. This finding suggests that students indeed fill out the questionnaire seriously.

The total average time spent on each problem and the total average mastery scores as listed in Table 3 and Figure 1, indicate the degree to which students' learning activities cover the intended course content. Problems with relatively low average scores should be improved in order to ensure course content coverage. How curricula can actually be improved using information derived from the TOC will be illustrated. 


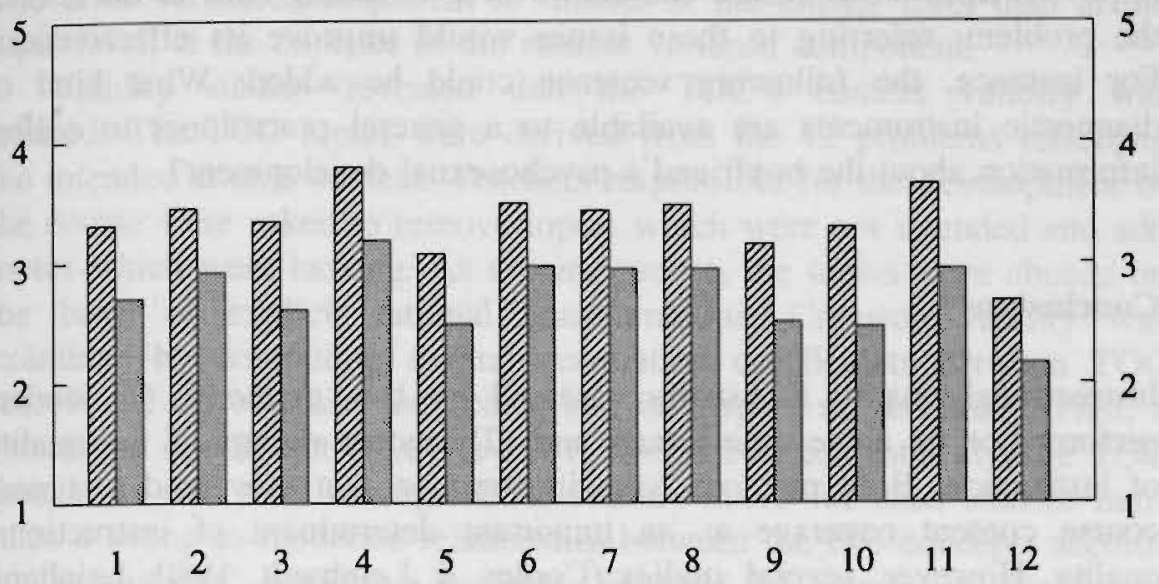

\section{Problems}

\section{Mastery}

Time

\section{Figure 1}

Average problem mastery scores (left vertical axis) and average problem time scores (right vertical axis), academic year 1991-1992.

The results in Figure 1 show that time spent on studying the different problems varies between little time (2) and much time (4). Mastery scores vary from insufficiently (2) to sufficiently (4). Problem 4 scores relatively high on both rating scales. The objectives specified for this problem are related to different stages of delivery and risks for mother and child during delivery. Problem 12 scores relatively low on both scales. This problem deals with psychosexual development of adolescents. Problems 5, 9 and 10 also score relatively low on both scales. These problems are respectively related to childbed, psychological and social aspects of child development and child growth. Examining rating scores on separate topics related to a low scoring problem provides information to improve the problem. For instance, Problem 12 dealing with psychosexual development scores very low, as already stated above. This problem consists of a description of a 20 -year-old girl, living together with her friend for several months. Since her boyfriend's former sexual preferences make her worry about their relation, she visits her general practitioner. Scores on the TOC related to this problem revealed that students scored relatively low on 'DSM-III classification', 'psychosexual anamnesis' and 'gender disorder of the transsexual type'. Low 
scores on these topics would indicate that Problem 12 should be improved in order to ensure content coverage. Adding cues to the text of the problem, referring to these issues would improve its effectiveness. For instance, the following sentence could be added: What kind of diagnostic instruments are available to a general practitioner to collect information about the boyfriend's psychosexual development?

\section{Conclusions}

Instructional quality is usually assessed by two methods: (1) student performance on achievement tests and (2) student ratings of the quality of instruction. Both methods have in common that they tend to ignore course content coverage as an important determinant of instructional quality. However, several studies (Cooley \& Leinhardt, 1980; Leinhardt \& Seewald, 1981; Schmidt et al., 1983) provide evidence for the importance of studying course content coverage when assessing instructional effectiveness. As a consequence, evaluation of educational effectiveness should focus on what actually happens during instruction or on course content coverage.

In this chapter, the TOC procedure is described, yielding information about students' learning activities during a course. This procedure provides information about what content is being studied by students, how much time is spent on studying the intended course content and the degree to which students master this content. Generalizability studies indicated that the TOC seems to be a reliable procedure. At the topic by student level, differences between topics or the variance of interest appeared to be higher than variance caused by differences between students. On the contrary, at the problem by student level, the variance between students was higher than the variance between problems. A possible explanation for the relatively large effects with respect to differences between students, at the problem by student level, may be the variability between students' interest in the subject-matter related to each problem or the variability between students' prior knowledge with regard to the various problems. Because of the clustering of topics around problems or subject-matter domains, variability between students becomes more apparent at the student by cluster level than at the student by topic level. Furthermore, decision studies indicated that at the topic by student level a minimum of 15 students is required to obtain reliable results. At the cluster level 10 students already provide reliable results. The results at the cluster level are more reliable, if relative decisions are applied, since the reliability coefficient does not include the variance 
component for students, but only the true variance and the error variance. The error variance component is smaller at the cluster level than at the topic level, at the expense of the student variance component.

Validity studies revealed that the TOC's content validity was assured. The TOC topics were derived from the 12 problems reflecting the intended course content. Teachers responsible for the development of the course were asked to remove topics which were not intended and add topics which were lacking. As a consequence, the topics were chosen on the basis of explicit rational considerations. Criterion validity was examined by computing several correlation coefficients between TOC scores and achievement test scores and time spent on self-study. First, a correlation coefficient of $.61 \quad(p<.001, \mathrm{~N}=98)$ between total average TOC time score and total average TOC mastery score for each student indicates a strong to moderate relationship between the two concepts according to students' subjective feelings. Second, the correlation coefficient between two independent measures both asking students to estimate time spent on learning activities during the course is $.42(p<.001, \mathrm{n}=64)$. This relationship is moderate and seems to provide some evidence for the criterion validity of the TOC. Third, the correlation coefficient between TOC time scores and the achievement test scores is $.22(p<.05, \mathrm{n}=94)$. This result is in accordance with results from studies examining classroom use of time and achievement which show only moderate correlations (Frederick \& Walberg, 1980). Lack of overlap between content tested and content presented to students may account for this moderate relationship. If time spent on the TOC should be a reliable predictor of student achievement, then, modifications in the test are required. The correlation between TOC mastery scores and achievement test scores was also fairly low. This result is not surprising with regard to the questionable validity of the achievement test.

Furthermore, the correlation coefficient between the average number of hours spent on self-study during the course and students' test scores is .11 (n.s., $n=63$ ), whereas the correlation coefficient between TOC time scores and the achievement test is .22 ( $p<.05, \mathrm{n}=94)$. Consequently, TOC time scores seem to be better predictors for student achievement than the actual number of hours spent. This finding is also confirmed in a review of the literature about the relationship between time and student achievement by Anderson (1985) who concluded that, when comparing the relationship between course content overlap and achievement with time spent in number of hours and student achievement, the former relationship tends to be stronger than the relationship between the latter two concepts. A possible explanation is that, when measuring course content overlap, only time spent on the intended learning activities is considered, 
whereas the actual number of hours spent on self-study may include time spent on topics not directly intended to be studied. In summary, the correlation coefficients between TOC time and TOC mastery scores, and between TOC time scores and the actual hours spent are moderate. The correlation between TOC time scores and test scores is fairly low. However, only a few studies have shown impressive evidence concerning the criterion validity of tests (Ebel, 1983). The major problem is the imperfect or uncertain validity of the criterion scores according to Ebel (1983).

Moreover, it was shown that the TOC is an appropriate procedure to indicate problem areas in a course. Problems 5, 9, 10, and 12 scored relatively low. These problems were respectively related to childbed, psychological and social aspects of child development, child growth and psychosexual development. Studying these problems in detail and comparing them with the other problems of the unit, revealed that they were related to psychological and sociological issues, such as psychological well-being of the mother during childbed, social development of children, and psychological effects of being extremely tall. Problem 4, on the other hand, which addresses physiological processes of delivery, scored relatively high. These findings correspond with faculty observations that students tend to prefer biological issues at the expense of psychological ones. Time and mastery scores on separate topics related to each problem indicate what content is covered by students and contain cues for problem improvement, as was shown in the results section of this chapter. In summary, the TOC seems to be a reliable procedure requiring relatively few raters to yield detailed information about the nature of the weaknesses of a course. It also provides feedback suitable for carrying out improvements. 
Anderson, L.W. (1985). Opportunity to Learn. In: T. Husén, \& T. N. Postlethwaite (Eds.). The International Encyclopedia of Education: Research and Studies (pp. 3682-3686). Oxford: Pergamon Press.

Barrows, H.S. \& Tamblyn, R.M. (1980). Problem-based Leaming. An Approach to Medical Education. New York: Springer Publishing Company.

Braskamp, L.A., Brandenburg, D.C., \& Ory, J.C. (1984). Evaluating Teaching Effectiveness. A Practical Guide. Beverly Hills: Sage.

Brennan, R.L. \& Kane, M.T. (1979). Generalizability Theory: A Review. New Directions for Testing and Measurement, 4, 33-51.

Carroll, J.B. (1963). A Model of School Leaming. Teachers College Record, 64, 723-733.

Cooley, W.W. \& Leinhardt, G. (1980). The Instructional Dimensions Study. Educational Evaluation and Policy Analysis, 2, 1, 7-25.

Costin, F., Greenough, W.T., \& Menges, R.J. (1971). Student Ratings of College Teaching: Reliability, Validity, and Usefulness. Review of Educational Research, 41, 511-535.

Crick, J.E. \& Brennan, R.L. (1983). Manual for Genova: A Generalized Analysis of Variance System. Iowa: American College Testing Program.

Dolmans, D.H.J.M., Gijselaers, W.H., Schmidt, H.G., \& Van der Meer, S.B. (1993). Problem Effectiveness in a Course Using Problem-based Learning. Academic Medicine, 68, 3, 207-213.

Ebel, R.L. (1983). The Practical Validation of Tests of Ability. Educational Measurement: Issues and Practice, Summer, 7-10.

Feldman, K.A. (1977). Consistency and Variability among College Students in Rating their Teachers and Courses: A Review and Analysis. Research in Higher Education, 6, 223-274.

Ferguson, G.A. (1981). Statistical Analysis in Psychology and Education (5th ed.). Auckland: McGraw-Hill.

Frederick, W.C. \& Walberg, H.J. (1980). Learning as a Function of Time. Journal of Educational Research, 73, 183-194.

Gettinger, M. (1984). Individual Differences in Time Needed for Learning: A Review of the Literature. Educational Psychologist, 19, 1, 15-29.

Holsti, O.R. (1969). Content Analysis for the Social Sciences and Humanities. Massachusetts: Addison-Wesley.

Krippendorf, K. (1981). Content Analysis. An Introduction to Its Methodology. Beverly Hills: Sage.

Leinhardt, G. \& Seewald, A.M. (1981). Overlap: What's Tested, What's Taught? Journal of Educational Measurement, 18, 2, 85-95.

Madaus, G.F. \& Kellaghan, T. (1992). Curriculum Evaluation and Assessment. In: P.W. Jackson (Ed.). Handbook of Research on Curriculum (pp. 119-154). New York: MacMillan.

Marsh, H.W. (1982). SEEQ: A Reliable, Valid, and Useful Instrument for Collecting Students' Evaluations of University Teaching. British Journal of Psychology, 52, 77-95. 
Marsh, H.W. (1984). Students' Evaluations of University Teaching: Dimensionality, Reliability, Validity, Potential Biases, and Utility. Journal of Educational Psychology, 76, 5, 707-754.

Murray, H.G. (1990). Student Instructional Ratings. The Impact on Quality of Teaching in Higher Education. Teaching News, 39, 7-13.

Rotem, A. \& Glasman, N.S. (1979). On the Effectiveness of Students' Evaluative Feedback to University Instructors. Review of Educational Research, 49, 3, 497511.

Schmidt, W.H., Porter, A.C., Schwille, J.R., Floden, R.E., \& Freeman, D.J. (1983). Validity as a Variable: Can the Same Certification Test be Valid for All Students? In: G.F. Madaus (Ed.). The Courts, Validity and Minimum Competency Testing (pp. 133-151). Hingham, M.A.: Kluwer-Nijhof.

Shavelson, R.J. \& Webb, N.M. (1991). Generalizability Theory. A Primer. London: Sage.

Shrauger, J.S. \& Osberg, T.M. (1981). The Relative Accuracy of Self-predictions and Judgments by Others in Psychological Assessment. Psychological Bulletin, 90, 2, 322-351.

Weber, R.P. (1985). Basic Content Analysis. Beverly Hills: Sage. 


\section{The Relationship between Student-generated Learning Issues and Self-study in Problem-based Learning}

\section{Abstract}

A major assumption of problem-based learning (PBL) is that learning issues, generated by students while discussing a problem, are used as guides for self-directed learning activities. This assumption, though basic to PBL, has never been tested. At the University of Limburg, the Netherlands, two procedures have been developed that reflect the extent to which students are able to identify important learning issues given a particular problem, and whether subsequent, independent, learning corresponds with these learning issues. The focus of the present chapter will be on the relationship between the two. We have explored to what extent student-generated learning issues are a major factor influencing the nature of students' self-study or whether other factors may be involved in decisions on what to study and how much time to spend on topics selected. First, the production of learning issues was studied and represented as the percentage of overlap between learning issues raised by students and pre-set faculty objectives for each problem. The second procedure consisted of the administration of a "Topic Checklist" (TOC) which purports to measure students' actual self-directed leaming activities. The TOC consists of a list of topics specifying the intended course content. Students were asked to indicate on a 5-point Likert scale how much time they had spent studying each topic and to what degree they had mastered that topic. Third, learning issues and TOC topics were compared directly in a qualitative sense. Comparisons between the procedures revealed that a low proportion of variance of TOC scores could be predicted from the percentage of faculty objectives identified for each problem and the direct match between learning issues and TOC scores. It is concluded that scrutinizing student-generated learning issues 
and topics covered during self-study may provide information about what content is covered by students in tutorial groups. The discrepancy between the results of the measurements suggests, however, that learning issues produced during group discussion are not the sole source on which students base self-study decisions. Several other factors may be involved, such as tutor guidance, content already covered in previous units, issues raised during sessions with resource persons, and the nature of the learning resources available. Therefore, the relationship between learning issues and content covered during self-study is not as straightforward as is suggested.

\section{Introduction}

Recommendations in the report of the panel on the General Professional Education of the Physician (GPEP), entitled "Physicians for the TwentyFirst Century" (Association of American Medical Colleges, 1984), have put in motion curricular changes in many medical schools. 'Conventional' approaches to education characterized by 'spoon-feeding' would not sufficiently prepare students for lifelong learning, since students in such curricula are assumed to be more or less passive recipients of information. According to the report, innovative approaches to education are required that encourage students to become active, independent, selfdirected learners and problem-solvers in order to prepare them for lifelong learning. An innovative approach to medical education that appears to accommodate to the recommendations as listed in the GPEP report is problem-based learning (PBL). Whereas a conventional approach to education tends to emphasize teacher control over the learning activities of students, mainly through lectures, PBL puts students in charge of their own learning, making them responsible for decisions on what to study and to what extent. Whereas conventional training generally can be considered 'teacher-centered', PBL is seen as more 'student-centered' (Barrows \& Tamblyn, 1980; Norman \& Schmidt, 1992). Problem-based learning encourages students to eventually take full responsibility of their own learning. These ideas are in accordance with work on the application of psychological science to education that have brought into reach the aim of fostering students' ability to become architects of their own knowledge (Glaser, 1991).

That PBL is indeed successful in inducing these expected behaviors in students is indirectly evidenced in a study by Blumberg and Michael (1992). Data from library circulation statistics showed that PBL students during pre-clinical years as well as during clerkship years borrowed more 
resource materials than students from a conventional track. It is generally assumed that this information-seeking behavior results from prior problem discussion and encouraging students to generate their own leaming issues in need of further exploration (Barrows, 1985; Walton \& Matthews, 1989). However, Blumberg and Michael (1992) suggest that group-generated learning issues may not be the sole determinant of content to be learned, but that self-directed learning activities are also influenced by factors, such as re-inforcement and encouragement by peers and faculty facilitators, and congruity between the various elements that make up the curriculum, such as books and articles referred to and subject-matter covered in resource sessions. They do not, however, provide empirical evidence that what students actually do may not only be determined by what they intend to do, i.e., the learning issues generated through small-group discussion. This discrepancy between what students intend to do and what they actually do will be illustrated below.

In PBL, problems are the starting-point for students' self-directed learning activities. Problems can be considered the most important instructional materials presented to students during a course; they embody the objectives of the teachers who produced them. Teachers do write problems with certain objectives in mind: the problem should introduce the student in a particular domain and help him acquire an understanding of that domain. Unlike conventional education, however, the control over student learning is indirect; objectives are usually not shared with students. The reason for this is that providing students with the objectives underlying each problem would take away the process of discovery of what is important to learn and, hence, would deprive students of the opportunity to acquire self-directed learning skills (Bruner, 1971). A group of 8 to 10 students guided by a tutor discusses problems such as these and tries to explain the phenomena in terms of their underlying processes, principles, or mechanisms (Schmidt, 1983). During these discussions issues emerge that require further exploration. It is assumed that these student-generated learning issues are used as guides for self-directed learning activities.

In conclusion, student learning in PBL is a process comprising several components which should occur in a specific sequence as the students work in small groups. This process can be briefly summarized as follows, teachers design problems with certain faculty objectives in mind, subsequently, students discuss these problems and generate learning issues. A major assumption of PBL is that these student-generated learning issues are used as guides for students' learning activities during self-study. These components are systematically outlined in Figure 1. 


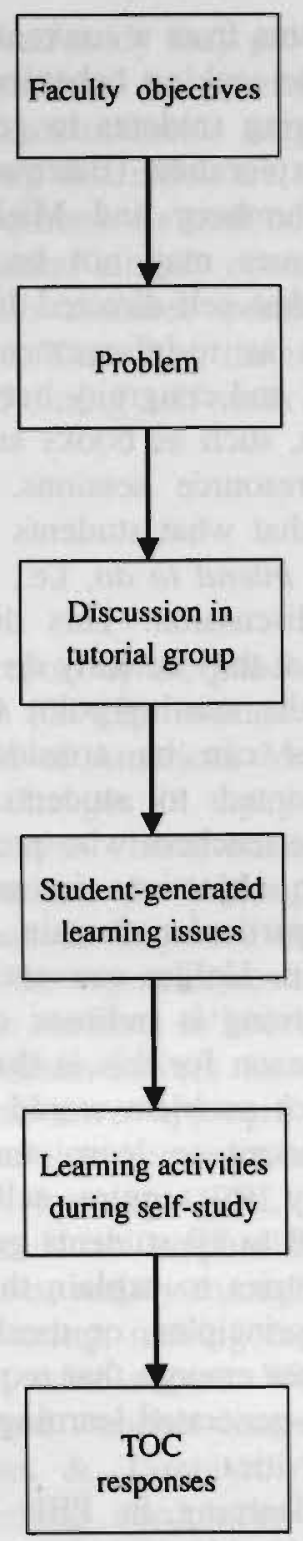

Figure 1

Student learning in PBL is a process comprising several components: teachers design problems with certain objectives in mind; subsequently, students discuss these problems and generate learning issues. These learning issues are the basis for students' learning activities during self-study, which are reflected by TOC responses. 
A problem usually consists of a description of a set of phenomena in need of some kind of explanation. An example of a problem is shown below. It is presented to the students at the Medical Faculty of the University of Limburg, the Netherlands, during a second year course on normal child development in the 1990-1991 academic year.

Problem: 'Unknown feelings'

Susan feels her baby moving in her womb. Beside this new experience, a number of things have changed during the last six months. Her breasts enlarged and have become more sensitive. Sometimes, she loses a few drops of milk. Furthermore, she has gained about six kilograms in weight and feels like a swollen balloon. Her husband complains of Susan eating too many sweets. Because Susan has gained weight, her clothes do not fit any more. Furthermore, she experiences some physical troubles. She feels clumsy the last few weeks, since she breaks a lot of things. Needlework, one of her favorite hobbies, is very difficult for her. For a few weeks she has been unable to stand temperatures above 25 degrees Celsius. Her shoes do not fit any more and her rings pinch. Because of heartburn behind her breastbone and tingling fingers, she sleeps poorly at night. Despite all these inconveniences, she really enjoys her pregnancy, she feels a fulfilled woman, a feeling she has never had before. (1990-1991)

As indicated already, during discussion students generate learning issues. Ideally, these student-generated learning issues should match faculty objectives. This statement is self-evident. If students produce issues for self-study entirely different from those intended, one could question why the particular problem was written in the first place, since it does not play any role in the decision process. In the second place, if students fail to generate the appropriate issues, the intended learning outcomes are not accomplished. An example of assessing the match between studentgenerated leaming issues and faculty objectives is shown below. Faculty had five objectives in mind while designing the problem 'Unknown feelings' presented above. These objectives were: (1) Adaptation of the mother's circulatory system and metabolism during pregnancy, (2) role of the placenta in the process of the adaptation of the mother's circulatory system and metabolism during pregnancy, (3) mother's organ changes (e.g., kidneys) during pregnancy, (4) consequences of changes in mother's body functions for mother and baby during early and late pregnancy, and (5) changes in mother's behavior and mood during pregnancy and factors influencing this behavior and mood. Given the particular problem, one tutorial group generated the following six learning issues: (1) Which mechanisms explain enlargement and sensitiveness of breasts? (2) which mechanisms explain gain in body weight, 
swollen feet and tingling fingers? (3) what explains clumsiness and poor sleeping during pregnancy? (4) which hormonal changes take place during pregnancy? (5) what psychological changes take place during pregnancy? and (6) does the fetus have a sleep-wake rhythm? Comparing the learning issues of this tutorial group with the pre-set objectives stated above, reveals that the third objective, "Addressing changes in the various organs (e.g. kidneys) during pregnancy," was not identified by the tutorial group. Students may not have raised this issue because of several reasons, such as lack of cues in the problem itself pointing to the importance of organ changes, lack of time or lack of motivation or interest. In addition, it might be possible that students spent time on this issue in previous units or during sessions with resource persons and felt that they already had mastered this issue. The fact that the organ-change issue was not raised, does not, however, automatically imply that these students did not study any relevant material. The literature might have revealed to them that this is an important element in understanding the changes occurring during pregnancy and, hence, students paid attention to the organ-change issue.

On the other hand, it might be possible that students, although they do identify the pre-set faculty objectives, they do not actually pursue the learning activities suggested by the learning issues they have raised. Students will not study certain learning issues when they have already studied the relevant material in previous courses. It is also possible that students pay much attention to a learning issue during discussion in the tutorial group and eventually decide not to spend time on this issue during self-study. From these examples, it may be clear that studentgenerated learning issues produced during group discussion may not be the sole source on which students base self-study decisions. In other words, the components of student learning in PBL as specified in Figure 1 may not solely determine students' learning activities, but several other factors might as well have a significant influence.

In this chapter, the major assumption of PBL that learning issues, generated by students while discussing a problem, are used as guides for self-directed learning activities is tested. Since, ultimately, students in a problem-based curriculum select their own topics for self-study and decide for themselves how much time to spend on studying each of these topics, it is not an easy task to acquire an insight into the nature of the learning issues raised and the learning going on when students individually pursue these learning goals. In this chapter, two procedures are described that are helpful in recording these activities. The first is based on the use of tutors as informants. They are asked to record the learning issues generated by their tutorial group for each problem. These learning 
issues are listed for each problem. Subsequently, pairs of expert raters are asked to judge the match between faculty objectives and studentgenerated learning issues. The amount of content covered for each problem is computed as the average percentage of faculty objectives identified by the tutorial groups participating in a particular course. The second procedure questions students about their actual learning activities. This procedure consists of a list of topics representing the subject-matter expected to be studied by the teachers who developed the problems. Students are asked to indicate on a 5-point Likert scale how much time they spent studying each topic and to what degree they assume they have mastered the specified topics. The third procedure consisted of a qualitative comparison between learning issues and topics. The author of this thesis judged whether each topic was covered by the learning issues generated by each tutorial group for that problem. All procedures are based on a comparison with the original instructional intentions of the teachers who designed the problem that gave rise to the various learning activities. We will discuss these procedures in some detail below. The goal of the present chapter is to report on a comparison of the results of these procedures and to account for possible discrepancies. This comparison of indicators of learning in PBL might assist in answering the question whether learning issues are the major force in driving students' learning, as is generally assumed in PBL (Barrows, 1985; Walton \& Matthews, 1989) or whether other factors may be involved.

\section{Method}

\section{Subjects}

This study was conducted in a second year course of the medical curriculum of the University of Limburg, the Netherlands. In total, 70 students in the 1990-1991 academic year participated in this study. In addition, 12 tutors were part of the experiment. Both students and tutors were randomly assigned to 12 tutorial groups. The number of participating students for each tutorial group varied between four and eight.

\section{Materials and Procedure}

The course under scope of study was a 6-week second year course. This course deals with subject-matter related to childbirth, psychomotor development, and psychosexual development. The materials in this study consisted of 12 problems and a list of topics specifying the subjectmatter that faculty expected students to cover for each problem. These materials are described below. 
The 12 problems were based upon 51 faculty objectives covering the course as a whole, one to eight objectives for each problem, with an average of 4.3 objectives. The tutors participating in this course were asked to record for each problem all learning issues generated by their tutorial group. Tutorial groups generated 1 to 10 learning issues for an individual problem, with an average of 3.6. Subsequently, 12 pairs of expert raters were asked to judge the match between faculty objectives and student-generated learning issues. They were instructed to judge individually the correspondence between student issues and faculty objectives (Dolmans, Gijselaers, Schmidt, \& Van der Meer, 1993). For each comparison, raters had to judge whether a particular learning issue was definitely similar to a particular faculty objective or was definitely dissimilar. The cases in which raters could not give definite judgements were considered dissimilar. A faculty objective was assumed to be identified if both raters agreed about its similarity to the learning issue judged. If both raters agreed that there was no similarity, then an objective was considered as being not identified by the students. If both raters disagreed, i.e., if one rater observed similarity and the other failed to do so, then an objective was also assumed not to have been identified. The average interrater agreement for the pairs of raters, as estimated by the Kappa-coefficient, was .45, which demonstrates a moderate level of agreement between raters (Dolmans et al., 1993). The amount of content covered for each problem was measured as the average percentage of faculty objectives identified by the 12 tutorial groups. These data were collected at the level of problem by tutorial group. Consequently, the data consisted of 12 (problems) by 12 (tutorial groups) or 144 datapoints.

Topics reflecting the content faculty expect students to cover during self-study for each problem were listed in the so-called 'TOpic Checklist' (TOC). Teachers responsible for the design of the problems were asked to derive these topics from the content of the problems. The resulting list of 126 topics reflected the course content assumed to be studied by students during self-study, and as such these topics can be seen as a blueprint of the course. Topics related to the problem presented above were, for instance: (1) metabolism during the last four months of pregnancy, (2) changes in hormonal activity during pregnancy, (3) changes in water-balance during pregnancy, (4) accumulation of fat and water, (5) changes that take place in breasts, (6) physiological changes in blood circulation, (7) the influence of placenta hormones on feelings of mothers-to-be towards pregnancy, (8) manifest phenomena during pregnancy, (9) changes in behavior and mood of the mothers-to-be, (10) metabolism during the first months of pregnancy, and (11) psychological 
aspects of pregnancy. In addition, eight topics, not related to the course content were included to estimate response set effects. Thus, the total number of topics included in the TOC was 134. For each topic, two Likert-type questions were formulated. First, students were asked to indicate whether they mastered each topic: (1) not at all, (2) insufficiently, (3) reasonably well, (4) sufficiently, or (5) well. Second, they had to indicate whether they had spent: (1) no time at all, (2) little time, (3) a fair amount of time, (4) much time, or (5) very much time on studying each particular topic. The first question measures students' perceptions about the degree to which they mastered the subject-matter as mentioned. The second question measures students' estimate of time spent on studying a particular topic.

At the end of the course, students were asked to fill out the TOC. Since the topics of the TOC were initially derived from the 12 problems, the topics could be categorized across problems. Subsequently, average time and mastery scores were computed for each problem. TOC scores were computed as the average score per problem. In addition, TOC data were aggregated at the level of tutorial groups to enable comparisons among learning issues raised (expressed as a match percentage) and tutorial groups' average time and mastery scores for each problem. Thus, due to the level of aggregation, the TOC data also consisted of 12 (problems) by 12 (tutorial groups) or 144 data-points.

A number of studies have been conducted to assess the TOC's reliability and validity. The results of these studies are reported in Dolmans, Gijselaers, and Schmidt (1993) and can be summarized as follows. Generalizability studies indicated that the TOC is a fairly reliable procedure. Furthermore, the TOC's content validity was assured, since the topics were selected on the basis of explicit rational considerations. Moreover, the criterion validity, measured as the correlation between the total average TOC scores for each individual student and corresponding achievement test score, was modest.

In addition, in a qualitative sense the learning issues generated in each tutorial group were compared with TOC topics. For this comparison, the author of this thesis judged whether each topic, that teachers had in mind while developing the problem, was covered by the learning issues generated by each tutorial group for that particular problem. The degree of correspondence was judged on a 5-point Likert scale: (1) not at all, (2) insufficiently, (3) reasonably well, (4) sufficiently, or (5) well.

Finally, two subsequent sessions of one tutorial group while working on the 'Unknown feelings' problem were observed by the author of this thesis. This was done to collect further qualitative data on how students produce, and subsequently deal with, learning issues. 
First, the amount of overlap between student-generated learning issues and faculty objectives will be presented. Second, the results of the TOC will be discussed. Third, TOC time and mastery scores will be compared. Fourth, the percentage of faculty objectives identified and TOC scores will be compared. Finally, the results of the qualitative comparisons between learning issues generated and TOC topics will be presented.

The average amount of overlap between learning issues and faculty objectives for the set of 12 problems was 64.2 percent $(S D=26.7)$. The amount of overlap for each of the 12 problems varied between 27.7 and 100 percent and differed significantly $(F(11,143)=6.84, p<.001)$. The percentage of overlap for each problem is shown in column 2 of Table 1. The amount of overlap between objectives and learning issues for each of the 12 tutorial groups varied between 45.7 and 77.5 percent, but did not differ significantly $(F(11,143)=1.24, p=.266)$.

Since the TOC topics were derived from the 12 problems average time scores and mastery scores could be computed for each problem. These results are also shown in Table 1. An estimate of the average time spent on the 12 TOC problems, expressed on a 5-point scale, ranging from: (1) no time at all, to (5) very much time, was $2.71(S D=.40)$. The average time spent for each problem varied between $2.05(S D=.30)$ and $3.19(S D=.34)$, as shown in column 3 of Table 1 . One-way analysis of variance indicated that time spent on TOC topics differed across problems $(F(11,143)=12.52, p<.001)$. The average time spent studying the eight topics not intended by faculty, but included for checking response set effects, was $1.95(S D=.25)$. This finding suggests that the students indeed filled out the questionnaire seriously. The average time spent varied across tutorial groups between $2.36(S D=.30)$ and $3.18(S D=.54)$. One-way analysis indicated that these scores differed significantly $(F(11,143)=6.06, p<.001)$. The average mastery score, measured on a five-point scale, ranging from: (1) not at all, to (5) very well, was 3.27 $(S D=.43)$. The average mastery scores for each problem varied between $2.43(S D=.29)$ and $3.70(S D=.34)$, also shown in column 5 of Table 1. The average mastery scores differed across problems $(F(11,143)=16.35$, $p<.001)$. The average mastery of topics included for checking response set effects was $2.60(S D=.25)$, which is low, but not as low as would be expected, since the average TOC mastery score for Problem 12 is lower, $2.43(S D=.29)$. An explanation for this finding is that some of the eight 'filler' items were related to a previous unit about the development of the embryo, which implies that, although students did not spend time on these topics during the unit at hand, they already mastered some of these 
topics. The average mastery scores varied across tutorial groups between $2.78(S D=.40)$ and $3.52(S D=.34)$. One-way analysis indicated that these scores differed significantly $(F(11,143)=3.83, p<.001)$.

The results of the qualitative comparisons between TOC topics and learning issues are shown in column 7 of Table 1. The average score, measured on a 5-point scale, ranging from: (1) not at all, to (5) well, was $3.18(S D=.64)$. The average score for each problem varied between 2.57 $(S D=.57)$ and $3.92(S D=.60)$. One-way analysis of variance indicated that this score differed across problems $(F(11,143)=5.63, p<.001)$, but not across tutorial groups.

Table 1

Percentages of overlap between faculty objectives and student-generated learning issues (column 2), average time scores and standard deviations [SD] (columns 3 and 4), average mastery scores and SD (columns 5 and 6) and average direct match scores between learning issues and topics and SD (columns 7 and 8 ) for 12 problems in a second year course on normal pregnancy, delivery, and child development, academic year 1990-1991.

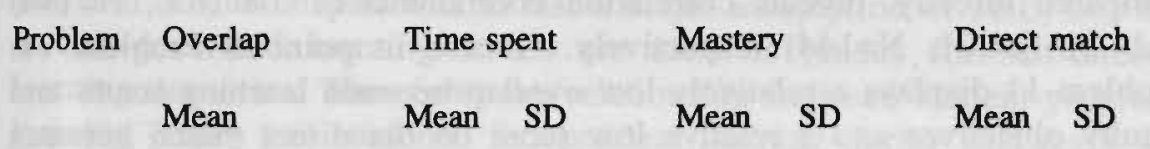

\begin{tabular}{llllllll}
\hline 1 & 76.3 & 2.69 & .29 & 3.21 & .23 & 3.52 & .31 \\
2 & 71.7 & 2.91 & .27 & 3.45 & .27 & 3.04 & .44 \\
3 & 70.8 & 2.56 & .21 & 3.28 & .29 & 3.31 & .57 \\
4 & 56.7 & 3.19 & .34 & 3.70 & .34 & 3.03 & .58 \\
5 & 63.3 & 2.43 & .23 & 2.99 & .26 & 2.70 & .26 \\
6 & 61.1 & 2.94 & .38 & 3.49 & .35 & 3.38 & .64 \\
7 & 60.4 & 2.80 & .33 & 3.29 & .38 & 3.92 & .60 \\
8 & 68.8 & 2.85 & .26 & 3.29 & .24 & 3.07 & .45 \\
9 & 56.3 & 2.55 & .29 & 3.10 & .30 & 3.52 & .85 \\
10 & 56.7 & 2.62 & .28 & 3.31 & .30 & 3.18 & .61 \\
11 & 27.7 & 2.97 & .29 & 3.68 & .18 & 2.96 & .42 \\
12 & 100.0 & 2.05 & .30 & 2.43 & .29 & 2.57 & .57 \\
& & & & & & & \\
Total & 64.2 & 2.71 & .40 & 3.27 & .43 & 3.18 & .64 \\
& & & & & & & \\
\hline
\end{tabular}


Comparing the results between average TOC time scores and mastery scores for each topic reveals that both procedures correlate highly, i.e., a large amount of time spent corresponds with a high mastery score and vice versa. The correlation coefficients between TOC time scores and mastery scores for each topic at the level of the individual student varied between $.46(p<.001, \mathrm{~N}=126)$ and $.89(p<.001, \mathrm{~N}=126)$. The median value was a correlation coefficient of .69 and the mode was a correlation coefficient of .76.

When the results are compared, i.e., the percentage of faculty objectives identified and the TOC scores for each problem, it is somewhat surprising to find that the results of both procedures reveal a moderate negative correlation. The Spearman rank correlation coefficient between the average problem overlap scores and the TOC time scores and mastery scores are both $-.36(p<.001, \mathrm{~N}=144)$. Both measures correlate negatively, i.e., a problem showing a high percentage of overlap displays relatively low averages on the relevant TOC topics and vice versa.

Comparing the average TOC time and mastery scores with the results of the qualitative analysis in which learning issues and TOC topics were compared directly, reveals correlation coefficients of .08 (n.s., $\mathrm{N}=144$ ) and $.21(p<.01, \mathrm{~N}=144)$ respectively. A case in point is Problem 11. Problem 11 displays a relatively low overlap between learning issues and faculty objectives and a relative low score on the direct match between learning issues and topics, whereas the TOC scores for this problem are relatively high. The same holds for Problem 4. Problem 12, on the other hand, shows relatively low TOC averages and a low score on the direct match of learning issues and topics, whereas all tutorial groups succeeded in identifying the pre-set faculty objective (that is: the correspondence between student-generated learning issues and faculty objectives was 100 percent). ${ }^{1}$ Problem 9 shows low values for all measures, except the direct match between learning issues and TOC topics. In summary, the order in which the problems are ranked across the procedures, overlap between issues and objectives or the direct match between learning issues and TOC scores is not highly related. Since the number of problems is necessarily limited, one cannot exclude the possibility that this finding is influenced by one or two extreme data-points. One example may be Problem 12, which can be considered atypical since it was based on only one faculty objective, which none of the groups had

1 The high level of overlap between issues and objectives for Problem 12, however, might be the result of the fact that the designer of this problem had only one objective in mind, i.e., "normal psychosexual development". It might not have been too difficult for groups to identify this objective as a goal for learning. 
difficulty in identifying. Therefore, the Spearman rank correlation coefficients were also computed excluding Problem 12. In the latter case, coefficients between the average problem overlap scores and the TOC time and mastery scores are $-.21 \quad(\mathrm{p}<.01, \mathrm{n}=132)$ and -.17 (n.s., $\mathrm{n}=132)$ respectively; coefficients between the direct match between learning issues and TOC topics on the one hand and the TOC time and mastery scores on the other are -.10 ( $n . s, n=132$ ) and .05 (n.s., $n=132$ ) respectively. Taking these values as descriptive rather than inferential statistics, the proportion of the variance of TOC scores that can be predicted from overlap between student-generated learning issues and faculty objectives, is not larger than .13 for time and mastery scores. Data from the same course in the previous year, in the academic year 1989-1990, produced Spearman rank correlation coefficients of .01 and .03 , (both n.s., $\mathrm{N}=142$ ) respectively.

\section{General Discussion and Conclusions}

The aim of this chapter was to test a major assumption of PBL, i.e., that student-generated learning issues are used as guides for self-directed learning activities. Therefore, the relationship between student-generated learning issues and students' independent learning during self-study was investigated. Based on the assumption of PBL that student-generated learning issues are the major source driving students during self-study, a high correlation would be expected between the percentage of faculty objectives identified and students' independent learning corresponding with these learning issues.

The high correlation coefficient between TOC time scores and TOC mastery scores indicates that students' perception of their own mastery and time spent are closely related. This suggests that there is a positive relationship between the amount of time students invest in a particular topic and their sense of mastery of this topic. This finding is in agreement with most theories of school learning that assume that amount of time spent on learning is causally related to mastery (Gettinger, 1984). Of course, there is the alternative possibility of the high correlation simply being the result of response set. However, the average time spent and mastery for the eight 'filler' items was fairly low as compared to the other TOC items. This indicates that a response set effect is a less likely explanation for the present finding.

The low proportion of the variance of TOC scores that can be predicted from overlap between student-generated learning issues and faculty objectives or a direct match between learning issues generated 
and TOC scores indicates that the relationship between student-generated issues and TOC scores at the problem level essentially can be considered negligible. This means that students may have identified most issues considered important by the teachers, and at the same time may not report that they have spent time on topics related to these issues (and have mastered them) and vice versa. In other words, what students plan to do, as expressed in the list of learning issues produced after problem discussion, is essentially unrelated to what they actually do.

There may be several explanations for these somewhat counterintuitive findings. A first possibility is that learning issues are not the sole or major factor influencing the nature of students' self-study, but several other factors may be involved in decisions on what to study. In other words, how student learning in PBL takes place as specified in Figure 1, i.e., teachers design problems with certain faculty objectives in mind, subsequently, students discuss these problems and generate learning issues on the basis of which they initiate learning activities during self-study, may only to some extent reflect what actually takes place.

A second possibility would be that, as already mentioned in the introduction section of this chapter, students pay much attention to a learning issue during discussion in the tutorial group, but eventually may decide not to spend time on this issue during self-study. Students may discuss this issue to activate their prior knowledge, but might feel that they have already mastered the subject-matter.

A third possibility is that students' actual learning activities are dependent on the nature of the problem at hand. For instance, students' motivation and interest with regard to studying psychology-related learning issues as compared to physiology-related learning issues may vary. For example, Problem 5 related to the psychological well-being of the mother during childbed, scored relatively low with respect to average time spent and average mastery scores, as shown in Table 1. However, most groups had no difficulty identifying the pre-set faculty objectives for this problem. The percentage of faculty objectives identified for Problem 5 was 63.3, whereas the total average percentage of faculty objectives identified for all 12 problems was 64.2 . Hence, it may be possible that the nature of the subject-matter dealt with in this problem might be less interesting, due to which TOC scores were relatively low. This finding is in accordance with faculty observations suggesting that medical students seem to prefer biological and physiological issues at the expense of psychological and sociological ones. Problem 4, dealing with physiological processes of delivery provides a pre-eminent example of this observation, since this problem scored relatively high on the TOC. 
Further illustrative evidence for these observations comes from direct observation in a tutorial group session by the author of this thesis. During the discussion, preceding the generation of the learning issue about psychological changes taking place during pregnancy, one of the students noticed that they should not only focus on physical changes during pregnancy, but since they are working in a PBL curriculum students were also expected to focus on psychological aspects of pregnancy. These remarks led students to the generation of a learning issue on psychological aspects of pregnancy. However, not only students' interest or motivation may influence students' learning activities during selfstudy, but also students' perceptions on the nature of the knowledge to be acquired. Faculty observations suggest that students experience more difficulties than usual when confronted with psychologically, socially, ethically, legally or economically oriented learning issues. Students complain that this literature is not as fact-oriented as the literature on biology issues. This perception of having to master 'vague subject-matter without success' might be reflected by low TOC scores for topics related to social and psychological aspects.

A fourth alternative explanation emerged while analyzing Problem 12. All groups succeeded in identifying the intended faculty objective for this problem, i.e., the percentage of overlap was $100 \%$. Most tutorial groups generated the issue "normal psychosexual development". This issue, however, is not an easy one: it is broadly defined and requires extensive study of the literature. Students may feel insecure about the results of these study activities. Thus, although a broadly defined issue may cover the intended faculty objectives sufficiently, it may hardly provide guidance for students and, hence, lead to relatively low TOC scores.

A fifth explanation, already mentioned in the introduction section of this chapter, is that although a particular learning issue was not raised, students still might have spent time on this issue, since it may emerge from their study of the literature as a relevant one. In other words, learning resources might reveal to students that a particular issue, although not raised during the discussion still is an important element in understanding the problem at hand and, therefore, deserves attention. In other words, the particular contents of the available learning resources may influence students' learning activities during self-study.

A sixth possibility arose while analyzing Problem 2 in detail. Problem 2 deals with physiological and psychological changes in mothers-to-be occurring during the last four months of pregnancy. Scrutinizing the learning issues generated by all 12 tutorial groups showed that most tutorial groups generated learning issues regarding 
changes in respiration, blood circulation, metabolism and the central nervous system and learning issues related to hormonal changes. Studying the average topic scores related to this problem showed on the contrary that the average time spent on changes in hormonal activity as well as the average mastery score on this topic were relatively low, 2.29 $(S D=.96)$ and $2.55(S D=1.09)$ respectively, whereas average time spent and mastery scores for all 11 topics related to Problem 2 are 2.91 $(S D=.27)$ and $3.45(S D=.27)$ respectively. A possible explanation for the low amount of time spent is that hormonal changes had already been covered in the previous unit focusing on the embryonic development. The low level of mastery, however, is not in line with this explanation; a recurrence of the topic hormonal changes would indeed reduce the amount of time spent but not necessarily the level of mastery. In conclusion, the discrepancy between learning issues raised and content covered during self-study may be caused by the fact that a particular issue had already been covered during previous units, due to which students assign less priority to these issues as compared to issues which are totally new to them. Thus, content covered in previous units may as well influence the nature of students' self-study.

A seventh explanation might be that particular learning issues although not listed, have still been mastered by students, since these issues are addressed during lectures or other additional curricular activities. For example, Problem 4 deals with childbirth. During a training program in physical examination skills in the skills laboratory, ${ }^{2}$ students learnt how to diagnose the second stage of delivery, how to give the right pushing instructions and how to manage the normal delivery in occiput presentation. Since normal child delivery was addressed during training in the laboratory, students' scores on the TOC for Problem 4 were very high, $3.19(S D=.34)$ and $3.70(S D=.34)$ respectively, whereas the percentage of relevant faculty objectives identified for this problem was moderate, 56.7.

An eigth possible explanation is that incongruity between the subjectmatter tested and the subject-matter addressed in the problems might influence students' learning activities during self-study. In some courses, questions are presented to students as self-assessment tools to provide them with feedback about their performance. Based on this self-assessment test, students might decide to spend some more time on a particular learning issue during self-study. In other words, the incongruity between

2 In the skills laboratory students can train their physical and social skills. 
topics addressed in the problems and issues covered in self-assessment tests may also drive students' learning in a PBL curriculum.

Direct observation by the author of this thesis during a tutorial group session discussing the problem 'Unknown feelings' may illustrate that tutor guidance also influences content covered by students during selfstudy. The discussion preceding the learning issue about the sleep-wake rhythm of the fetus as listed in the example of the problem 'Unknown feelings' in the introduction section is illustrative, since this learning issue was not expected by faculty to be generated and was not listed as a faculty objective. The preceding discussion will be outlined briefly. The tutorial group discussed the mothers' diminished night's rest because of heartburn behind her breastbone and difficulties finding a suitable sleeping position. A minute later, the tutor asked the students: "What comes to your mind when you think about a baby moving in his mother's womb late at night?" Immediately after this intervention of the tutor one student asked: "Does the fetus have a sleep-wake rhythm?" This question was raised as a learning issue and was a response to a salient detail in the tutor's question and the preceding discussion about the mother's poor sleeping at night, rather than to the main focus of the problem. This example illustrates that student-generated learning issues and students' self-study are determined by factors other than those related to the content of the problem itself. Tutors' guidance also influences content covered during self-study and tutorial group sessions.

A final explanation of the discrepancy between percentage of faculty objectives identified and time spent and mastery may rely in the methodology used. The percentage of faculty objectives identified may provide only partial information about the effectiveness of problems, since teachers' priorities regarding specific objectives related to a particular problem are not taken into account. TOC topics, on the contrary, are formulated at a more specific level, which makes it possible that issues considered as more important are represented by more topics than issues considered as less important. As a result, TOC topics might to some extent better reflect teachers' priorities than learning issues generated by students. Due to these differences, existing relationships between learning issues and learning activities may be blurred. In addition, the discussion preceding the generation of learning issues provides students with cues as to what they actually will study. This might imply that, although the learning issues generated are not clearly formulated, resulting in a low percentage of faculty objectives identified, students know exactly what topics should be covered during self-study, accounting for high TOC scores. Another methodological problem that might play a part is that, although students did not identify a faculty objective for a particular 
problem, they might have identified this objective while working on another problem. In this case, the percentage of faculty objectives identified may be low for a particular problem, but students might have spent time on this issue, due to which TOC time and mastery scores may also be high. For example, the issue of organ changes that take place in a pregnant woman is identified by some tutorial groups when analyzing Problem 1 which dealt with the development of the fetus during the last four months of pregnancy, whereas this issue was specified as a faculty objective for Problem 2 focusing on physiological and psychological changes that take place during the last four months of pregnancy.

From the arguments listed thus far, it may become apparent that subsequent stages of discussing problems, generating leaming issues and studying corresponding topics during self-study, expressed as TOC responses, presented in Figure 1, are not so directly related to each other as assumed in PBL. Not only student-generated learning issues, but several other factors may play a part. These factors are summarized in Figure 2.

In summary, the results of the comparison between learning issues and TOC topics suggest that student-generated learning issues are not necessarily a major factor influencing the nature of students' self-study, but several other factors may be involved in decisions on what to study and how much time to spend on topics selected. Hence, the assumption of PBL that learning issues are used as the major source for self-directed learning activities is not supported by the results of this study. Several explanations were raised that suggest why the relationship is not as straightforward as is often expected. Factors such as topics covered during discussion, the nature of the problems at hand, broadly defined learning issues, content covered during resource sessions or additional curricular activities, congruity between content covered in tests and content covered in problems, and tutor guidance may influence the nature of students' self-study. Thus, what students actually do may not only be determined by what they intend to do.

Future research should focus on these other factors influencing students' learning activities in PBL. This research, however, may require more sophisticated analyses, for example interviewing students, keeping daily logs of students' learning activities or screening the literature or other sources that students use during self-study. Since procedures to do this in an appropriate way are not available yet, some work is still ahead before we really can answer the question of what happens to the learner in problem-based leaming. 


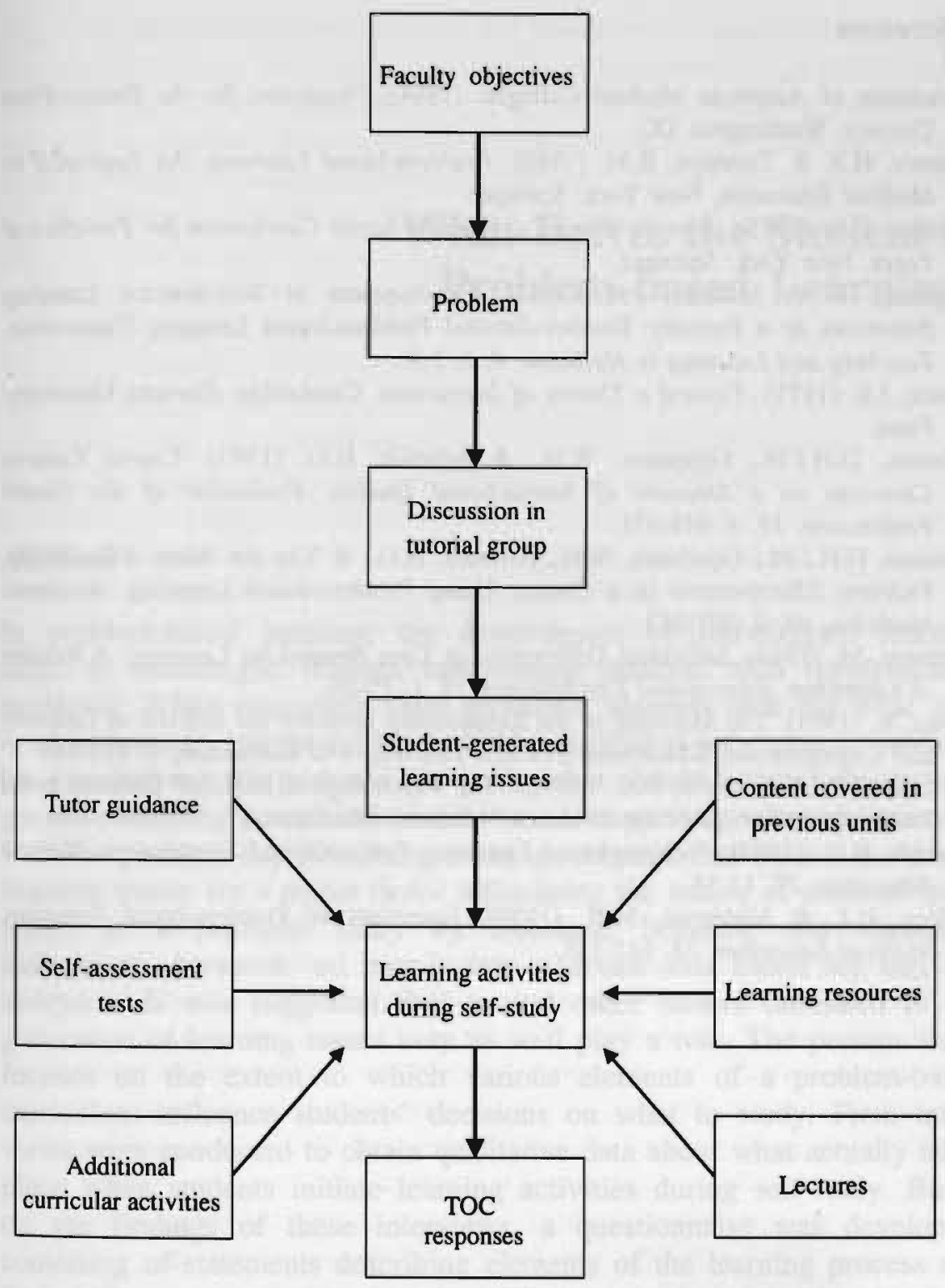

Figure 2

Students' learning activities and hence, corresponding TOC responses are influenced by several other factors that may be involved in decisions on what students actually study. 


\section{References}

Association of American Medical Colleges. (1984). Physicians for the Twenty-First Century. Washington, DC.

Barrows, H.S. \& Tamblyn, R.M. (1980). Problem-based Learning. An Approach to Medical Education. New York: Springer.

Barrows, H.S. (1985). How to Design a Problem-based Curriculum for Pre-clinical Years. New York: Springer.

Blumberg, P. \& Michael, J.A. (1992). Development of Self-directed Learning Behaviors in a Partially Teacher-directed Problem-based Learning Curriculum. Teaching and Learning in Medicine, 4, 1, 3-8.

Bruner, J.S. (1971). Toward a Theory of Instruction. Cambridge: Harvard University Press.

Dolmans, D.H.J.M., Gijselaers, W.H., \& Schmidt, H.G. (1993). Course Content Coverage as a Measure of Instructional Quality. Evaluation of the Health Professions, 16, 4, 448-471.

Dolmans, D.H.J.M., Gijselaers, W.H., Schmidt, H.G., \& Van der Meer, S.B. (1993). Problem Effectiveness in a Course Using Problem-based Learning. Academic Medicine, 68, 3, 207-213.

Gettinger, M. (1984). Individual Differences in Time Needed for Learning: A Review of Literature. Educational Psychologist, 19, 1, 15-29.

Glaser, R. (1991). The Maturing of the Relationship Between the Science of Learning and Cognition and Educational Practice. Learning and Instruction, 1, 129-144.

Norman, G.R. \& Schmidt, H.G. (1992). The Psychological Basis of Problem-based Learning: A Review of the Evidence. Academic Medicine, 67, 557-565.

Schmidt, H.G. (1983). Problem-based Learning: Rationale and Description. Medical Education, 17, 11-16.

Walton, H.J. \& Matthews, M.B. (1989). Essentials of Problem-based Learning, Medical Education, 23, 542-558. 


\section{What Drives the Student in Problem-based Learning?}

\section{Abstract}

In problem-based learning, the development of self-directed learning skills is encouraged through confronting students with (professional) problems. While discussing these problems, students seek out what they need to learn to understand biomedical and clinical principles or mechanisms underlying the problem. To guide what should be studied, students generate learning issues and search for corresponding relevant literature. Basic to problem-based learning is the assumption that student-generated learning issues are a major factor influencing the nature of students' selfstudy. In a previous study by Dolmans, Schmidt, and Gijselaers (submitted), however, no convincing evidence was found for this assumption. It was suggested that several other factors unrelated to the generation of learning issues may as well play a role. The present study focuses on the extent to which various elements of a problem-based curriculum influence students' decisions on what to study. First, interviews were conducted to obtain qualitative data about what actually takes place when students initiate learning activities during self-study. Based on the findings of these interviews, a questionnaire was developed, consisting of statements describing elements of the learning process and their influence on student learning. Elements included in the questionnaire were: the initial problem discussion, the generation of learning issues, reference literature, course objectives, lectures, content tested, other students, and the futor. The students reported that all these elements may have an impact on decisions on what to study. Moreover, first year students tend to rely more on the literature cited in the references list and content covered in lectures and tests than students in the other three curriculum years. In general, the influence of these elements 
seemed to show a decrease over the four curriculum years. The influence of the initial tutorial discussion and student-generated learning issues, on the contrary, tended to increase over the four curriculum years. These findings suggest that students in a problem-based curriculum become more accomplished, self-directed learners over the four curriculum years, even though they are provided with many clues which may play a role in their decisions on what to study.

\section{Introduction}

The development of self-directed learning skills in problem-based learning is encouraged through confronting students with (professional) problems. Tutorial groups, comprising 8 to 10 participants, meet twice a week during a 2 -hour session in which they discuss these problems. A problem usually consists of a description of a set of phenomena in need of some kind of explanation. The task of the group is to explain these phenomena in terms of underlying (biomedical or psychosocial) processes, principles or mechanisms (Schmidt, 1983). During the analysis of the problem, students make use of pre-existing ideas, opinions and prior knowledge. While discussing the possible explanations, students seek out what they do not know yet and what they need to leam to better understand the phenomena described in the problem. This provides them with both the direction and extent of study that needs to be undertaken to acquire a deep understanding of the problem (Barrows, 1985). To that end, students generate leaming issues.

Basic to problem-based learning is that student learning is organized around problems. Barrows (1985) claims that the problem serves as a challenge to students' reasoning or problem-solving skills and as an organizer for their learning. The only way to discover what you already know, what you have really stored in your memory, is to work with a problem. Through problem analysis students realize what they already know and do not have to study. More importantly, however, they discover what they really do not know and must concentrate on in their study. When students discuss a problem they ask themselves whether or not their knowledge and skills are adequate to deal with this problem. This provides them with both a sense of direction and the depth of study that needs to be undertaken. Through problem discussion, students identify their own learning needs and formulate these needs as learning issues for further perusal. These issues are listed and serve as guides for what they should learn during self-study. The generation of learning issues by students is assumed to stimulate the development of self- 
directed learning skills (Blumberg, Michael, \& Zeitz, 1990; Walton \& Matthews, 1989). The main advantage of encouraging self-directed learning skills is that students learn how to deal with problems in the future, preparing themselves to become independent, self-directed, lifelong learners (Barrows \& Tamblyn, 1980). The creation of a pattern of lifelong learning is required to keep in step with current knowledge and good practice in medicine (Walton \& Matthews, 1989).

Since problems are a major factor influencing the nature of students' self-study, a direct relationship is expected between the learning issues generated and the students' learning activities during self-study. In a previous study, Dolmans et al. (submitted) investigated the relationship between student-generated learning issues and students' actual learning activities. They compared the learning issues generated by each tutorial group with the faculty-generated objectives. In addition, they measured students' learning activities through a list of topics on which students were asked to indicate on a 5-point Likert scale how much time they had spent on studying each topic and to what degree they had mastered that topic. Since it is assumed that student-generated learning issues are the major source driving students' self-study, a correlation between learning issues produced and learning activities carried out was expected. The results, however, revealed a moderate negative correlation between both procedures. These results suggest that the learning issues generated may define only to some extent what students will actually study during a course.

Several explanations for the apparent lack of the match between student-generated learning issues and students' learning activities during self-study may be possible. For instance, a particular issue, although not raised during the initial discussion, may become relevant as students scan the literature. It is also possible that students do not generate a particular issue because they covered this issue during a previous unit or because the issue was covered during a lecture. This implies that, although the students did not identify this issue, students' mastery of the topics related to that issue may be high. The tutor's point of view may also play a role in decisions on what to study.

From this description, it becomes apparent that not only studentgenerated learning issues, but several other elements of a problem-based curriculum may as well have an impact on students' actual learning activities. Students in a problem-based curriculum do not only work on problems, but are also confronted with general faculty objectives, lectures, and tutors, which, together with self-generated learning issues, might influence the nature of the students' self-study. Faculty objectives may provide the students with a framework about what is expected from 
them during a course. The tutor may ask questions such as: "What does that mean?" and "are there any other explanations?" in order to probe the student's knowledge deeply (Barrows, 1988). It is obvious that these questions will influence on which issues students concentrate and, hence, which issues may become a focus of self-study. In other words, it is unlikely that student-generated learning issues are the sole factor influencing the nature of students' self-study.

The aim of the present study is to identify the extent to which various elements of a problem-based curriculum influence students' decisions on what to study. First, interviews were conducted among students to explore what kind of considerations may play a role in deciding what to study during a course. Based on the findings in these interviews, a questionnaire was constructed containing statements about elements of a problem-based course that may influence the nature of students' self-study. The elements of a problem-based curriculum that were included in the questionnaire focused on the initial problem discussion, the generation of learning issues, reference literature, course objectives, lectures, content tested, other students, and the tutor. The questionnaire was administered to students in four different curriculum years. This was done to find out to what extent experience-related differences among students may occur.

\section{Method}

\section{Materials}

The study was conducted at the Medical Faculty of the University of Limburg in Maastricht, the Netherlands, in the academic year 1992-1993. The first four years of the curriculum are structured as a series of 6-week courses. About 150 students participate in each curriculum year. These students are randomly assigned to 18 tutorial groups, each comprising eight to nine students. Each tutorial group is guided by a tutor.

Prior to the construction of the questionnaire, six first year students were interviewed by the author of this thesis to explore what actually happens when students initiate learning activities during self-study and what kind of considerations might play a role in choosing the literature and deciding what to study. The following questions were addressed to them: "Try to describe what kind of activities you will conduct for the next tutorial group meeting", "what kind of resources are you going to consult?", "how do you select these resources?", and "what factors influence which subject-matter will be covered during self-study?". 
Students were told to keep in mind the course in which they were currently working, while answering these questions.

Based on their responses, a questionnaire was developed. The questionnaire was subdivided in themes reflecting aspects that might influence students' learning activities during self-study. The questionnaire contained 33 statements: two statements about the function of the initial problem discussion, five items about the role of student-generated learning issues, seven statements about the selection of reading materials, three items about the influence of course objectives, three statements about the role of lectures, eight items about the influence of content tested, two items about the role of other students, and three statements about the influence of the tutor. Students were asked to indicate on a 5point Likert scale whether they (1) totally disagreed, (2) disagreed, (3) were neutral, (4) agreed, or (5) totally agreed with each statement. While judging these statements they were asked to keep in mind their learning activities for self-study during the last academic year.

\section{Procedure}

The questionnaire was administered to all students of the first four curriculum years, at the end of the academic year 1992-1993. In total 407 students filled out the questionnaire. The response rate was $77 \%$ $(n=115)$ in the first year, $77 \%(n=115)$ in the second year, $49 \%(n=73)$ in the third year and $69 \%(n=104)$ in the fourth year. The response rate in the third year was rather low, because many students had left for elective studies abroad.

The results of the questionnaire will be presented around the same themes as the ones around which the questionnaire was organized: the function of initial problem discussion, the role of student-generated learning issues, the selection of reading materials, the influence of course objectives, lectures, tests, other students and the tutor. Students' comments collected from the interviews will be presented to further demonstrate what kind of considerations may play a part in students' decisions on what to study regarding the learning issues generated in the tutorial group session. The students interviewed are identified by A, B, C, and so forth.

\section{Results and Discussion}

\section{The Function of the Initial Problem Discussion}

Learning issues are generated on the basis of problem discussion. During this discussion, students analyze a problem new to them and try to find 
out what information is required to explain the mechanisms underlying the phenomena described in the problem. In this analysis, students acquire insight into the subject-matter that is dealt with in the problem. The learning issues that are listed can be seen as a result of this analysis.

It may be obvious that the discussion preceding the generation of learning issues contains important information about the direction of students' self-study. This assumption is corroborated by the data presented in Table 1.

As can be seen in Table 1, the influence of the tutorial group on what students will study seems to be higher in curriculum years 3 and 4 than in curriculum years 1 and 2 . This finding might be explained by an increased experience of students in generating learning issues that provide clear guidelines regarding what content should be studied. Students' comments during the interviews highlighted that the discussion preceding the generation of learning issues plays a different role for students in decisions on what they study. One student (first year) said that the initial problem discussion provides him with clues which he uses when searching for relevant information:

F: "The discussion of a problem is an important guide in deciding what should be studied. Learning issues directly specify what should be studied, but they are often formulated in such a manner that it is not possible to search for these issues in an index. Words that are used during the brainstorm can often be used to search in an index and provide clear guidelines what content should be studied. If I do not possess much knowledge about a particular subject, I usually write down some words that are mentioned during the brainstorm."

Table 1

Mean scores, with standard deviations between brackets, for curriculum years 1 to 4 . The $F$-values and the $p$-values are also included.

\begin{tabular}{|c|c|c|c|c|c|c|c|}
\hline & & 1 & 2 & 3 & 4 & $F$ & $p$ \\
\hline 1 & $\begin{array}{l}\text { The discussion in the tutorial } \\
\text { group determines to a large } \\
\text { extent what I will study }\end{array}$ & $\begin{array}{r}3.11 \\
(1.05)\end{array}$ & $\begin{array}{r}3.14 \\
(0.97)\end{array}$ & $\begin{array}{r}3.48 \\
(0.96)\end{array}$ & $\begin{array}{r}3.46 \\
(1.08)\end{array}$ & 3.636 & 0.013 \\
\hline 2 & $\begin{array}{l}\text { The tutorial group discussion } \\
\text { is an important stimulus for }\end{array}$ & & & & & & \\
\hline & $\begin{array}{l}\text { my leaming activities during } \\
\text { self-study }\end{array}$ & $\begin{array}{r}3.77 \\
(0.98)\end{array}$ & $\begin{array}{r}3.76 \\
(0.90)\end{array}$ & $\begin{array}{r}3.93 \\
(0.89)\end{array}$ & $\begin{array}{r}3.78 \\
(0.75)\end{array}$ & 0.649 & 0.584 \\
\hline
\end{tabular}


Another student (first year) said that the initial problem discussion intrinsically motivated him:

A: "If we explore a particular topic during the initial discussion of a problem, it really influences my self-study. In this circumstance, I am more actively involved in the subject-matter. One looks at a problem from various angles and this encourages me to spend more time on self-study."

\section{The Role of Student-generated Learning Issues}

Students generate learning issues which they decide are prerequisites to a better understanding of the problem (Blumberg et al., 1990). As such, these issues provide guidelines during self-study. Evidence for this important claim of problem-based learning is found in the data, presented in Table 2.

The results show that the importance of learning issues as a starting point for students' learning activities seems to increase over the four curriculum years (albeit not significantly). This finding may be explained by the students' increased experience in generating clear learning issues, as already argued above. When students were asked in the interviews to describe how they make use of these issues during self-study, it became apparent that student-generated learning issues indeed aid the direction of what students are going to study and in particular influence the selection of reading materials. One student (first year) said:

D: "In general, I first take a look at the learning issues generated and the problem. Next, I start searching for difficult words in a medical dictionary to obtain some global information about these difficult terms. Subsequently, I search in the references list for relevant literature. Sometimes a particular chapter of a book is recommended. If no particular chapter is recommended, I search in the index of the recommended books for key words and its corresponding pages. Next, I start reading these pages. Mostly I use several books. After reading $I$ summarize and write down the relevant information."

The results in Table 2 further demonstrate that the generation of personal learning issues, in addition to the ones generated in the tutorial group, seems to increase over the four curriculum years (albeit not significantly). This finding provides evidence for the assumption that students become better self-directed learners as a result of being in the curriculum for a longer period of time. Furthermore, the results demonstrate that students' learning activities during self-study are not only restricted to information related to the learning issues generated. Students not only focus on those parts of the text that provide information directly relevant to the learning issues generated, but also to the related text around it. 
This finding suggests that students associate a learning issue with a larger context which also needs to be studied and understood. Students' comments during the interviews highlighted that learning issues generally tend to focus on specific aspects of the subject-matter, whereas students assume that they are expected to master the subject-matter in a broader sense. One student (first year) said:

A: "When reading a chapter in a book, mostly I read more than I think would be necessary to be studied for that particular learning issue. Most paragraphs contain some extra information and explore a particular issue more deeply. Usually I study these paragraphs too."

Table 2

Mean scores, with standard deviations between brackets, for curriculum years 1 to 4 . The $F$-values and the $p$-values are also included.

$\begin{array}{lllllll}1 & 2 & 3 & 4 & F & P\end{array}$

3 The learning issues generated are the most important starting point for my learning activities during self-study

$\begin{array}{rrrrrr}3.40 & 3.37 & 3.44 & 3.68 & 1.882 & 0.132 \\ (1.14) & (1.07) & (1.09) & (0.95) & & \end{array}$

4 I study to a large extent independently from the learning issues generated

$\begin{array}{rrrrrr}2.98 & 2.96 & 2.63 & 2.49 & 5.484 & 0.001 \\ (1.03) & (1.06) & (1.12) & (0.97) & & \end{array}$

5 In addition to the leaming issues generated in the tutorial group, I generate my own (personal) learning issues

$\begin{array}{rrrrrr}2.80 & 2.90 & 3.03 & 3.20 & 2.220 & 0.085 \\ (1.25) & (1.18) & (1.14) & (1.19) & & \end{array}$

6 My learning activities during self-study are restricted to information that is related to the learning issues generated

$\begin{array}{rrrrrr}2.03 & 2.04 & 1.95 & 1.92 & 0.393 & 0.758 \\ (1.00) & (0.99) & (0.88) & (0.97) & & \end{array}$

7 I do not only study those parts of the text that provide information directly relevant to the learning issues generated, but I also study related text around it
4.29
4.22
4.36
4.31
$0.494 \quad 0.687$
$\begin{array}{llll}(0.87) & (0.86) & (0.67) & (0.65)\end{array}$ 


\section{The Selection of Reading Materials}

Students in a problem-based curriculum are encouraged to consult different resources. In each course book, suggestions for learning resources are listed at a rather global level. Several items were included in the questionnaire about the use of different resources and the influence of the list of resources on students' self-study. The results are presented in Table 3.

Table 3

Mean scores, with standard deviations between brackets, for curriculum years 1 to 4 . The $F$-values and the $p$-values are also included.

$\begin{array}{llllll}1 & 2 & 3 & 4 & F & p\end{array}$

8 The problem-based approach to medicine encourages me to consult different sources of $\begin{array}{llllll}3.73 & 3.83 & 3.89 & 3.90 & 0.607 & 0.611\end{array}$ literature

$\begin{array}{llll}(1.02) & (0.98) & (1.00) & (0.95)\end{array}$

9 Usually, I make use of more than one resource when studying a particular topic

$\begin{array}{rrrrrr}3.77 & 3.67 & 3.70 & 3.62 & 0.420 & 0.739 \\ (1.02) & (0.96) & (0.97) & (1.06) & & \end{array}$

10 I think that I have become better able to find relevant literature as time passes

11 By making use of different sources of information, the discussion in the tutorial group usually attains a deeper level
4.12
4.23
4.42
4.45
$4.561 \quad 0.004$

$\begin{array}{llll}(0.79) & (0.78) & (0.67) & (0.70)\end{array}$

12 I usually confine myself to the reference literature cited in the course book when searching for relevant literature
4.26
3.79
3.86
2.89
36.290 .000
$\begin{array}{llll}(0.74) & (0.98) & (0.97) & (1.16)\end{array}$

13 I hardly review literature beyond the sources that are in-

6.7530 .000 cluded in the course book (1.23) (1.05) (1.15) (1.08)

14 I study almost all issues by making use of a few handbooks (1.02) (0.89) (1.09) (1.03) 
The data in Table 3 indicate that students indeed make use of different sources of information. The results further demonstrate that students, in particularly during the first year, confine themselves to the reference literature cited in the course book when searching for relevant literature. During the fourth curriculum year, students make less use of the reference literature cited in the course book. This finding again provides evidence for the assumption that students in a problem-based curriculum become better self-directed learners.

In addition, the results show that students in the second and fourth curriculum year make more use of a few handbooks to study almost all subject-matter than students in the first and third curriculum year. In the second curriculum year, students are confronted with basic science issues, such as anatomy and physiology. Based on previous experiences with the usefulness and readability of anatomy and physiology books, students display a preference for particular books. In the fourth year, on the contrary, students are confronted with clinical issues. However, during their fourth curriculum year, students feel that their knowledge of basic science issues should be refreshed, since they enter the clinical clerkships in curriculum year 5 .

Asking students during the interviews what kind of action they would conduct regarding the learning issues generated for the next meeting, most students started to give an overview of the resources they were going to use during their self-study. Obviously, during the process leading to the generation of learning issues, students get an idea of the literature that will be useful. This seems to demonstrate that students situate the learning issues to be studied in the broader context of knowledge to be acquired during their study. This particularly holds for studying the mechanisms of action of the heart, the kidneys and the lungs.' Students know that they should learn something about the anatomy and physiology of these organs, and as a consequence make use of a few handbooks. One student (first year) said during the interviews:

F: "When studying heart, kidneys and lungs, I make use of a physiology book, since I am sure that $I$ can find something in it about this subject. Subsequently, I make use of a pathology book and read the chapter about the respiratory system. I read as long as I think will be necessary to have read everything that is of importance."

1 Six first year students were interviewed during a course dealing with issues such as mechanisms of action of heart, kidneys and lungs. 
Several students said during the interviews that they prefer particular books based on previous experiences with the usefulness and readability. Another argument often mentioned was that students prefer to use books which are also often used by other students in the tutorial group. One student (first year) said:

D: "The books that I used to study the learning issues generated were chosen on previous experiences in other courses. I am used to these books, I know what is in them, I know that these books are good, and I know that this book is the one that is generally used by all students when studying physiology. The book is also included in the reference literature in the course book."

\section{Course Objectives}

In each course book, global course objectives are listed. These objectives provide students with information about the subject-matter dealt with in the course and as such are assumed to influence students' self-study. Three questions were included in the questionnaire about this aspect of a problem-based curriculum. The results are shown in Table 4.

Table 4

Mean scores, with standard deviations between brackets, for curriculum years 1 to 4 . The $F$-values and the $p$-values are also included.

$\begin{array}{lllllll}1 & 2 & 3 & 4 & F & P\end{array}$

15 At the start of a course, I consult the course objectives stated in the course book

$\begin{array}{rrrrrr}3.77 & 3.55 & 3.54 & 3.50 & 1.178 & 0.318 \\ (1.11) & (1.20) & (1.21) & (1.26) & & \end{array}$

16 At the end of the course, I consult the course objectives to check whether I covered all subject-matter I was expected to cover

$\begin{array}{llllll}3.46 & 3.52 & 3.19 & 3.39 & 1.072 & 0.361\end{array}$

$\begin{array}{llll}(1.24) \quad(1.20) & (1.32) \quad(1.29)\end{array}$

17 During the course, the course objectives influence what kind of learning activities I am going to conduct

$\begin{array}{llllll}3.45 & 3.61 & 3.53 & 3.17 & 3.086 & 0.027\end{array}$

(1.13) (1.11) (1.07) (1.12) 
The results in Table 4 indicate that students at the start of a course consult the course objectives stated in the course book. Students also consult the course objectives at the end of the course to check whether they covered all subject-matter they were expected to cover. The influence of the course objectives on students' self-study shows an increase from curriculum year 1 to curriculum year 2 and a decrease in the third and fourth curriculum years. A possible explanation for this finding is that first year students pay less attention to the course objectives, because they are not aware of the guidance provided in these objectives. Students in the third and fourth years, on the other hand, need less guidance since they have become better self-directed learners. The interviews also revealed that most students use the course objectives at the end of the course as a check whether they covered the subject-matter intended to be studied during the course. One student (first year) said:

\section{A: "The day before the test takes place, I read the course objectives to obtain information about what we were expected to study during this course."}

\section{Lectures}

In each course, a limited number of lectures is included. The questionnaire contained three items about the influence of these lectures on students' self-study. These results are shown in Table 5.

\section{Table 5}

Mean scores, with standard deviations between brackets, for curriculum years 1 to 4 . The $F$-values and the $p$-values are also included.

$\begin{array}{lllllll}1 & 2 & 3 & 4 & F & p\end{array}$

18 The lectures, generally, are relevant to the issues covered

$\begin{array}{rrrrrr}4.27 & 3.82 & 3.90 & 4.08 & 7.477 & 0.000 \\ (0.64) & (0.88) & (0.90) & (0.70) & & \end{array}$
by the problems

19 Topics covered during lectures influence which topics I select for self-study

$\begin{array}{rrrrrr}3.45 & 2.91 & 3.13 & 3.20 & 4.922 & 0.002 \\ (0.97) & (1.05) & (1.20) & (1.11) & & \end{array}$

20 Lectures are an important source of information to decide which topics I will study more extensively 
The results in Table 5 seem to indicate that the influence of topics covered during lectures on students' self-study is strongest in curriculum year 1. The influence of topics covered during lectures on students' selfstudy is, however, also dependent on the perceived relevance of these lectures. Since the relevance of the lectures is rated lower in curriculum years 2,3 , and 4 , it is not surprising to find that the lectures in those curriculum years have less influence on students' decisions on what to study than the lectures in year 1 . In general, first year students tend to rely more on content covered in lectures than students in the other three curriculum years. A possible explanation for this finding is that first year students are less experienced self-directed learners. The interviews revealed that students deal with content covered during lectures in a different manner. One student (first year) said that lectures give him an overview of what he is expected to study during a course.

D: "During a lecture it often becomes clear what topics should be known. Afterwards, when studying the learning issues, a lot of things attract attention, ...oh.., that is what I have heard this morning."

Another student said that a lecture gives him information about what he is expected to study during a course:

F: "A lecture gives me some information about what is important to be studied. Although they are brief, they provide guidelines what subject-matter should be studied. This more or less confirms that I am studying the right issues during self-study."

One student said that he used the lecture as a guide for studying the literature relevant for the course at hand:

E: "During some lectures I write down some key words that are often mentioned. Afterwards I search in the literature for these words and spend some time on them during self-study."

\section{The Influence of Content Tested}

In each course book, a self-assessment test is included to provide students with formative feedback about their performances. At the end of each course an achievement test is administered to the students, which is also aimed at providing students with formative feedback. Several items were included about this aspect of a problem-based course. The results are shown in Table 6. 
Mean scores, with standard deviations between brackets, for curriculum years 1 to 4 . The $F$-values and the $p$-values are also included.

$\begin{array}{lllllll}1 & 2 & 3 & 4 & F & P\end{array}$

21 I usually fill out the questions of the self-assessment test included in the course book

$\begin{array}{rrrrrr}4.54 & 4.30 & 4.37 & 4.26 & 1.843 & 0.139 \\ (0.78) & (1.02) & (0.99) & (1.12) & & \end{array}$

22 I take a look at the questions included in the tests to get an idea of how deeply I should study particular subject-matter

$\begin{array}{lllllll}4.04 & 3.42 & 3.05 & 3.38 & 9.480 & 0.000\end{array}$
(1.20) (1.30) (1.49) (1.31)

23 The questions that are included in the tests to a large extent determine what I will study

$\begin{array}{rrrrrr}2.68 & 2.45 & 2.25 & 2.27 & 4.073 & 0.007 \\ (1.05) & (0.82) & (1.06) & (1.15) & & \end{array}$

24 The closer the date the test will be administered to us, the more time I spend on test preparation (1.17)

$\begin{array}{rrrrrr}4.01 & 3.79 & 3.49 & 3.55 & 3.655 & 0.013 \\ (1.17) & (1.10) & (1.31) & (1.33) & & \end{array}$

25 The closer the date the test will be administered to us, the less time I spend on studying the learning issues generated in the tutorial group

$\begin{array}{rrrrrr}2.49 & 2.45 & 2.12 & 2.17 & 3.043 & 0.029 \\ (1.10) & (1.04) & (0.99) & (1.10) & & \end{array}$

26 With a view to the test I confined myself to the literature suggested in the course book

$\begin{array}{rrrrrr}2.77 & 2.50 & 2.06 & 2.06 & 11.093 & 0.000 \\ (1.17) & (1.12) & (0.91) & (0.94) & & \end{array}$

27 I do not spend any time on studying particular issues, if I am convinced that these issues $\begin{array}{rrrrrr}2.27 & 2.15 & 1.83 & 2.00 & 2.941 & 0.033 \\ (1.21) & (1.01) & (0.89) & (1.00) & & \end{array}$

28 The learning issues generated in the tutorial group are tuned to the subject-matter expected to be tested

$\begin{array}{rrrrrr}3.01 & 3.06 & 2.95 & 3.06 & 0.184 & 0.908 \\ (1.19) & (1.18) & (1.19) & (1.15) & & \end{array}$


The results in Table 6 indicate that students usually fill out the questions of the self-assessment test included in the course book. In addition, there is a significant difference across the four years in the average score on the statement affirming that students take a look at the questions included in the test to get an idea of how deeply they should study particular subject-matter. First year students scored highest on this item. The interviews revealed that, especially, at the end of the course, students fill out the self-assessment test in order to decide whether or not they have mastered certain subjects. If students notice that they do not possess enough knowledge about a particular domain, they will pursue certain learning activities regarding the items tested. One student (first year) said during the interviews:

\section{E: "Usually, I fill out the self-assessment test at the end of the course before the end-of-the-course examination. When filling out this test, I notice that I do not master certain topics. Subsequently, I search for information regard- ing these issues and sometimes several other topics, closely related to this issue, will also be studied."}

A disadvantage of including a self-assessment test in the course book is that students may tune their learning activities to the content that is tested. This would imply that students' learning activities are not guided by the learning issues generated in the tutorial group, which would hence be detrimental to the development of self-directed learning skills. In order to test this assumption, several questions were included in the questionnaire to investigate the extent to which students' self-study is test-driven. The results indicate that students in the first and second curriculum years are more test-driven than students in the third and fourth curriculum years. In general, the results demonstrate that students indeed prepare themselves for the achievement test, but also spend time studying the learning issues generated.

\section{The Influence of Other Students}

Since students in a problem-based curriculum work in tutorial groups, it may be expected that students also rely on other students during independent self-study. Several questions were included about the influence of other students. The results are shown in Table 7.

The results in Table 7 demonstrate that students do not at a regular basis enquire about which learning issues are generated by other tutorial groups. However, students make use of the suggestions of other students when selecting relevant resources, especially in the first, second and third curriculum years. Some students reported in the interviews that they 
were in some cases dependent on other students for deciding what to study. If they did not attend the tutorial group meeting in which the learning issues were generated, they could of course ask other students which learning issues were generated. One student (first year) said:

A: "If the learning issues are not clearly formulated, then it is very difficult to decide what to study. Mostly I ask other students what learning issues they did generate, and this is very helpful."

Students also rely on their peers if they have doubts about the subjectmatter that they are expected to cover. One student (first year) said:

E: "Sometimes I ask other students about the learning issues generated in their tutorial group. During one course period, I systematically asked for these issues, since our tutor was a novice in the domain. The tutor said nothing during the sessions. Although our tutor said that it was not necessary to spend time on a particular issue, students in other tutorial groups said that they did study those subjects. Those students were guided by an expert tutor, and that is why I assumed that it was necessary to explore the issues raised in our tutorial group more deeply, whereas our tutor said that it was not necessary."

Table 7

Mean scores, with standard deviations between brackets, for curriculum years 1 to 4 . The $F$-values and the $p$-values are also included.

$\begin{array}{lllllll}1 & 2 & 3 & 4 & F & p\end{array}$

29 At a regular basis, I enquire about which learning issues are generated by other tutorial groups

$\begin{array}{rrrrrr}2.50 & 2.82 & 2.77 & 2.51 & 1.755 & 0.155 \\ (1.30) & (1.28) & (1.26) & (1.22) & & \end{array}$

30 When selecting relevant resources, I make use of other students' suggestions

$\begin{array}{rrrrrr}4.07 & 4.11 & 4.19 & 3.78 & 4.032 & 0.008 \\ (0.91) & (0.77) & (0.72) & (0.97) & & \end{array}$




\section{The Influence of the Tutor}

The tutor also influences what students will study, since he or she guides the tutorial group process and uses his or her expert knowledge - if any when discussing the problem. The results of the questions about the influence of the tutor are shown in Table 8. These results demonstrate that tutors provide in general a moderate stimulus to students' learning activities. In addition, tutors stimulate students less in making use of different sources of information over the curriculum years. A possible explanation for this finding is that students become better self-directed learners and, as a consequence, are better able to select reading materials. According to students' comments during the interviews, some tutors play a major role whereas other tutors play a minor one. In such cases, students collect information regarding the learning issues generated in other tutorial groups. One student (first year) said:

B: "The tutor influences what I will study I think. He guides us fairly well. Particular topics are being repeated, since we did not master that topic. This is only one example of his influence. The tutor is an expert in anatomy, which is a basic discipline, and as a consequence he has a lot of knowledge. However, this differs across tutors. One tutor plays only a minor role, whereas another tutor plays a major role."

Table 8

Mean scores, with standard deviations between brackets, for curriculum years 1 to 4 . The $F$-values and the $p$-values are also included.

31 In general, tutors stimulate my learning activities

32 In general, tutors stimulate students to make use of different sources of information

33 In general, tutors have an important influence on the selection of learning issues

$\begin{array}{lllllll}1 & 2 & 3 & 4 & F & p\end{array}$

3.15

3.16

3.19

$0.304 \quad 0.823$ (0.87) (0.95) (1.11) (1.12)

3.04

2.81

2.75

2.45

$6.137 \quad 0.000$

$\begin{array}{llll}(0.94) & (1.01) & (1.09) & (0.98)\end{array}$

3.49

3.42

3.34

3.43

$\begin{array}{llll}(0.93) & (0.97) & (0.95) & (0.93)\end{array}$ 
Fundamental to problem-based learning is that student learning is organized around problems. During initial problem analysis, students identify their learning needs and generate learning issues which serve as guides during self-study. As a consequence, these student-generated learning issues are supposed to play a central role in students' decisions on what to study. A detailed analysis of a problem-based curriculum, however, reveals that it is unlikely that student-generated learning issues are the only factor influencing students' self-study, since students are not only confronted with problems, but also with course objectives, lectures, reference literature, tests, other students' points of view and tutors' ideas. The present study was aimed at identifying to what extent the several elements of a problem-based curriculum influence the nature of students' self-study. The results demonstrate that the availability of a references list, course objectives, lectures, tests, other students and the tutor all have an impact on students' learning activities during self-study. Moreover, first year students tend to rely more on the literature cited in the references list and content covered in lectures and tests than students in the other three curriculum years. In general, the influence of these elements seems to diminish over the four curriculum years. The influence of the initial problem discussion and the learning issues generated, on the contrary, seems to show an increase over the four curriculum years (this increase, however, is not always significant). These findings suggest that students in a problem-based curriculum indeed become better selfdirected learners as a result of being in the curriculum for a longer period of time and, hence, become more experienced. In conclusion, students in a problem-based curriculum are provided with many clues and directions that directly or indirectly play a role in their decisions on what to study, such as reference literature, course objectives, lectures, and tests.

This finding is in agreement with the results of a study of Blumberg and Michael (1992). They addressed the question whether studentgenerated learning issues are a major force driving students' self-directed learning skills. They compared the use of library resources among students in a traditional curriculum and students in a problem-based learning curriculum in which they are required to determine their own learning issues, but can also compare their learning issues with facultygenerated objectives. The data showed that students in the problem-based learning curriculum acquire behaviors that reflect continued and selfdirected learning skills. Blumberg and Michael (1992) concluded that the availability of teacher-generated learning objectives does not subvert the 
development of self-directed leaming skills. They argue that the key to encouraging self-directed learning skills lies in consistency among all aspects of the curriculum, such as (1) the student-generated learning issues, (2) faculty objectives, (3) the material covered in resource sessions, and (4) the material that is tested. 


\section{References}

Barrows, H.S. (1985). How to Design a Problem-based Curriculum for Pre-clinical Years. New York: Springer.

Barrows, H.S. (1988). The Tutorial Process. Springfield, Illinois: Southern Illinois University School of Medicine.

Barrows, H.S. \& Tamblyn, R.M. (1980). Problem-based Learning. An Approach to Medical Education. New York: Springer.

Blumberg, P. \& Michael, J.A. (1992). Development of Self-directed Learning Behaviors in a Partially Teacher-directed Problem-based Learning Curriculum. Teaching and Learning in Medicine, 4, 1, 3-8.

Blumberg, P., Michael, J.A., \& Zeitz H. (1990). Roles of Student-generated Learning Issues in a Problem-based Curriculum. Teaching and Learning in Medicine, 2, 3, 149-154.

Dolmans, D.H.J.M., Schmidt, H.G., \& Gijselaers, H.G. (submitted). The Relationship Between Student-generated Learning Issues and Self-Study in Problem-based Learning. Submitted for publication.

Schmidt, H.G. (1983). Problem-based Learning: Rationale and Description. Medical Education, 17, 11-16.

Walton, H.J. \& Matthews, M.B. (1989). Essentials of Problem-based Learning. Medical Education, 23, 542-558. 


\section{Discussion and Conclusion}

This thesis deals with aspects of what actually happens to the learner in a problem-based curriculum. The principal idea behind problem-based learning (PBL) is that learning should be organized around problems which are related to the profession, rather than around subjects which are derived from academic disciplines. These problems usually consist of a description of a set of observable phenomena or events which are in need of some kind of explanation. Teachers design these problems with certain faculty objectives in mind. Students analyze these problems, attempting to understand the underlying principles or processes through small-group discussion. In doing so, they activate whatever they already know about the problems. However, students' prior knowledge in itself is not sufficient to attain a deep understanding. During discussion usually some questions remain unanswered which subsequently serve as a guide for independent and self-directed learning (Schmidt, 1983). These questions are called student-generated learning issues.

Encouraging students to decide for themselves what is relevant to learn in PBL is assumed to foster students' development of self-directed learning skills, which enables students to 'learn how to learn' and to prepare themselves to become independent, lifelong learners. In addition, since students in PBL independently conduct literature searches, they acquire the ability to continue their education after they graduate (Barrows \& Tamblyn, 1980). However, critics sometimes argue that students lack the basic knowledge and skills to work independently. Students, at least initially, are thought to be unable to identify all the 'required' knowledge. Besides, faculties have to account for the quality of their educational programs, and hence the quality of their graduates. Therefore, faculty feel a need to ensure that no aggravating gaps exist in students' knowledge. 
In summary, student learning in PBL consists of several elements which are transformed in other elements. Faculty objectives are translated into a problem, which in turn is translated into a set of learning issues after small-group discussion, which subsequently guide students' learning activities during self-study. The investigations reported in this thesis were aimed at finding evidence for this conceptualization of PBL. Three questions were addressed. First, to what extent do students generate learning issues which correspond with pre-set faculty objectives? Second, do students perform learning activities as intended by faculty? Third, are student-generated learning issues a major factor driving students' selfstudy or do other factors have a significant influence? The first question was addressed in Chapters 2 and 3. The second question was dealt with in Chapter 4. Finally, the third question was addressed in Chapters 5 and 6 . Each chapter will be briefly discussed and the major conclusions will be summarized.

\section{Student-generated Learning Issues}

In Chapter 2, three studies were reported that investigated to what extent students in a problem-based curriculum are able to identify the objectives that teachers had in mind while developing the problem. To that end, tutors were asked to note on a form the learning issues generated for each problem by his or her tutorial group. The degree of correspondence between student-generated learning issues and faculty objectives was studied to answer this question. Results showed that an average of 64 percent of the faculty objectives were identified by 12 tutorial groups during one course period. For 10 of the 12 problems, the overlap was close to this average (within 15 percentage points). In the course under study, on average, 15 percent of the faculty objectives were definitely not identified by the students. In Study 2 , it was concluded that these objectives were either related to other curricular activities, (such as training sessions), were too broadly defined (requiring an extensive search in the literature), or were related to psychology and sociology. Since PBL accords students an active role in the acquisition of knowledge, students are free to choose their own learning issues. As a consequence, they may generate learning issues not expected by faculty. Study 3 showed that students in the course under study indeed generated 'unexpected' learning issues; i.e., learning issues not reflecting any of the faculty objectives. Nevertheless, these unexpected learning issues were judged to be relevant and worthwhile. For the course under study, 6.2 percent of the total number of learning issues generated by all tutorial 
groups were unexpected by faculty. Further exploration revealed that these learning issues were either related to students' prior knowledge deficiencies, or to patient management and medical intervention rather than to physiology or pathophysiology. Additional curricular activities or students' personal interest in, and experiences with the subject-matter were also sources of unexpected learning issues. In Chapter 2, it was concluded that at least the majority of the faculty objectives were identified by all tutorial groups. In addition, students also generate unexpected learning issues, the nature of which indicates that students in PBL seem to adapt their learning so as to satisfy their own needs and interests.

A limitation of the studies reported in Chapter 2 is that it is not always certain that students actually pursue the learning activities suggested by the learning issues they raise. Learning issues may only to some extent reflect actual learning. This issue was dealt with in Chapter 5. In addition, it was concluded that the percentage of overlap between faculty objectives and learning issues provides opportunities to detect ineffective problems, i.e., problems that do not lead students to generate the appropriate learning issues. This issue was explored in Chapter 3.

\section{Problem Improvement}

The aim of the studies reported in Chapter 3 was to investigate to what extent problems were improved based on the use of student-generated learning issues. The effectiveness of a problem was defined as the degree of correspondence between student-generated learning issues and pre-set faculty objectives (Dolmans, Gijselaers, Schmidt, \& van der Meer, 1993).

In the first study, results from a questionnaire, containing items about the usefulness of student-generated learning issues for problem improvement, were reported. This questionnaire was administered to teachers responsible for the design of the courses. The results indicated that student-generated learning issues were actually used for problem improvement. Being presented with a list of student-generated learning issues initiates a discussion among teachers about the major objectives to be identified for each problem. As such, student-generated learning issues encourage faculty to specify for themselves the objectives to be reached for each problem. It was argued that clearly specifying the intended objectives may stimulate staff to design problems based on explicit and rational considerations.

In the second study, two case studies were reported. The data consisted of the percentage of faculty objectives identified for each 
problem before and after re-designing the problems of two particular courses. Data were collected in those two courses during two consecutive academic years. The findings from both courses demonstrated that, contrary to expectations, the percentage of faculty objectives identified did not automatically increase after improvements were made. Moreover, the problems that were improved were only partly those which scored low with respect to the percentage of faculty objectives identified. Obviously, problems were not exclusively improved based on knowledge of the student-generated learning issues. Several reasons were suggested for the finding that the percentage of overlap between faculty objectives and student-generated learning issues did not improve after changes were made. First, a trade-off mechanism may occur; that is, changing a particular problem influences the effectiveness of other problems. Second, students' priorities with regard to studying particular subjectmatter may influence the effectiveness of problems. For example, most medical students may prefer biology-related issues and physiologyrelated issues at the expense of social science issues, with the result that the percentage of faculty objectives identified for a social science problem may be lower. Changing a psychological or sociological problem may not result in a higher percentage of faculty objectives identified, since the subject-matter covered in such a problem does not really interest many students or is considered 'vague' and, therefore, discarded. A third explanation may be that percentages of faculty objectives identified provide only partial information about the effectiveness of problems. Faculty's priorities assigned to particular objectives incorporated in a problem are not taken into account when assessing problem effectiveness through the percentage of correspondence between faculty objectives and learning issues. However, faculty may find some objectives more important than others, which, hence, may influence decisions regarding which problems should be improved. In summary, although the results of both case studies did not show evidence for the assumption that the effectiveness of problems actually improves by making use of student-generated learning issues, it was concluded in Chapter 3 that learning issues nevertheless provide faculty with a useful tool, suggesting avenues for course improvement.

\section{Course Content Coverage}

The emphasis of the investigations discussed so far was on studentgenerated leaming issues. As already mentioned above, one of the limitations of learning issues is that they only reflect what students plan 
to study. However, it is not at all certain that students actually pursue the learning activities suggested by the learning issues they generate. As a consequence, the second question addressed in this thesis was: Do students in PBL actually conduct learning activities that correspond with the learning activities that were intended by faculty? In order to answer this question, a procedure was developed aimed at assessing students' learning activities during self-study. In Chapter 4, the development, reliability, validity and usefulness of this procedure was discussed. The procedure was called the TOpic Checklist (TOC). The TOC consists of a list of topics reflecting the intended course content. Teachers responsible for the design of the course were asked to produce these topics based on their intentions with the course. The list of topics can be seen as a blueprint of the course content. At the end of the course, students were asked to rate to what extent they had mastered each topic and how much time they had spent on studying each topic.

Generalizability theory was used to assess the reliability of the procedure. Decision studies indicated that at the topic level, a minimum of 15 students is required to obtain reliable results. For the problem level, comprising the average scores of the topics related to one problem, the scores of 10 students already provide reliable results.

It was concluded that the TOC's content validity was sufficient, since the topics were chosen on the basis of rational considerations; that is, topics were actually derived from the 12 problems reflecting the intended course content. In order to assess the TOC's criterion validity, additional data were collected. First, the average percentage of items correctly answered on an achievement test administered to the students at the end of the course period was computed. Second, students were asked to estimate the actual number of hours spent on self-study per week during the course. The correlation coefficients between the total average TOC time scores, mastery scores and achievement test scores were fairly low. It was suggested that these fairly low coefficients may be caused not so much by lack of validity of the TOC but by insufficient content validity of the achievement test itself. The achievement test did not seem to adequately cover the intended course content, since correlation coefficients among the data for individual problems varied to a large extent. The correlation between the total average TOC time scores and the actual number of hours spent on self-study per week was moderate. It was concluded that the latter outcome seemed to provide some evidence for the criterion validity of the TOC.

A consequence of students selecting their own topics for self-study, might be that students' actual learning activities may not cover the curriculum content expected to be covered by faculty, as already 
described above. In Chapter 4, it was argued that the TOC can be used as a procedure for indicating problem areas in course content coverage. The total average time spent on each problem and the total average mastery scores indicate the degree to which students' learning activities cover the intended course content. Problems with relatively low average scores are candidates for improvement in order to ensure course content coverage.

\section{Student-generated Learning Issues as Guides for Self-study}

In PBL it is assumed that student-generated learning issues are actually used as guides for self-study. This basic assumption of PBL has never been tested. Since, in this thesis, a procedure was developed to assess student-generated learning issues, described in Chapter 2, and a procedure was designed to assess students' learning activities during selfstudy, described in Chapter 4, the results of both procedures could be compared. Thus, the question to be addressed in Chapter 5 was whether student-generated learning issues predict their learning activities, i.e., whether these learning issues really drive student learning.

When comparing the results of both procedures, i.e., the percentage of faculty objectives identified for each problem and the TOC scores for each problem, it was somewhat surprising to find that the results of both procedures were negatively correlated (albeit moderately). The Spearman rank correlation coefficient between the average problem overlap scores and the TOC time scores and mastery scores were both $-.36 \quad(p<.001$, $\mathrm{N}=144$ ). However, this correspondence between learning issues and students' corresponding learning activities during self-study is assessed by means of a quantitative measure (the correlation between the percentage percentage of faculty objectives identified on the one hand and TOC scores for each problem on the other). As a consequence, these results focus on how much content was covered, instead of what content was actually being covered by students in the learning issues generated and topics covered during self-study. Therefore, in a qualitative sense the learning issues generated in each tutorial group were compared with TOC topics. Comparing the average TOC time scores and mastery scores with the results of the qualitative analysis in which learning issues and TOC topics were compared directly reveals correlation coefficients of .08 (n.s., $\mathrm{N}=144)$ and $.21 \quad(p<.01, \mathrm{~N}=144)$ respectively. In summary, the order in which the problems are ranked across the procedures, overlap between issues and objectives or the direct match between learning issues and TOC scores are not highly related. Since the number of prob- 
lems included was limited, namely 12 , the possibility that this finding was influenced by one or two extreme data-points could not be excluded.

Based on the low proportion of the variance of TOC scores that could be predicted from overlap between student-generated learning issues and faculty objectives, it was concluded in Chapter 5 that the relationship between student-generated learning issues and TOC scores at the problem level essentially could be considered negligible. This implies that what students plan to do, as expressed in the list of learning issues produced after problem discussion, seems to be essentially unrelated or even negatively related to what they actually $d o$. This finding suggests that learning issues are not a major factor influencing the nature of students' self-study. As a consequence, other factors may be involved in decisions on what to study.

Several explanations were suggested for these findings. First, students may pay much attention to a learning issue during discussion in the tutorial group, but eventually may decide not to spend time on this issue during self-study, because they cannot find relevant literature, do not have enough time, or assume that they already have mastered the issue. Second, students' motivation and interest may play a role. For example, as observed by faculty members, students are more interested in physiological learning issues than psychological learning issues. Third, some learning issues may be too broadly defined. This may contribute towards a high percentage of faculty objectives being covered for a particular problem. Broad learning issues, however, may not provide much guidance to students, since they may require an extensive search of the literature and, consequently, may lead to relatively low TOC scores. Fourth, learning resources may reveal to students that a particular issue, although not raised during the discussion, is nevertheless an important element in understanding the problem at hand and, therefore, deserves attention. Fifth, content covered in previous units may influence the nature of students' self-study. Sixth, particular learning issues, although not listed, may still be mastered by students, if these issues are addressed during lectures or other additional curricular activities. Seventh, incongruity between the subject-matter tested and the subject-matter addressed in the problems might influence students' learning activities during selfstudy. Eight, the tutor may also play a part. Finally, methodological problems may account for this negative correlation between studentgenerated learning issues and TOC scores. TOC topics may to some extent better reflect teachers' priorities than learning issues generated by students, since topics are defined at a more fine-grained level ( 51 faculty objectives versus 126 topics). Another methodological problem is that, although students may not identify a faculty objective for a particular 
problem, they may have identified this objective while working on another problem. Our procedures are unable to deal with this situation. Consequently, in Chapter 5, it was concluded that the relationship between student-generated learning issues and students' learning activities is not as straightforward as is often suggested by various authors (Blumberg, Michael, \& Zeitz, 1990). In summary, what students actually do may not only be determined by what they intend to do, as summarized in student-generated learning issues, but also by other factors, such as the ones mentioned above.

In Chapter 6, results were reported from a study that focuses on the extent to which various elements of a problem-based curriculum influence students' decisions on what to study. First, interviews were conducted among students. They were asked to report what actually takes place when initiating learning activities and what kind of considerations play a role in deciding what to study. Based on the results of these interviews, a questionnaire was constructed, consisting of statements describing elements of the learning process and their influence on student learning. Elements included in the questionnaire were: the initial problem discussion, the generation of learning issues, reference literature, course objectives, lectures, content tested, other students, and the tutor. Students were asked to indicate on a 5-point Likert scale how much they agreed with each statement. The students reported that all elements may have an impact on decisions on what to study. In addition, first year students tend to rely more on the literature cited in the references list and content covered in lectures and tests than students in the other three curriculum years. In general, the influence of these elements tended to show a decrease over the four curriculum years. The influence of the initial problem discussion and the learning issues generated, on the contrary, tended to show an increase over the four curriculum years (this increase, however, is not always significant). This finding suggests that students in a problem-based curriculum become more accomplished self-directed learners as a result of being in the curriculum for a longer period.

In summary, contemporary conceptions of PBL include the idea that faculty objectives, problems, learning issues and learning activities entertain a one-to-one relationship with each other; in other words, that one can be seen as a direct transformation of the other. The investigations described in this thesis cast doubt on this idea. First, it was shown that students covered 64 percent of the intended faculty objectives in the course within this study. This implies that students are to a large extent able to identify what they are expected to learn, although some tutorial groups might miss particular objectives. Second, the proportion of the 
variance of TOC scores, a measure of students' learning activities during self-study, that could be predicted from overlap between studentgenerated learning issues and faculty objectives and the direct match between learning issues and TOC topics was very low. This finding suggested that the learning issues generated might not be the only force driving students' learning activities during self-study. Third, it was concluded that not only student-generated learning issues, but several other factors, such as self-assessment tests, reference literature, and so forth, also play a part in students' decisions on what to study. These elements, however, do not seem to be detrimental to the development of students' self-directed learning skills.

In Chapter 3, it was concluded that student-generated learning issues provide faculty with a useful tool to detect ineffective problems suggesting avenues for problem improvement. In Chapter 4 , it was argued that TOC scores could also be used to determine ineffective problems. Scores on particular topics might be useful to provide guidelines to improve the effectiveness of problems. However, the results of the study described in Chapter 6, indicating that not only student-generated learning issues but several other factors might play a part in students' decisions on what to study, imply that both learning issues and TOC scores might only to a limited extent be useful for problem improvement.

\section{Educational Implications}

In PBL a dilemma exists between the development of self-directed learning skills by students and faculty's responsibility to ensure course content coverage. This dilemma makes curriculum design a painstaking activity. The antithetical responsibilities require faculty to develop problems which on the one hand guide students to the intended course content, and on the other indirectly prescribe what students should know for the problem at hand. In addition, problems should give the students enough freedom to generate their own learning issues. As stated by Bruner (1971), the major condition for activating exploration of alternatives in a task is the presence of some optimal level of uncertainty. A routine task provokes little exploration; one that is too uncertain may arouse confusion and anxiety with the effect of reducing exploration. Hence, optimal design in PBL means that, given a problem, studentgenerated learning issues to a large extent correspond with faculty objectives. In addition, these learning issues should be generated based on a discussion in the tutorial group which encourages students to activate relevant prior knowledge. In other words, a problem should not 
be designed in such a manner that the learning issues can be generated without any discussion.

In Chapter 2, aimed at investigating the overlap between faculty objectives and student-generated learning issues, it was demonstrated that faculty objectives that were not identified by students (1) were related to other curricular activities, (2) were too broadly defined, or (3) were related to psychology and sociology issues. Faculty objectives in the first category were not identified by students for a particular problem, because this objective was already dealt with in another element of the course, for instance a training session. Although it may be valuable to offer students different opportunities to achieve a particular faculty objective, course developers should try to guarantee consistency among all aspects of the curriculum. If a problem is aimed at identifying a faculty objective which has already been covered in another element of the course, this problem will be seen as ineffective by most students. As a consequence, if a particular objective is aimed at in different parts of the curriculum, it should be kept in mind what the surplus value is of offering particular subject-matter to students by multiple instructional methods (problems, training sessions, etc.).

With regard to the second category of faculty objectives, i.e., faculty objectives that were too broadly defined, it is evident that course developers should carefully select which objectives should be reached within a course. Furthermore, they should keep in mind whether these objectives can be reached within the time constraints of the course and whether appropriate reading materials will be available for students.

The third category of objectives that were not identified by students were related to psychology and sociology. One of the salient findings in several of the studies reported in this thesis was that medical students tend to prefer biological and physiological issues over social science issues. Students reported in interviews, described in Chapter 6, that they experience more difficulties than usual when confronted with these latter issues. Students' complaints are that the literature on social science issues is not as fact-oriented as the literature on biological and physiological issues. However, social science issues are important issues to be covered in a medical curriculum, since environmental factors and lifestyle are assumed to be important determinants of health and illness. As a consequence, faculty members should put extensive efforts in designing problems that encourage students to study social science issues. The data in Chapter 2 suggest in this respect that, if faculty objectives of a certain problem focus on both biology or physiology issues and social science issues, students generate biology and physiology issues at the expense of 
social science issues. By contrast, if a problem only focuses on social science issues, students do generate these issues and do identify the required objectives. This finding seems to indicate that course developers should keep in mind that if physiological or biological issues are combined with social science issues within a problem, students may omit the social science issues. Clear cues should be built into a problem in order to guide students to social science issues. In addition, it may be necessary to stress the importance of the social science issues in the instructional guide.

The results in Chapter 3 indicate that problems did not actually improve, measured as the percentage of overlap between learning issues and faculty objectives, after changes were carried out based on information about the learning issues generated. However, the collection of learning issues generated in the tutorial groups seems to be worthwhile. A list of learning issues generated by the students initiates a discussion among the course developers about the main objectives to be achieved within a course. Furthermore, it fosters course developers to design problems with clear faculty objectives in mind. The collection of student-generated learning issues in all tutorial groups is not overly time-consuming, since students note down the learning issues generated on a blackboard at the end of each tutorial group meeting and the tutor should only copy these issues. However, the production of a report in which all learning issues are listed for each problem requires far more time and energy. This effort seems to be especially worthwhile at the start of a new course or if several new problems are implemented.

Besides the collection of learning issues, another procedure presented in this thesis can be used by course developers to detect ineffective problems. This procedure, the TOpic Checklist (TOC), consists of a list of topics that students are expected to study during a course. The topics should be selected by the designers of the problems. At the end of the course, this list is presented to the students and they are asked to indicate how much time they had spent on studying each topic and to what extent they master each topic. This procedure provides course developers with information about the subject-matter covered by students, not only during the discussion in the tutorial group, but also during self-study. However, this procedure cannot be as easily implemented as the collection of learning issues, since the design of such a list and analyzing the results requires much time. However, if a particular course or several problems within a course cause difficulties for course designers, the procedure may be useful. For example, a problem that does not lead students to studying 
the intended subject-matter. Rating scores on separate topics of the TOC related to that particular problem could be examined to identify which topics scored low. If students fail to master particular topics, problem designers should ask themselves to what extent the problem really invoked study activities intended with these topics. Adding cues to the text of the problem referring to these low scoring topics would probably improve its effectiveness. In addition, a list of topics that students are expected to study during a course can be considered as a blueprint of the course. As such, it can also be used as a blueprint for the generation of test items for the construction of a test. Taken together, the TOC is a useful instrument to collect information about students' learning activities during a course.

In Chapter 5, it was demonstrated that student-generated learning issues are not the sole or major factor influencing the nature of students' selfstudy. The study in Chapter 6 indicates that several other elements also play a part in students' decisions on what to study, such as reference literature, course objectives, lectures and tests. Reference literature cited in the course book seems to influence strongly students' decisions on what to study. This is not at all surprising, since a list of reference literature saves students a lot of time. However, by conducting literature searches students acquire the ability to continue their education after they graduate. Therefore, suggestions for reference literature should be specified in the course book at a more global level, i.e., these references should not be listed for each problem, but should be organized around themes. Moreover, these references should include more materials than students can study within the period of a 6-week course.

Schmidt (1990) listed several considerations underlying this approach. First, students are confronted with several different materials to encourage them to consult more sources at an early stage. When studying different literature sources, students will experience that these sources may sometimes reflect different and sometimes contradictory views. Second, it teaches the student the boundaries of scientific knowledge; thus, that some questions that students might raise themselves cannot be answered.

The course objectives, another element of the curriculum, provide students with a general overview of the subject-matter covered during the course and as such also influence students' decisions on what to study. It may be clear that these course objectives should be formulated at a rather global level, otherwise they may subvert the generation of learning issues in the tutorial group. 
Lectures, another part of the curriculum, also influence students' decisions on what to study. Course developers should keep in mind that lectures do not contribute towards the development of self-directed learning skills. However, a lecture may be worthwhile in particular situations, for example, if the field of study is unknown to students, i.e., the field of study is first introduced in the curriculum and students hardly possess prior knowledge in this subject-matter domain. A lecture may also be worthwhile if the findings that will be reported are new and not yet documented in the literature (Snellen-Balendong, 1993).

Another element of the curriculum that influences students' selfstudy are tests. In the medical curriculum of the University of Limburg, a self-assessment test is included in the course book. At the end of the course an examination is administered to the students. The aim of these tests is to provide students with formative feedback about their performances. The results, presented in Chapter 6, showed that students in the first and second year are more test-driven than students in the third and fourth year. A disadvantage of students' being test-driven is that the learning issues generated in the tutorial group may become of less importance than the content that is tested. This process will be stimulated by attaching more importance to test results within a curriculum.

Finally, the key to encouraging self-directed learning skills lies in consistency among all aspects of the course, such as the student-generated learning issues, faculty objectives, the material covered in lectures, trainings, and content tested. If there is a discrepancy between these elements of the curriculum, students receive concurring messages which may hamper students' development of self-directed learning skills.

\section{Further Research}

The studies presented in this thesis resulted in several questions which need further research. The data did not show unequivocal evidence for the assumption that the learning issues generated are the most important factor driving student learning. As a consequence, further investigations are required with regard to what actually happens to the leamer in PBL. Several factors were mentioned in this thesis influencing what students will study. However, more research should be done to find out how these factors actually influence student learning. Some of the questions that remained to be unanswered are the following. To what extent are students encouraged to search for relevant literature themselves if specific reference literature is presented to them, if the main topics to be studied are addressed during lectures? Is the student's development of self- 
directed learning skills guaranteed in a curriculum with these somewhat teacher-centered components? Do students indeed become lifelong learners; i.e., do students search more for literature after graduation than students in a traditional curriculum? Which literature resources do students consult at a regular basis? Which considerations play a part in students' decisions on the learning materials they select? Library circulation data could be collected to answer some of these questions.

In addition, it would be interesting to investigate the impact of changes in faculty policy on the extent to which different elements of the curriculum influence students' self-study. For example, if more importance will be attached to test results in a curriculum, it might be possible that students will change their study activities and will rely more on instructional activities that provide them with a feeling about what content they are expected to master according to the test.

In the studies aimed at investigating course content coverage, student-generated learning issues and student ratings of topics covered during self-study were used. It might be valuable to analyze recordings of the discussion in the tutorial group, to ask students to keep daily logs of their learning activities, or to analyze the literature or other sources that students consult for a particular course in order to further investigate what actually happens to the learner.

Efforts are also needed in establishing criteria for the construction of problems. How should problems be designed in such a way that they on the one hand encourage the development of self-directed learning skills and on the other ensure that content will be covered by students? In other words, what would be the optimal level of uncertainty induced by problems in PBL? Is it possible to formulate guidelines for problem designers about the impact of different aspects of a problem, such as its structure, format, and content specific elements, on students' decisions on what to study? What is the influence of these characteristics of problems on time spent during self-study, on the learning issues generated in the tutorial group, and on students' achievement on test items related to the subject-matter addressed in the problem? Further research should focus on how to design problems that motivate students to spend time on issues that are not directly related to physiology or biology. 


\section{References}

Barrows, H.S. \& Tamblyn, R.M. (1980). Problem-based Learning. An Approach to Medical Education. New York: Springer.

Blumberg, P., Michael, J.A., \& Zeitz H. (1990). Roles of Student-generated Learning Issues in a Problem-based Curriculum. Teaching and Learning in Medicine, 2, 3, 149-154.

Bruner, J.S. (1971). Towards a Theory of Instruction. Cambridge: Harvard University Press.

Dolmans, D.H.J.M., Gijselaers, W.H., Schmidt, H.G., \& Van der Meer, S.B. (1993). Problem Effectiveness in a Course Using Problem-based Learning. Academic Medicine, 68, 3, 207-213.

Schmidt, H.G. (1983). Problem-based Learning: Rational and Description. Medical Education, 17, 11-16.

Schmidt, H.G. (1990). Onderwijskundige aspecten van probleemgestuurd onderwijs. [Educational Aspects of Problem-based Learning]. In: W.M.G. Jochems (Ed.). Aktiverend Onderwijs. The Netherlands: Van Gorcum.

Snellen-Balendong, H.A.M. (1993, August). Lectures in a Problem-based Learning Curriculum. An Anachronism or an Accepted Learning Resource? Paper presented at the International Conference on Student-centred Education, the 8th General Meeting of the Network of Community-oriented Educational Institutions for Health Sciences. 
a

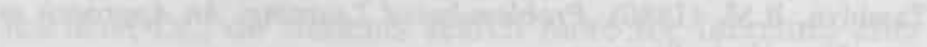

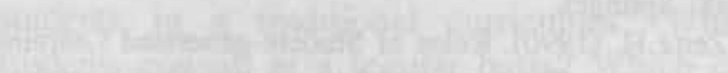

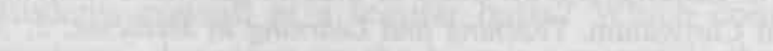

and

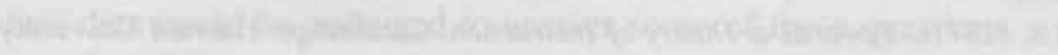

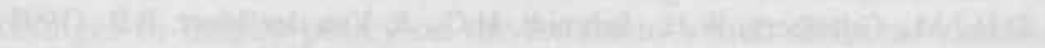

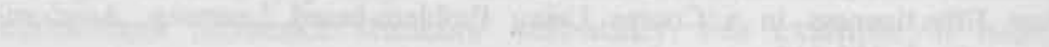

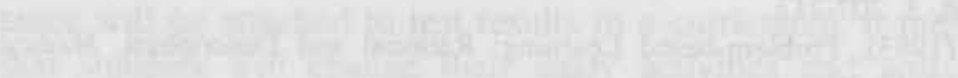

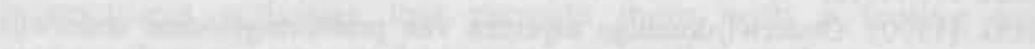

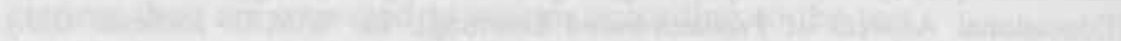
The

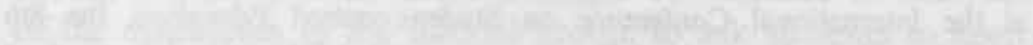

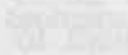

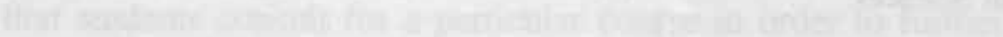

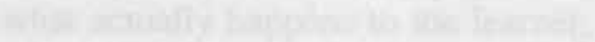

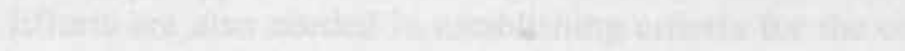

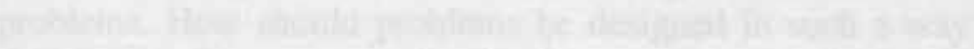

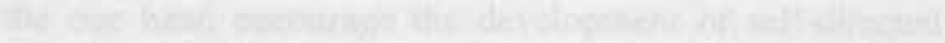

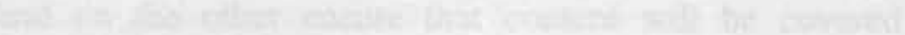

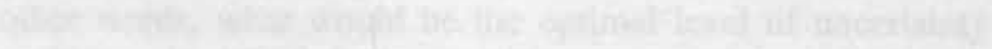
(4.

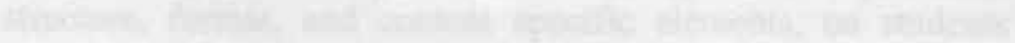
14. 


\section{Samenvatting}

In dit proefschrift staat het leren van de student in probleemgestuurd onderwijs centraal. De studies zijn uitgevoerd aan de Medische Faculteit van de Rijksuniversiteit Limburg in Maastricht die gekenmerkt wordt door een probleemgestuurd curriculum. In de literatuur wordt het leren van de student in probleemgestuurd onderwijs als volgt omschreven. Docenten construeren taken waarmee zij bepaalde onderwijsdoelen voor ogen hebben. Deze taken worden in groepen van 8 à 10 studenten, de onderwijsgroep, bediscussieerd. Tijdens deze discussie activeren studenten de aanwezige voorkennis en genereren ideeën over de onderliggende concepten of mechanismen die in de taak beschreven zijn. Tijdens deze analyse wordt studenten duidelijk dat additionele informatie nodig is, omdat een aantal vragen onbeantwoord blijft ten aanzien van de fenomenen zoals beschreven in de taak. Deze vragen, die leerdoelen worden genoemd, dienen vervolgens als leidraad voor de zelfstudie-activiteiten van studenten. Gedurende hun zelfstudie gaan studenten op zoek naar relevante literatuur of andere hulpbronnen. In een volgende bijeenkomst van de onderwijsgroep, gewoonlijk twee dagen later, rapporteren studenten aan elkaar wat ze gevonden hebben betreffende de geformuleerde leerdoelen en proberen deze informatie te synthetiseren.

Probleemgestuurd onderwijs zet studenten ertoe aan zelf verantwoordelijkheid te nemen voor hetgeen ze leren, zodat ze 'leren hoe te leren'. Studenten worden aangespoord zelfstandig informatie te verwerven, een vaardigheid waarvan zij in hun latere beroep als medicus gebruik zullen moeten maken, mede gezien de snel veranderende kennisontwikkeling. Critici beweren echter dat studenten, vooral in het begin van hun studie, niet in staat zijn zelf te bepalen wat ze moeten leren. Indien studenten zelf keuzes moeten maken, kan dat leiden tot deficienties in hun kennis. De faculteit heeft echter de verantwoordelijkheid te 
garanderen dat haar afgestudeerden geen emstige lacunes in hun kennis hebben. Kortom, in probleemgestuurd onderwijs is sprake van een dilemma waarbij enerzijds studenten aangespoord worden tot zelfwerkzaamheid en anderzijds de faculteit dient te garanderen dat studenten geen deficiënties hebben in hun kennis. Dit betekent dat taken geconstrueerd dienen te worden die enerzijds studenten sturen naar de beoogde leerstof en anderzijds studenten de ruimte geven zelf leerdoelen te genereren.

Het leren van de student in probleemgestuurd onderwijs bestaat uit een aantal elementen die getransformeerd worden in andere elementen. De onderwijsdoelen die docenten voor ogen hebben worden vertaald in taken, waaruit vervolgens door studenten leerdoelen gegenereerd worden tijdens de onderwijsgroepsbijeenkomsten. Deze leerdoelen vormen vervolgens de leidraad voor studenten tijdens hun zelfstudie-activiteiten. Het doel van de studies die in dit proefschrift gerapporteerd zijn was na te gaan in hoeverre deze conceptualisering van probleemgestuurd onderwijs gereflecteerd wordt in de praktijk van het onderwijs. Drie vragen stonden centraal. Ten eerste, in welke mate genereren studenten leerdoelen die overeenkomen met de onderwijsdoelen van docenten? Ten tweede, verrichten studenten tijdens hun zelfstudie die leeractiviteiten die overeenkomen met hetgeen docenten voor ogen hadden? Ten derde, vormen leerdoelen een belangrijke leidraad voor zelfstudie-activiteiten van studenten of hebben ook andere factoren een belangrijke invloed? De eerste vraag stond centraal in de hoofdstukken 2 en 3 . De tweede vraag werd behandeld in hoofdstuk 4 en de derde vraag stond centraal in de hoofdstukken 5 en 6 . Van elk hoofdstuk volgt een korte samenvatting.

In hoofdstuk 2 zijn drie studies beschreven waarin is nagegaan in hoeverre studenten in staat zijn leerdoelen te formuleren die overeenkomen met de onderwijsdoelen die docenten voor ogen hebben bij de constructie van taken. Hiervoor werd docenten gevraagd op een formulier de leerdoelen te noteren die door hun onderwijsgroep geformuleerd werden. Deze studie werd uitgevoerd gedurende het zesde blok van het tweede leerjaar, getiteld "Geboren en Getogen". Dit blok gaat over de normale ontwikkeling van het kind vanaf de geboorte tot aan de adolescentie. Uit de resultaten bleek dat gemiddeld 64 procent van de onderwijsdoelen van de onderzochte onderwijseenheid werd gerealiseerd. Gemiddeld genomen werd vijftien procent van de onderwijsdoelen niet geïdentificeerd door de studenten. Uit de tweede studie kwam naar voren dat deze niet-geïdentificeerde onderwijsdoelen gerelateerd waren aan extra curriculaire activiteiten, zoals trainingen op het skillslab, breed gedefinieerd waren en daardoor een uitgebreide literatuurstudie vereisten, of betrekking hadden 
op psychologische of sociologische onderwerpen. Bovendien bleek uit de derde studie dat studenten leerdoelen genereerden die niet verwacht werden door de docenten die de taken construeerden. Deze niet-verwachte leerdoelen, in totaal $6,2 \%$ van alle geformuleerde leerdoelen, werden ingedeeld in vier categorieën. De eerste categorie betrof leerdoelen die gerelateerd waren aan een gebrek aan voorkennis bij studenten. De tweede categorie leerdoelen had betrekking op behandeling en interventies in plaats van fysiologie en pathofysiologie. Leerdoelen betreffende behandeling en interventie werden in het zesde blok van het tweede leerjaar niet verwacht door de docenten, omdat deze onderwerpen pas in latere studiejaren aan de orde komen. De derde categorie betrof leerdoelen die betrekking hadden op extra curriculaire activiteiten. De vierde categorie betrof leerdoelen gerezen uit de persoonlijke interesse in en ervaring met de leerstof. Deze bevindingen bevestigen dat studenten in probleemgestuurd onderwijs naast de beoogde leerdoelen ook leerdoelen genereren die tegemoetkomen aan hun eigen behoeften en interesses.

In hoofdstuk 3 stond de vraag centraal in hoeverre informatie over de gegenereerde leerdoelen gebruikt kan worden voor het verbeteren van taken. De effectiviteit van een taak werd hierbij gedefinieerd als de mate van overeenstemming tussen de leerdoelen, geformuleerd door studenten en onderwijsdoelen, beoogd door docenten. In de eerste studie werd docenten gevraagd een vragenlijst in te vullen betreffende de bruikbaarheid van leerdoelen voor het bijstellen van taken. Uit de resultaten bleek dat taken inderdaad bijgesteld werden op basis van de gegenereerde leerdoelen. Bovendien kwam naar voren dat de lijst van geformuleerde leerdoelen voor docenten een aanzet vormt voor een discussie over de belangrijkste doelen die ze met de taken voor ogen hebben. Deze discussie bevordert dat de constructie van taken gebaseerd wordt op expliciete en rationele overwegingen.

De tweede studie betrof twee case studies. Gedurende twee opeenvolgende academiejaren werden gegevens verzameld over de mate waarin de leerdoelen overeenkomen met de onderwijsdoelen die docenten beogen. De effectiviteit van taken bleek echter niet automatisch toe te nemen nadat veranderingen werden aangebracht in de taken op basis van informatie over de gegenereerde leerdoelen. Verschillende redenen werden genoemd die deze resultaten zouden kunnen verklaren. Ten eerste, trade-off mechanismen zouden een rol kunnen spelen waarbij het veranderen van een bepaalde taak van invloed is op de effectiviteit van andere taken. Ten tweede, aangezien veel studenten geneeskunde een voorkeur hebben voor biologische en fysiologische leerdoelen, hetgeen vaak ten koste gaat van sociaal-wetenschappelijke leerdoelen, resulteert 
het veranderen van een psychologische of sociologische taak niet automatisch in een hoger percentage van geïdentificeerde onderwijsdoelen. Een derde verklaring is dat leerdoelen slechts gedeeltelijk informatie verschaffen over de effectiviteit van taken. De verschillen in prioriteit tussen de onderwijsdoelen die docenten met een bepaalde taak beogen worden niet in beschouwing genomen indien de effectiviteit van een taak gebaseerd wordt op basis van het percentage overlap tussen leerdoelen en onderwijsdoelen. Bepaalde onderwijsdoelen kunnen van groter belang zijn dan andere onderwijsdoelen, wat van invloed kan zijn op beslissingen omtrent het bijstellen van taken.

In studies die tot nu toe beschreven zijn lag de nadruk op de leerdoelen die door studenten geformuleerd werden. Leerdoelen zijn echter slechts voornemens van studenten betreffende de leeractiviteiten die zij gedurende hun zelfstudie zullen verrichten. De vraag die in de tweede studie centraal staat is: Verrichten studenten die leeractiviteiten die verwacht worden door de docenten die de taken construeerden? Hiertoe is een procedure ontwikkeld om de leeractiviteiten van studenten te meten. In hoofdstuk 4 worden de resultaten beschreven van studies naar de betrouwbaarheid, validiteit en bruikbaarheid van deze procedure, de zogenaamde TOpic Checklist (TOC). Docenten, verantwoordelijk voor de constructie van taken, werden gevraagd te specificeren welke onderwerpen zij beoogden met de taken. Deze lijst van onderwerpen vormt de blauwdruk van de leerstof die centraal staat bij de betreffende taken. Aan het einde van een onderwijsperiode van zes weken werd studenten gevraagd op een 5-puntsschaal van 'geen tijd' tot 'zeer veel tijd' aan te geven hoeveel tijd zij besteed hebben aan elk onderwerp. Bovendien werden zij gevraagd aan te geven in welke mate zij elk onderwerp beheersen, eveneens op een 5-puntsschaal van 'helemaal niet' tot 'goed'. Uit generaliseerbaarheidstudies bleek dat een minimum aantal van 15 studenten nodig is om betrouwbare uitspraken te kunnen doen over verschillen tussen onderwerpen. Om betrouwbare uitspraken te kunnen doen over verschillen tussen de gemiddelde scores op taken is een aantal van tien studenten al voldoende. De TOC is dus een betrouwbare procedure om informatie te verkrijgen over de onderwerpen die studenten tijdens een blok bestudeerd hebben.

Aangezien de onderwerpen geselecteerd zijn door docenten die de taken construeerden wordt aangenomen dat de inhoudsvaliditeit van de procedure gewaarborgd is. Om de criteriumvaliditeit van de TOC te bestuderen werden additionele gegevens verzameld. Ten eerste, het gemiddelde percentage goed beantwoorde items werd berekend op een toets die afgenomen werd aan het einde van de onderwijsperiode van zes 
weken. Ten tweede werd studenten gevraagd te schatten hoeveel uren zij per week aan zelfstudie besteed hadden. Correlaties tussen tijd besteed aan of beheersing van de onderwerpen uit de TOC met de goedscore op de toets waren redelijk laag. De correlatie tussen tijd besteed aan de onderwerpen uit de TOC met het aantal geschatte uren zelfstudie per week was middelmatig. Deze laatste correlatiecoëfficiënt levert enig bewijs voor de criteriumvaliditeit van de procedure. In hoofdstuk 4 werd bovendien beargumenteerd dat de TOC ook gebruikt kan worden voor het bijstellen van taken. Indien de gemiddeld bestede tijd en de gemiddelde score voor beheersing voor een bepaalde taak laag is, is het zinvol de tijd, besteed aan de afzonderlijke onderwerpen en de beheersing van deze onderwerpen voor die betreffende taak nader te bekijken en na te gaan in hoeverre de betreffende onderwerpen ook daadwerkelijk in de taak zijn ingebouwd. Door het toevoegen van sleutelwoorden die verwijzen naar de laag-scorende onderwerpen kan de taak verbeterd worden.

In hoofdstuk 5 stond de vraag centraal in hoeverre leerdoelen een belangrijke leidraad vormen voor de zelfstudie-activiteiten van studenten. Voor het beantwoorden van deze vraag werden de resultaten van de procedure zoals beschreven in hoofdstuk $2, \mathrm{nl}$. het percentage onderwijsdoelen dat geïdentificeerd werd voor elke taak, en de procedure beschreven in hoofdstuk 4, te weten de gemiddelde TOC-score voor elke taak, vergeleken. Daarnaast werden de leerdoelen zoals geformuleerd in de onderwijsgroepen in kwalitatieve zin vergeleken met de onderwerpen uit de TOC. Beide vergelijkingen leverden lage percentages verklaarde variantie op. Dit betekent dat de taken volgens de procedures, nl. overlap tussen leerdoelen en onderwijsdoelen met de TOC-scores en de directe match tussen leerdoelen en de onderwerpen uit de TOC, omgekeerd gerangschikt worden. Wat studenten van plan zijn te gaan bestuderen, tot uiting komend in de gegenereerde leerdoelen, blijkt niet direct samen te hangen met wat ze werkelijk bestuderen.

Er zijn enkele verklaringen genoemd voor deze resultaten. Ten eerste is het mogelijk dat studenten tijdens de discussie veel tijd besteden aan een bepaald onderwerp dat uiteindelijk niet wordt meegenomen als leerdoel, omdat ze geen tijd hebben of ervan uitgaan dat ze het onderwerp reeds beheersen. Ten tweede, de interesse en motivatie van studenten kan een rol spelen. Zoals reeds eerder vermeld, zijn studenten geneeskunde in het algemeen meer geïnteresseerd in fysiologische onderwerpen dan sociaal-wetenschappelijke onderwerpen. Hierdoor is het mogelijk dat studenten wel de leerdoelen identificeren, maar er tijdens hun zelfstudie weinig tijd aan besteden. Ten derde, sommige leerdoelen zijn zeer breed geformuleerd. Dit draagt enerzijds bij aan een hoog 
percentage geïdentificeerde onderwijsdoelen voor de betreffende taak, maar dergelijke leerdoelen vormen anderzijds voor studenten geen goede leidraad omdat zij een uitgebreide literatuurstudie vereisen. Ten vierde, alhoewel een bepaald leerdoel aanvankelijk niet geïdentificeerd was, kan tijdens de zelfstudie blijken dat dit onderwerp nauw gerelateerd is aan de geformuleerde leerdoelen en eveneens bestudeerd dient te worden. Ten vijfde, de overlap van de inhoud van een taak met de leerstof die in vorige taken aan bod is geweest kan een rol spelen. Ten zesde, bepaalde leerdoelen, ondanks dat deze niet als leerdoel geformuleerd werden naar aanleiding van een taak, kunnen toch beheerst worden omdat deze aan bod zijn geweest gedurende lezingen of andere extra curriculaire activiteiten. Ten zevende, discrepanties tussen de onderwerpen die getoetst worden en de onderwerpen die in de taken aan bod komen kunnen van invloed zijn op de zelfstudie-activiteiten van studenten. Ten slotte, de invloed van de tutor kan een rol spelen.

In hoofdstuk 6 werden de resultaten gepresenteerd van een studie naar de mate waarin verschillende factoren van een probleemgestuurd curriculum van invloed zijn op de leeractiviteiten van studenten gedurende hun zelfstudie. Hiervoor werden interviews afgenomen bij studenten van één onderwijsgroep. $\mathrm{Zij}$ werden gevraagd weer te geven hoe ze te werk gaan tijdens hun zelfstudie en welke overwegingen daarbij een rol spelen. Op basis van de factoren die genoemd werden tijdens de interviews is een vragenlijst samengesteld. De factoren die in de vragenlijst opgenomen zijn, betreffen: de rol van de discussie in de onderwijsgroep, de rol van leerdoelen, de invloed van literatuurverwijzingen, blokdoelstellingen, lezingen, de invloed van toetsvragen, andere studenten en tutoren. Uit de resultaten bleek dat alle genoemde factoren van invloed zijn op hetgeen studenten bestuderen. Bovendien werd gevonden dat de invloed van literatuurverwijzingen en de invloed van de inhoud van lezingen en toetsen op de zelfstudie-activiteiten van studenten groter is in studiejaar 1 dan in de overige studiejaren. In het algemeen nam de invloed van deze elementen af gedurende de vier studiejaren. De invloed van de discussie in de onderwijsgroep en de gegenereerde leerdoelen op hetgeen studenten bestuderen nam daarentegen toe gedurende de vier studiejaren. Deze bevindingen suggereren dat studenten in een probleemgestuurd curriculum meer zelfwerkzaam worden naarmate ze langer participeren in het curriculum. 
Kortom, hedendaagse concepties over probleemgestuurd leren gaan ervan uit dat onderwijsdoelen, taken, leerdoelen en leeractiviteiten een één-opéén relatie met elkaar onderhouden, dat wil zeggen, dat het ene element gezien kan worden als een directe transformatie van het andere element. De studies zoals beschreven in dit proefschrift geven geen bewijs voor deze conceptualisering. Ten eerste werd aangetoond dat door studenten $64 \%$ van de onderwijsdoelen van een onderwijseenheid van zes weken geïdentificeerd werd. Dit betekent dat studenten in sterke mate in staat zijn te identificeren wat ze beoogd worden te leren, alhoewel sommige onderwijsgroepen bepaalde leerdoelen niet zullen identificeren. Ten tweede, de variantie in het percentage overlap tussen onderwijsdoelen en leerdoelen die verklaard wordt door de TOC-scores, een maat voor de leeractiviteiten van studenten gedurende hun zelfstudie, was erg laag. Dit resultaat suggereert dat leerdoelen niet de enige leidraad zijn voor de zelfstudie-activiteiten van studenten. Ten derde werd geconcludeerd dat niet alleen leerdoelen maar ook andere factoren, zoals de toets, de tutor en de blokdoelstellingen van invloed zijn op de beslissingen van studenten over de onderwerpen die bestudeerd worden tijdens hun zelfstudie. 


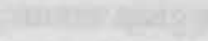

C.

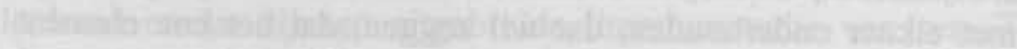

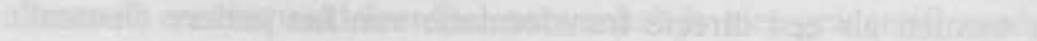

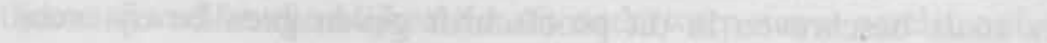

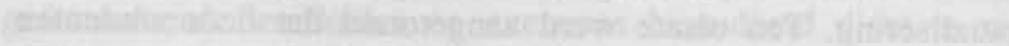

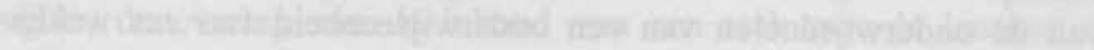

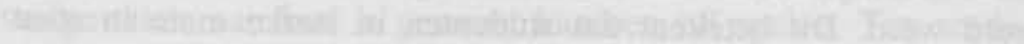

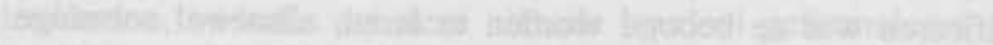

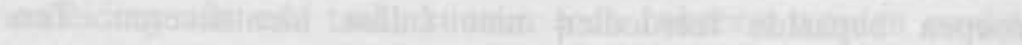

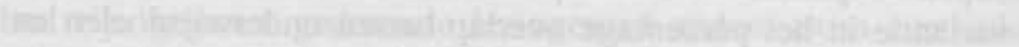

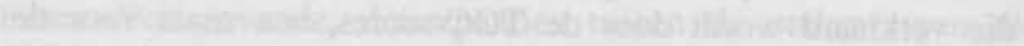

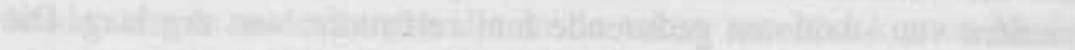

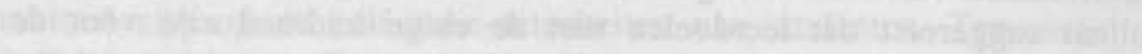
Tha

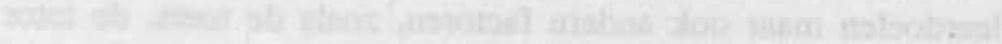
15. The and

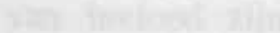

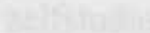
|

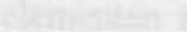

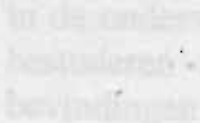

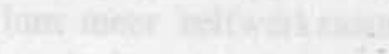

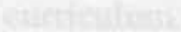




\section{Curriculum Vitae}

Diana Dolmans was born in Hulsberg, June 3, 1966. She finished Atheneum-A in 1984 at the St. Jans College in Hoensbroek. Subsequently, she studied Educational Psychology at the University of Nijmegen. Since graduation in 1989, she has been working at the Department of Educational Development and Research at the University of Limburg in Maastricht, first as PhD-student and presently as university teacher. 


\section{How; Students Learn in a Problem-based Curriculum}

\section{Diana Dolmans}

This thesis deals with aspects of what actually happens to the learner in a problem-based curriculum. The principal idea behind problem-based learning is that student learning consists of several elements which are transformed in other elements. Faculty objectives are translated into a problem. usually consisting of a set of phenomena in need of some kind of explanation. Students analyze these problems, attempting to understand the underlying principles or processes through smallgroup discussion. During discussion usually some questions remain unanswered. These questions are called student-generated learning issues and serve as a guide for independent and self-directed leaming. The investigations reported in this thesis are aimed at finding evidence for this conceptualization of problem-based learning. Three questions were addressed. First, to what extent do students generate learning issues which correspond with preset faculty objectives? Second. do students perform learning activities as intended by faculty responsible for the design of problems? Third, are student-generated learning issues a major factor driving students' self-study or do other elements of the curriculum have a significant influence?
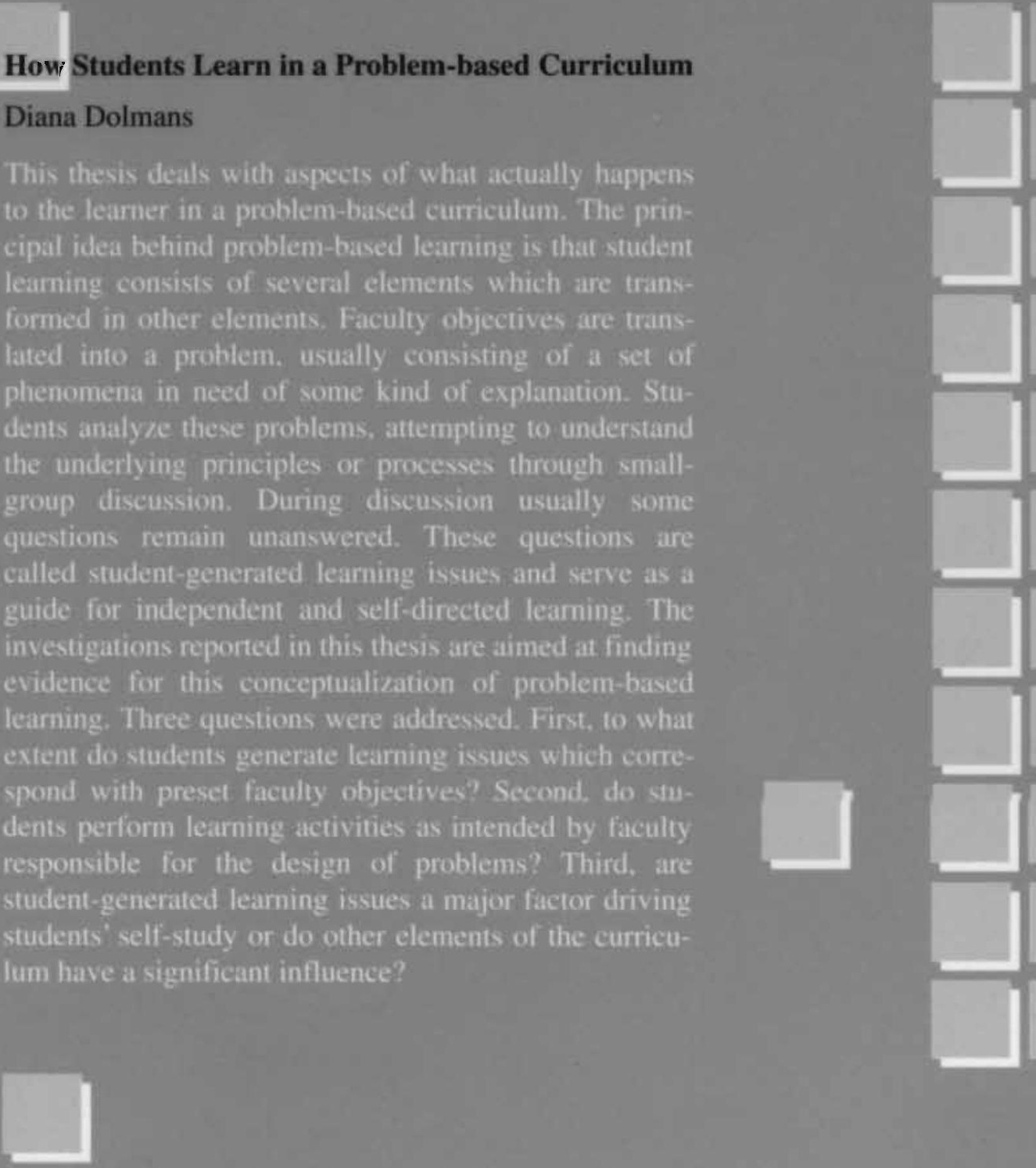